University of Missouri, St. Louis

IRL@UMSL

8-15-2020

\title{
Talent Retention: An Empirical Examination of a 21st Century United States Department of Agriculture
}

James Ellis Jordan Jr

University of Missouri-St. Louis, james.jordan@mail.umsl.edu

Follow this and additional works at: https://irl.umsl.edu/dissertation

Part of the Organizational Behavior and Theory Commons

\section{Recommended Citation}

Jordan, James Ellis Jr, "Talent Retention: An Empirical Examination of a 21st Century United States Department of Agriculture" (2020). Dissertations. 998.

https://irl.umsl.edu/dissertation/998

This Dissertation is brought to you for free and open access by the UMSL Graduate Works at IRL @ UMSL. It has been accepted for inclusion in Dissertations by an authorized administrator of IRL @ UMSL. For more information, please contact marvinh@umsl.edu. 
Talent Retention:

An Empirical Examination of a $21^{\text {st }}$ Century United States Department of Agriculture

James Ellis Jordan, Jr.

Disclaimer: This research paper, written by James Ellis Jordan Jr., was prepared in his personal capacity. The opinion expressed herein are his own and do not reflect the views of Rural Development, the USDA, nor the United States Government.

Master of Business Administration, Webster University, 2007

Bachelor of Science in Accounting, University of Missouri-St. Louis, 2002

A Dissertation Submitted to The Graduate School at the University of Missouri- St. Louis in partial fulfillment of the requirements for the degree of Doctor of Business Administration with an Emphasis in Organizational Behavior

December 2020

$\underline{\text { Advisory Committee }}$

Ekin K. Pellegrini, Ph.D. Chairperson

James Breaugh, Ph.D.

John Meriac, Ph.D.

Copyright, James Ellis Jordan, Jr., 2020 


\begin{abstract}
Federal organizations at all levels are experiencing difficulty retaining talented employees and must examine current strategies to retain talented high performing employees. Thirty-one percent of government-wide employees will be eligible to retire by 2022 (GAO, 2019). As a result, government organizations need to examine generational expectations and values related to talent retention, which may prove beneficial when developing strategies for the current workforce. Semi-structured interviews were conducted with twenty-five Generation $\mathrm{X}$ and millennial federal government employees to gain an in-depth understanding of their insights related to talent retention in the federal government context. Additionally, supplemental quantitative data were collected that integrate leader-member exchange (LMX) research to help inform talent retention in the federal government. Findings from this study emphasize Generation $\mathrm{X}$ and millennial federal government employees' experiences and identify seven categories outlining the reasons why they chose to stay: organizational pride, communication, workplace culture, job resources, learning and development, career growth, leadership. Some of these drivers of talent retention have been identified in previous literature; however, until now, they have not yet been shown to be relevant in the federal government context. The study also uncovered two novel drivers of talent retention termed organizational pride and 360 communication (a sub-category of communication). Results expand previous talent retention research by providing new insights into federal government employees' experiences and what drives them to stay. This study's findings have numerous theoretical and practical implications that are discussed. Findings will serve as a foundation for future research on Generation $\mathrm{X}$ and millennials on talent retention in the federal government. Based on the study's findings, I
\end{abstract}


conclude with seven recommendations that reinforce the positive value of organizational pride, 360 communication, career growth, and learning and development. Keywords: Talent retention, Generation X, millennials, USDA, Rural Development 


\section{Acknowledgments}

To my wife, Dr. Elizabeth Jordan, you always believed in me and pushed me to follow my dreams. Thank you for always being "proud of me" no matter what and being my lifeline throughout this process. To my children, Caitlyn, Isaiah, and James III, thank you all for understanding when I couldn't make all of our family outings or binge-watch our favorite shows. I appreciate all your love and support.

To my dissertation chair, Dr. Ekin Pellegrini, you cautioned me not to let life get in the way and to no matter what, stay the course. There were some struggles and times that I wanted to quit, and I am thankful for your guidance throughout this journey and your tough support at times to help me complete this dissertation journey. In you, I have gained a life-long friend and mentor.

To Dr. James Breaugh, thank you for your willingness to serve on my dissertation committee. I truly value all your feedback and challenging me to think differently about my approach to this research. To Dr. John Meriac, I am so glad you agreed to serve on my dissertation committee, and I am forever grateful. It was an honor to have my work reviewed and approved by both of you.

To my parents, James and Faye Jordan, my true inspiration, I admire you both and I am thankful for your support through this process. Thank you for always working so hard while I was on the journey and being so supportive. To my parents-in-law, Maurice and Joyce Williams and my uncle and aunt, Ivory and Alice Odom, thank you all for your continued love and support and your prayers throughout this process.

To my countless other family members and friends, I wish I could name each person one by one, but it would take up all the pages of this dissertation. Please know that your words of encouragement, prayers, love, and support helped me through this entire 
process.

To the St. Louis Alumni Chapter of Kappa Alpha Psi Fraternity, Incorporated, who showed me that achievement is not a buzz word but a way of life. May we continue to pass down this tradition.

Last, but certainly not least, to the study participants. Thank you for your openness, honesty, and enthusiasm to share your experiences. It is because of you that this work was even possible. Many thanks as well to my leadership in the Rural Development Business Center, specifically Alison S., Christine M., Anthony B., and the Chief Operating Officer, Angilla Denton. Thank you. 


\section{Table of Contents}

\section{CHAPTER 1. INTRODUCTION}

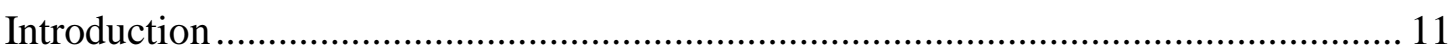

Human Capital Challenge in the Federal Government.............................. 13

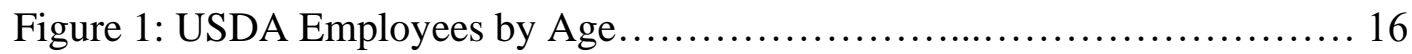

Table 1: USDA Employment Trends By Age.................................. 17

U.S. Department of Agriculture (USDA) Context................................17

Table 2: USDA Separations by Year.............................................. 20

Purpose and Contribution of this Research.................................... 20

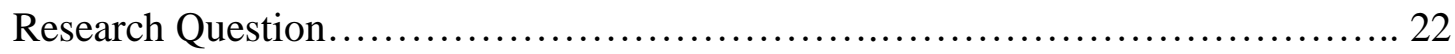

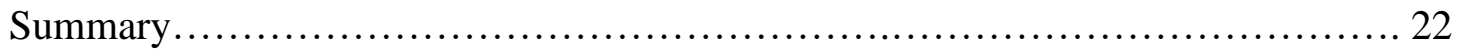

\section{CHAPTER 2. THEORETICAL BASE AND HYPOTHESES}

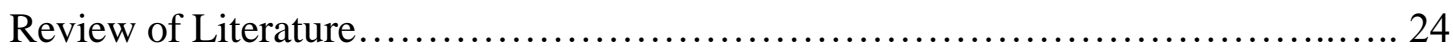

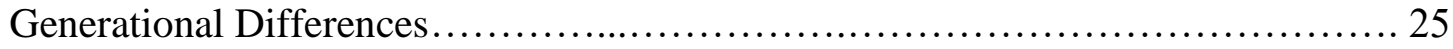

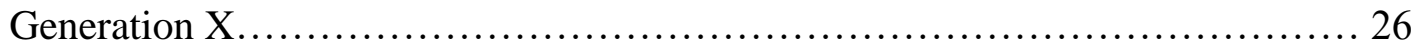

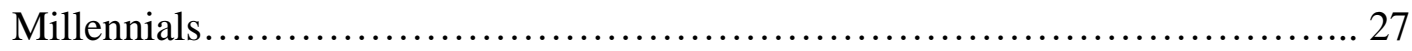

Generation X and Millennials............................................. 28

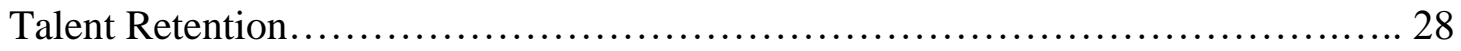

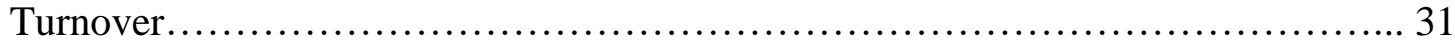

Retention Strategies............................................................ 33

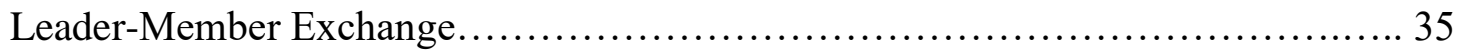

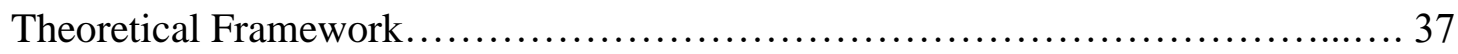


Resource-Based View............................................. 37

Human Capital Theory................................................ 38

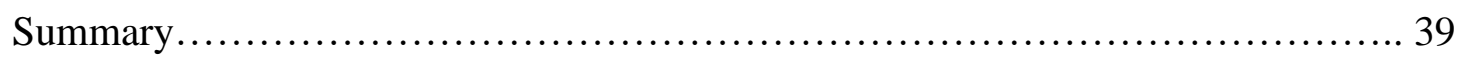

\section{CHAPTER 3. METHODOLOGY}

Research Design................................................... 40

Sampling Process.................................................... 42

Table 3: Sample Demographic Characteristics............................ 45

Interviews........................................................... 45

Table 4: Means, Standards Deviations, and One-Way Analyses of Variance

(ANOVA) Results for Effects of Interview Methods on Study Variables............ 47

Semi Structured Interview Transcription............................... 48

Data Analysis......................................................... 49

Table 5: Categories and Sub-Categories................................. 50

Quantitative Measures................................................ 52

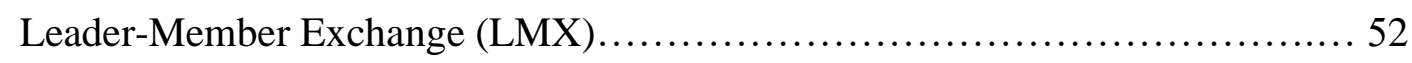

Research Perspective: Paradigms and Ethics.............................. 53

Assumptions........................................................ 54

Conclusion........................................................... 55

\section{CHAPTER 4. RESULTS}



Sub-Category: Mission of the Organization............................. 57

Sub-Category: Impacting People's Lives................................ 59

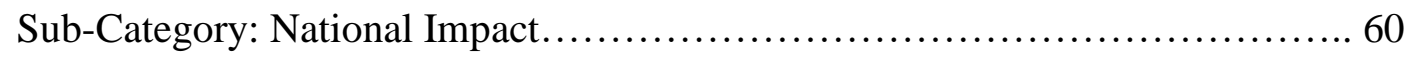


Sub-Category: Corporate Social Responsibility $\ldots \ldots \ldots \ldots \ldots \ldots \ldots \ldots \ldots \ldots \ldots \ldots$

Category 2: Communication.............................................. 61

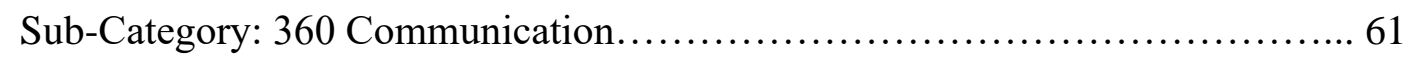

Sub-Category: Communication with the Direct Manager..................... 62

Sub-Category: Communication with Senior Leadership $\ldots \ldots \ldots \ldots \ldots \ldots \ldots \ldots \ldots . \ldots 2$

Sub-Category: Unified Messaging................................... 63

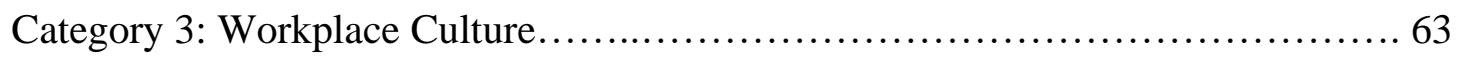

Sub-Category: Family-Like Environment.............................. 64

Sub-Category: Decentralized Organizational Structure....................... 64

Sub-Category: Recognition........................................ 66

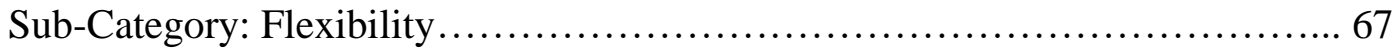

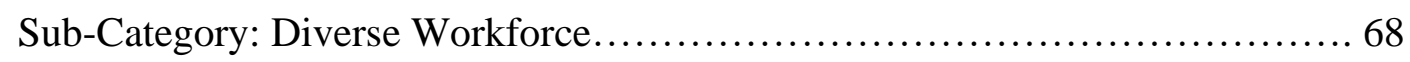

Sub-Category: Transparency of Organizational Goals....................... 69

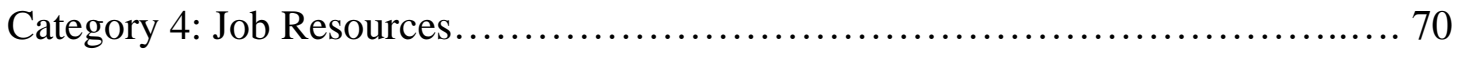

Sub-Category: Up-to-date Technology ................................. 70

Sub-Category: Efficient Procedures................................... 71

Category 5: Learning \& Development.................................... 71

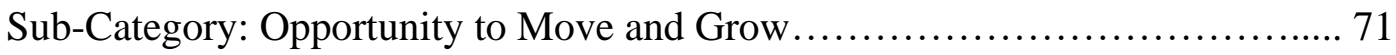

Sub-Category: Relevance of Training ................................. 72



Sub-Category: Opportunities for Promotion............................ 73

Sub-Category: Internship Programs.................................. 74

Category 7: Leadership............................................... 75 


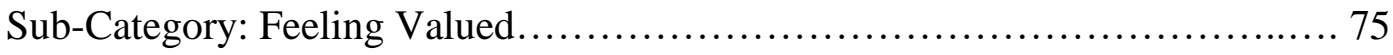

Sub-Category: Leadership Support...................................... 76

Sub-Category: Trust in Leadership..................................... 77

Quantitative Results................................................. 77

Table 6: Means, standard deviations, and correlations among the study variables... 80

\section{CHAPTER 5. DISCUSSION}

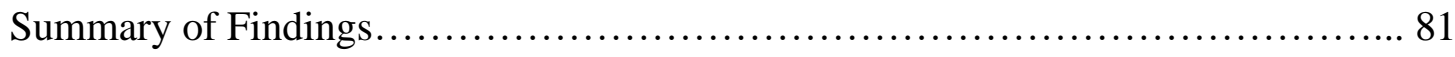

Discussion of Findings ................................................ 83

Organizational Pride..................................................... 83

Communication.................................................... 85

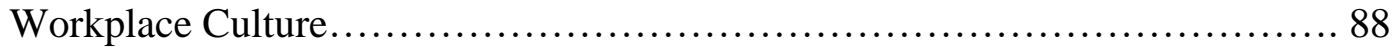

Job Resources.................................................... 90

Learning and Development........................................ 91

Career Growth.................................................... 92

Leadership...................................................... 93

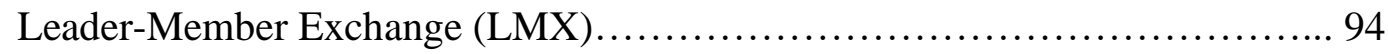

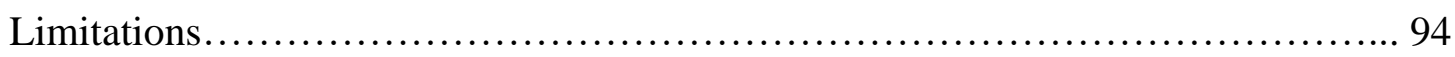

Theoretical Contributions............................................... 96

Practical Implications .................................................. 98

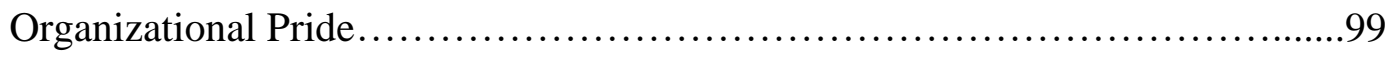

360 Communication................................................ 102

Learning and Development........................................ 103

Career Growth.................................................... 103 
Future Directions.................................................. 104

Conclusion............................................................. 107

Summary ....................................................... 107

References................................................................ 109

Appendix A: Determining Study Participants............................. 132

Appendix B: Recruitment Email Initial Invitation to Participate................ 133

Appendix C: Semi-Structured Interview Guide............................. 135

Appendix D: Informed Consent...................................... 141

Appendix E: Pre-Interview Reflection Question............................ 144

Appendix F: Union "Notice" Correspondence........................... 145

Appendix G: IRB Approval Letter................................... 147 


\section{Chapter 1: Introduction}

The shifting demographics of the U.S. workforce and the increasing shortage of skilled labor in many parts of the country make it crucial to retain talent within the organizations. Today organizations are making sizeable investments in talent management efforts, and the outcomes of these retention practices are vital for organizational competitiveness (Kostanek \& Khoreva, 2018).

Many organizations have difficulty retaining talented personnel in the $21^{\text {st }}$ century. Although this challenge is not new, it has increasingly become a topic of conversation as organizations are facing a mass exodus due to an increase in employee retirements and a favorable job market (Caramela, 2018; Kohnke, 2019; Wright, 2018). Organizations find it challenging to find ways to retain talented employees in an environment of dwindling budgets and an inability to hire employees to backfill their vacant positions. Organizations need quality staff to carry out their missions.

Talent retention is more critical now than ever and impacts public and private organizations. Organizations should evaluate differences among the generations in the workforce and adjust their strategies to retain talented employees. If the organizations don't improve their strategies, they may negatively influence an employee's decision to remain with the organization (Pitts, Marvel, \& Fernandez, 2011). In the public sector, the human capital search must seek strong, capable, and committed employees to fill those gaps (Ingraham, Selden \& Moynihan, 2000). As such, the public sector must be able to compete with the private sector, and the talent competition is fierce.

According to the Government Accountability Office (GAO) (2019), 31.6\% of government-wide employees will be eligible to retire by 2022. This is a significant loss 
to the federal government, and $31.6 \%$ does not include normal attrition. This talent loss may make finding the right people with the right skills increasingly difficult (Allen, 2008). According to Ployhart (2006), employers across the globe report struggling to hire employees with the skills essential for a $21^{\text {st }}$ century workforce.

Many federal organizations have already been experiencing talent shortages and continue to do so, specifically in the current pandemic environment. As a result of the novel coronavirus pandemic, agencies expect the budget restrictions to worsen, which may negatively impact the talent pipeline. Employees are needed to complete work that makes sure the country's infrastructure remains sound and that those that depend on the federal government continue to have their needs met. With the evolving workplace impact of the pandemic and its associated financial impact, such as hiring restrictions, having a better understanding of talent retention has never been more vital.

Allen (2008) states that "insufficient educational systems, increasingly mobile employees, and generational differences in perceptions about the nature of work and careers" may intensify talent retention challenges (p.5). There are currently five generations that coexist in the workplace. The Silent Generation (born between 19281945), Baby Boomers Generation (born between 1946-1964), Generation X (born between 1965-1980), millennials (born between 1981- 2000), and the Generation 2020 (born after 2000) (Fry, Igielnik, \& Pattern, 2018; Meister \& Willyerd, 2010). According to Alton (2017), by 2020, nearly half of the workforce will be comprised of millennials. Mastercard's Global Chief Talent Officer Kelly Joscelyne (2018) further suggests that millennials will comprise $75 \%$ of the world's workforce by 2025 , and $87 \%$ believe the success of an organization should be measured by having a sound strategy beyond 
financial success. These generational differences in work values and work expectations may have significant implications for companies that are grappling with talent retention issues. Although the data suggest that millennials will dominate the working population over the next five years, as a practitioner and researcher, I am specifically concerned whether younger workers require the same retention strategies as older workers. It is important to study millennials and their workplace behaviors. Still, I believe examining both Generation $\mathrm{X}$ and millennials will provide a more thorough insight into the strategies organizations should develop to retain talented employees. I also believe that different generation groups are not fundamentally different but are simply at different stages of their lives and careers.

\section{Human Capital Challenge in the Federal Government}

Agencies are increasingly in need of strengthening their efforts and the use of available incentives to maintain talent. The current workforce is more retirement eligible, and filling gaps in talent left by those employees are causing strategic human capital issues during times of continual budget constraints. Budget restrictions may require agencies to plan more purposefully, prioritize their organizational needs, gage outcomes, allot resources more prudently, and respond to personnel issues more expeditiously while achieving the organizational mission. The United States (U.S.) Federal Government is increasingly impacted by dwindling resources, and therefore retaining a talented workforce is vital to fulfilling the mission. The potential loss of workers impedes the capability of the federal government to continue to protect citizens based on the constitution and federal laws. This study is focused on the U.S. Department of Agriculture (USDA). The mission of the USDA is "to provide economic opportunity 
through innovation, helping rural America to thrive, to promote agriculture production that better nourishes Americans while also helping feed others throughout the world, and to preserve our Nation's natural resources ..." (United States Department of Agriculture, N.D.). All citizens benefit from agencies and programs created by the national government. Therefore, it is vitally essential for agency leaders to identify and use efficient talent management strategies to retain high-performing employees to fulfill the federal government's mission. Organizations are finding it challenging to keep employees committed in times of dwindling budgets and an inability to hire competent personnel due to hiring freezes. Therefore, organizations must develop best practices to retain talented employees.

The increasing talent retention problem is one that has plagued the federal government for some time now and, after much work, still is a challenge for federal government agencies. Human capital management has been a challenging issue with the Government Accountability Office (GAO) since 2001, as announced in President George W. Bush Management Agenda. In March 2007, the Managing Director of Strategic Issues for the Government Accountability Office testified before the Subcommittee on Financial Services and General Government, Committee on Appropriations, House of Representatives to discuss Federal Workforce Challenges in the $21^{\text {st }}$ Century. GAO (2007) found that agencies continued to encounter human capital challenges in numerous areas. One area of importance was that of acquiring, developing, and retaining talent. GAO found that "agencies need to strengthen their efforts and use of available flexibilities to acquire, develop, motivate, and retain talent" (GAO, 2007, Highlights Section). The federal government offers agencies the ability to use flexibilities, such as 
the use of special pay incentives to entice employees in specific occupations, student loan repayments, and tuition reimbursement to address the talent retention issues. However, agencies do not always use these incentives that may help to retain employees because they don't have the funding to implement or agencies are not sure these incentives will indeed increase talent retention, and therefore, they direct funding to other agency needs. This study will examine if agencies are using these incentives and whether they have an impact on employee retention. GAO (2007) suggests, “Augmented efforts are needed to improve...retention strategies to ensure that agencies have the needed talent" (GAO, 2007, p.2).

In July 2019, the Director of Strategic Issues testified before the Subcommittee on Regulatory Affairs and Federal Management, Committee on Homeland Security and Governmental Affairs, U.S. Senate, to discuss the ongoing human capital challenge again. This time focusing on cultivating federal recruitment efforts. GAO testified that after 12 years of bringing this issue to the forefront, the issue remains within the U.S. Federal Government. Although some improvement has been made, there is still a need for agencies to "motivate and retain employees by connecting them to their agency's mission" (GAO, 2019, p.12). In 2019, there remains considerable work to be done to continue to address the human capital challenge in the U.S. Federal Government. According to Wright (2018), millennials account for $35 \%$ of the workforce, and Gen Xers account for 33\% of the work force (Wright, 2018). This is consistent with the Office of Personnel Management's (OPM) Federal Workforce Data. Fedscope.opm.gov contains workforce data specifically for the public to review and analyze. The numbers in OPM's Fedscope database tells the story. Figure 1 shows the U.S. Department of 
Agriculture (USDA) employees by age for the fiscal years 2014 through 2018, and Table 2 shows the employment trends for the Fiscal Years 2014 through 2018 for the USDA.

Figure 1: USDA Employees by Age

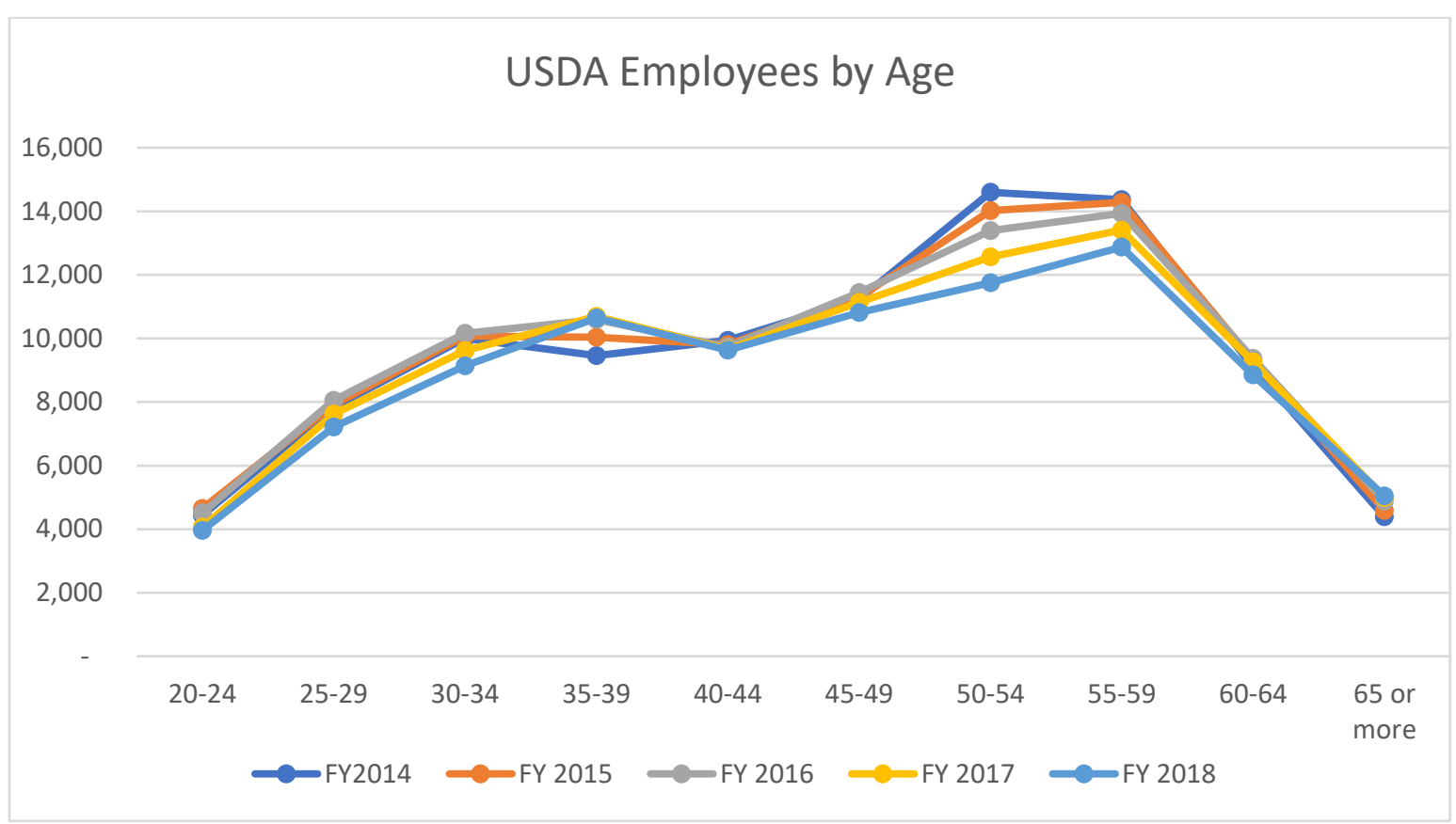

Source: United States Office of Personnel Management, 2019a

Figure 1 and Table 1 show an interesting trend that the highest number of employees tend to cluster around the ages of 45 through 60 in all fiscal years. These represent Baby Boomers (ages 50-68 in 2014 to ages 55-73 in 2018) and Generation X employees (ages 34-49 in 2014 to ages 39-54 in 2018) and if this trend continues the majority of these employees will soon be outnumbered by employees that are currently members of the later years of Generation Xers and the millennial generation. 
Table 1: USDA Employment Trends by Age

\begin{tabular}{|c|c|c|c|c|c|}
\hline Age & FY2014 & FY 2015 & FY 2016 & FY 2017 & FY 2018 \\
\hline $20-24$ & $5 \%$ & $5 \%$ & $5 \%$ & $4 \%$ & $4 \%$ \\
\hline $25-29$ & $8 \%$ & $8 \%$ & $8 \%$ & $8 \%$ & $8 \%$ \\
\hline $30-34$ & $10 \%$ & $10 \%$ & $11 \%$ & $10 \%$ & $10 \%$ \\
\hline $35-39$ & $10 \%$ & $10 \%$ & $11 \%$ & $11 \%$ & $12 \%$ \\
\hline $40-44$ & $10 \%$ & $10 \%$ & $10 \%$ & $10 \%$ & $11 \%$ \\
\hline $45-49$ & $12 \%$ & $12 \%$ & $12 \%$ & $12 \%$ & $12 \%$ \\
\hline $50-54$ & $15 \%$ & $15 \%$ & $14 \%$ & $13 \%$ & $13 \%$ \\
\hline $55-59$ & $15 \%$ & $15 \%$ & $14 \%$ & $14 \%$ & $14 \%$ \\
\hline $60-64$ & $9 \%$ & $10 \%$ & $10 \%$ & $10 \%$ & $10 \%$ \\
\hline 65 or more & $5 \%$ & $5 \%$ & $5 \%$ & $5 \%$ & $6 \%$ \\
\hline
\end{tabular}

Source: United States Office of Personnel Management, 2019a

The trends in both Figure 1 and Table 1 further indicate that the USDA workforce demographics are changing, and leaders need to evaluate current strategies and update them as necessary to retain talented employees to continue to support the mission in the future.

\section{U.S. Department of Agriculture (USDA) Context}

The U.S. Federal Government is accountable for safeguarding citizens and performs based on the constitution and federal laws. Members of society benefit from organizations and programs created by the national government; therefore, leaders need to pinpoint and use policies to retain top personnel to achieve the federal government's purpose. As of 2018, the U.S. Federal Government employed 4,111,307 million employees worldwide to help meet the needs of U.S. citizens. Of this total, 2,061,248 (50\%) are Executive Branch Civilian employees, and the remaining employees are Postal 
Service and Uniformed Military employees (United States Office of Personnel Management, 2019a; Jennings \& Nagel, 2020).

My study focuses primarily on the talent retention issues faced by Rural Development (RD), specifically the Business Center and three other USDA agencies within the Executive Branch. In November 2017, USDA Secretary Perdue released a memorandum mandating the realignment of several offices within the USDA. The primary goal of this realignment was to improve customer engagement, maximize efficiency, and improve agency collaboration. As part of this mandate, each mission area in USDA was directed to effectuate a consolidated business center to provide mission area wide enterprise solutions. Formally known as Operations and Management, the newly designed Business Center was created on September 30, 2018, and placed into the RD structure.

The RD Business Center is a centralized business hub with six-core offices, a subagency of RD, which is an agency under the umbrella of USDA. The RD Business Center consists of the financial, technology, human resources, enterprise, procurement management, and civil rights offices. The chief responsibilities of the Business Center include supporting RD's mission-critical operations, restructuring key business functions, and reducing costs through team-based and cross-functional methods. The RD Business Center shares in the global mission of RD “...to help improve the economy and quality of life in rural America..." (Rural Development, 2019b) and "to provide economic opportunity through innovation, helping rural America to thrive, to promote agriculture production that better nourishes Americans while also helping feed others throughout the world, and to preserve our Nation's natural resources ..." (United States Department of 
Agriculture, 2019). With over 25 agencies and offices and almost 100,000 employees that serve the U.S and abroad, USDA is committed to helping the American people (United States Department of Agriculture, 2019). Even in times of decreased spending mandated by a decrease in annual appropriations, USDA still must continue its vital work.

Similar to the talent challenges in other agencies, USDA is facing critical talent retention issues. A reduction in staff through normal attrition, a significant increase in retirements, and the lack of funding to hire replacements necessitate the need for the USDA to develop strategies to aid in the retention of talented high-performing employees. According to the United States Office of Personnel Management (2019b), USDA has lost over 84,000 employees between the years of 2015 and 2018 through transfers to other federal government agencies, retirements, and employees leaving the federal government. In other words, USDA faced an attrition rate of approximately $22 \%$ between the years 2015 to 2018 . This can be attributed to sequestration, the federal government's method of applying required spending cuts across programs and agencies during the budgeting process, as well as several furloughs the federal government experienced that may have played a significant role in separations. During this time of increasing budget restraints and the continuing financial uncertainty related to the pandemic, it has never been more important for the USDA to develop strategies to retain its talented employees. Table 2 shows the number of employee separations for the fiscal years 2015 through 2018 . 
Table 2: USDA Separations by Year

\begin{tabular}{|l|c|c|c|c|}
\hline & FY 15 & FY 16 & FY 17 & FY 18 \\
\hline $\begin{array}{l}\text { Number of total employee separations as a percent of } \\
\text { the total number of employees }\end{array}$ & $21 \%$ & $21 \%$ & $22 \%$ & $22 \%$ \\
\hline $\begin{array}{l}\text { Number of separations related to discipline and } \\
\text { performance issues as a percent of the total number of } \\
\text { employees }\end{array}$ & $<0 \%$ & $1 \%$ & $1 \%$ & $1 \%$ \\
\hline $\begin{array}{l}\text { Number of separations related to discipline and } \\
\text { performance issues as a percent of the total number of } \\
\text { separations }\end{array}$ & $2 \%$ & $2 \%$ & $3 \%$ & $3 \%$ \\
\hline
\end{tabular}

Source: United States Office of Personnel Management, 2019b

Table 2 indicates that approximately $21 \%$ of the total number of employees separated from USDA each year, with only $1 \%$ of those employees having any discipline or performance issues. This means that most of the employees who separate are highperforming employees whom the USDA would want to retain. Also, Table 2 indicates that the separations that are related to discipline or performance issues are only $3 \%$ of the total number of separations. These numbers indicate approximately $97 \%$ of those separated each year were employees that received a rating of at least fully successful and were employees that the agencies should want to retain. Of the $97 \%$ of separated employees with at least a fully successful performance rating, 91\% were voluntary separations from USDA, and only about $6 \%$ each year were either individual transfers or mass transfers whose job functions moved to another agency. This means that of those who left their agencies, $91 \%$ were voluntary separations, which supports the importance and urgency of effective talent retention initiatives.

\section{Purpose and Contribution of this Research}

Organizations are experiencing a loss of employees as a result of normal attrition and an increase in retirements. As this trend continues, organizations will continue to experience significant gaps in talent. Federal agencies need to intensify efforts and use of 
tools to retain top talent. The budget constraints don't help federal agencies with this dilemma but requires agencies to plan better for current and upcoming challenges in talent retention. There is a need for federal agencies to understand the dynamics associated with talent retention and worker values and expectations that have implications for talent retention. Identifying the causes that impact staff retention and using that information to develop strategies that positively impact employee retention is necessary to have continued growth and efficiency.

My study addresses the problem associated with the retention of talented employees. U.S. federal agencies that fail to adapt to and understand this problem may continue to fail to attract and retain talented employees. The U.S. Federal Government is increasingly impacted by declining resources, and retaining talented personnel is imperative to fulfilling the mission. The potential loss of employees may impede the ability of the federal government to fulfill its purpose. Agency leaders are finding it challenging to retain talented employees in times of dwindling budgets and an inability to hire competent employees due to decreases in annual appropriations to fund agencies year after year. Each agency's priority is to support customers and achieve their mission. Organizations must develop the best strategies to retain their employees. It is vital that organizations, including federal agencies, move from rigid strategies to new policies that adapt to the needs of their changing workforce. Organizations that fail to adapt will likely fail to retain talented employees (Kostanek \& Khoreva, 2018).

The goal of this study is to conduct a qualitative examination to determine effective strategies federal agencies can use for talent retention among Generation Xers and millennials. According to Allen (2008), an all-inclusive employee retention program 
is crucial in attracting and retaining talented employees, as well as decreasing turnover and its associated expenses. Talent retention strategies improve a company's efficiency and overall business performance (Allen, 2008). It is more effective to maintain a talented employee than to hire, guide, and train an additional employee of the same caliber (Nguru \& Hichuhi, 2018). Therefore, organizations must develop talent retention strategies that result in better employee retention. Through a qualitative examination of talented Generation X and millennial government employee attitudes towards federal government employment practices and benefits, this study aims to discover actionable insights for agencies interested in retaining talented employees. This study focuses on USDA agencies, and the findings informing talent retention issues should prove beneficial to the federal government context.

\section{Research Question}

How can the United States Department of Agriculture retain talent?

\section{Summary}

A talent retention problem exists in the U.S. federal government. The critical issue is that the future capability of the U.S. federal government to provide vital services rest on its ability to retain talented employees. The purpose of this study's qualitative design is to explore employee work values and expectations and identify strategies the federal government can use to implement practices to retain talented employees. The study design will consist of semi-structured interviews with 25 talented Generation $\mathrm{X}$ and millennials employees within RD's Business Center and three other USDA agencies located throughout the United States. The purpose is to understand high-performing Generation $\mathrm{X}$ and millennial employee perspectives on talent retention issues and to 
make substantive conclusions from the study's findings for a comprehensive list of actionable insights and recommendations on talent retention. The study will include respondents from across the country for a broader representation of challenges and perspectives.

The following chapter will present a thorough review of the emerging literature on Generation $\mathrm{X}$ and millennial work values and expectations, as well as a review of previous research on talent retention and turnover, and leader-member exchange (LMX), followed by a discussion of the study's guiding theoretical framework. Chapter 3 presents the research design, sample characteristics, the analyses employed, and why this methodology was chosen. The results of the study will be presented in Chapter 4 . Finally, Chapter 5 will discuss the study's findings, its limitations, contributions, theoretical implications, and practical contributions, as well as directions for future research. 


\section{Chapter 2: Theoretical Base and Hypotheses}

\section{Review of Literature}

The purpose of this study was to determine through a qualitative examination, effective strategies federal agencies can use for talent retention among talented (i.e., high performing) Generation Xers and millennials. Talent retention is an essential topic with implications that impact all organizations. There is an extensive amount of literature that focuses on retaining Generation Xers and millennials in the workplace (Ibidunn, Osibanjo, Adeniji, Salau, \& Falola, 2015; Kostanek \& Khoreva, 2018; Park \& Gursoy, 2012). However, there is no empirical research exploring the issue of retaining talented employees in the U.S. Federal Government, and strategies agencies can use for talent retention. This chapter outlines the findings of an exhaustive review of literature relating to Generation Xers and millennials in the workplace, talent retention, turnover, and leader-member exchange (LMX) to offer context to the study of retaining talented employees in the U.S. Federal Government.

In performing the literature review, the following online databases and search engines were used: ABI/INFORM Complete, Business Source Complete, ResearchGate, Google Scholar, and ProQuest. The key search terms and combination of search terms that were used in various online databases included the following: millennials, generation $x$, talent retention, retention, turnover intentions, federal government turnover, retention and federal government, leader-member exchange, resource-based view theory, human capital theory. All terms yielded studies relevant to the problem and the research question. 


\section{Generational Differences}

The literature on generational differences includes diverse perspectives regarding the relationship between the behaviors, expectations, and values of individuals born in a set of years and the shared collective attitudes and experiences among them (Lyons \& Kuron, 2014). The personality traits developed in early developmental years shape individuals' behaviors and decisions over a lifetime (Lyons \& Kuron, 2014).

Understanding the differences and characteristics of each generation provides a deeper understanding of the distinct issues each generation cares about. There is importance in scientifically studying generational differences in the workplace. Scientific research allows organizations to recognize the values and expectations of employees through rigorous research rather than judging them according to stereotypes (Hershatter \& Epstein, 2010; Ng \& McGinnis Johnson, 2015; Thompson \& Gregory, 2012). Organizations, managers, and human resource professionals must understand career patterns to make the adaptations necessary for current and future generations (Baruch, Szucs, \& Gunz, 2015).

A Pew Research Center Study (2018) indicated that approximately 200,000 baby boomers (born 1946 to 1964) exit the workforce monthly and are replaced by Generation X (born 1965 to 1980), millennials (born 1981 to 1996), and Post-millennial (born after 1996) workers. The increasing shift in generations within organizations has a significant impact on the work culture and overall worker attitudes. According to Pew Research (2018), as of 2017, 56 million millennials (those ages 21 to 36 in 2017) were employed or looking for work, more than the 53 million Generation Xers who accounted for a third of the workforce. 
Generation X. Over the last several years, numerous research studies have been conducted that delve into Generation X characteristics (Becton, Walker, \& Jones-Farmer, 2014; Hannam \& Yordi, 2011; Lyons, Ng, \& Schweitzer, 2014; Park \& Gursoy, 2012; Smith \& Nichols, 2015; Trapero, Villa-Castano, Vazquez, \& De la Garza Garcia, 2017). Generation Xers have been described as an empowered, self-directed, tech competent, flexible, practical, self-reliant, and a self-governing generation. Generation Xers have been found to work hard within a planned workday, and many dislike being micromanaged while carrying out a task and prefer supervisors to keep their distance and let them complete their assignments (Lyons et al., 2014; Park \& Gursoy, 2012). Also, they tend to prefer direct communication that is clear and concise (Hannam \& Yordi, 2011).

Generation X places emphasis on a balance between work and home, they want flexible work arrangements, and they are willing to change jobs frequently to meet their needs (Hannam \& Yordi, 2011; Trapero et al., 2017). Technology-wise, members of Generation $\mathrm{X}$ are savvier than former generations, because they grew up with the internet and various technologies, such as cell phones and fax machines (Festing \& Schafer, 2004). Previous research has also identified that Generation Xers' workplace expectations may play a dominant role in influencing how these workers prefer to be supervised. According to Constanza, Badger, Fraser, Severt, and Gade (2012), Generation Xers believe a job is a job, a means to an end, and they view each job as a steppingstone to something better. They tend to see corporate loyalty as being beneficial until something better comes along. Although they have been described as a generation that resists corporate loyalty, they desire time with and positive reaction from their managers and connectedness with other organizational colleagues. 
Millennials. The Deloitte global millennial survey (2019) reveals that only $28 \%$ of millennials expect to work in their current jobs for more than five years, and $43 \%$ expect to leave within two years. The study also revealed that for employees who expect to stay longer than five years, their employers' priorities are more likely to match their priorities relating to diversity, flexibility, work culture, corporate social responsibility, and ethics. Stewart, Oliver, Cravens, and Oishi (2017) suggest that millennials associate organizational commitment and organizational culture with retention and selfperformance.

Over the last several years, numerous research studies delved into millennial characteristics (Allen, Allen, Karl, \& White, 2015; Beccalori, 2017; Ferri-Reed, 2014; Hershatter \& Epstein, 2010; Ng \& McGinnis Johnson, 2015; Thompson \& Gregory, 2012). Characteristics such as expectations for positive feedback and praise are found to be consistent for millennials across work contexts (Hershatter \& Epstein, 2010). Previous research has also shown that millennials are highly mobile and expect significant change and variety in their job assignments and careers (Lyons et al., 2014). Millennials do not want an organization to work at in which they could stay long term. This represents a significant shift from the career interest of the past, in which long-term employment in a single organization was the goal or expectation for baby boomers and Generation X (Lyons et al., 2014; Ng, Schweitzer, \& Lyons, 2012). Millennials also place great emphasis on work-life balance, and they are willing to limit career in favor of a desirable lifestyle and may forgo increases in pay and career growth if the requirements don't meet their personal needs (Ng \& McGinnis Johnson, 2015; Thompson \& Gregory, 2012). Additionally, millennial generation employees value corporate social 
responsibility, work-life balance, training, and development opportunities (Festing \& Schafer, 2014)

According to Festing and Schafer (2014), millennials were born into an era of the computer and are adept at working with technology which often leads them to be an asset to those organizations in need of knowledge of new technologies which is especially important in the current age of increasing corporate digital transformation. Ertas (2015) suggests that millennial workers may depart their jobs at a higher proportion than previous generations. Ertas (2015) findings further suggest that job satisfaction may be one of the most significant drivers of turnover. This implies that organizations should attempt to improve organizational practices valued by millennial workers and create strategies that positively impact job satisfaction to retain millennials (Ertas, 2015).

Generation X and Millennials. Based on the literature, Generation X and millennials tend to be more individualistic than the previous generations. Both generations learn quickly, are very well educated, and are technologically savvier than previous generations, since they grew up in the era of the internet. Both generations place less value on being loyal to their employers and are more likely to change jobs than employees of earlier generations. According to Becton, Walker, and Jones-Farmer (2014), although literature seems to be split on generational stereotypes and their impact, research agrees that to be effective, organizations should opt to develop strategies that address the needs and values of all employees regardless of the generation cohort.

\section{Talent Retention}

Turnover and retention research began over six decades ago with the introduction of organizational equilibrium theory (March \& Simon, 1958). March and Simon's (1958) 
theory emphasized balancing both employee and organization contributions (inputs made to the organization) and inducements (compensation to participants). In March and Simon's (1958) seminal work, there are two decisions made when interactions occur between the organization and employee. One of the decisions relate to that of deciding to produce, and the other decision relates to deciding to participate. The production decision determines whether the employee is willing to work hard and deliver as much as is required. The decision to participate determines whether employees choose to stay or leave the organization. Both decisions independently operate and impact an employees' impetus to leave an organization (Holtom, Mitchell, Lee, \& Eberly, 2008). Early turnover and retention research continued to evolve into new models and constructs. Researchers such as Mobley (1977) who identified what employees go through when considering turnover; Mobley, Griffeth, Hand, and Meglino (1979) who studied what influences withdrawal and the moderating effects of job satisfaction, expected utilities, and impulsivity on an employee's turnover decision; and Steers and Mowday (1981) who studied the influence of job performance and job satisfaction on employee's decision to leave or stay with an organization. Meyer and Allen (1991) developed a model that suggests three components of commitment (affective, continuance, normative) that help to understand turnover and withdrawal behaviors and attitudes. However, these models and constructs focused on the process an individual goes through when separating from an organization and the individuals' relationship with their environment. None of the studies focused on examining the employee's decision to stay with the organization.

Within the last two decades, Mitchell, Holtom, Lee, Sablynski, and Erez (2001) seminal work introduced the construct of job embeddedness as a model to understand 
why employees stay with an organization. Mitchell et al., (2001) identified three significant characteristics of job embeddedness: "(1) the extent to which people have links to other people or activities, (2) the extent to which their job and community are similar to or fit with the other aspects in their life and space and, (3) the ease with which links can be broken — what they would give up if they left, especially if they had to physically move to another city or home" (p.1104). It is essential to understand what drives workers to depart an organization, and it is just as important to understand why workers choose to stay (Allen, 2008). Previous studies have suggested that employees might become embedded in their jobs and communities; they develop connections and relationships, on and off the job, which have repercussions for talent retention. (Allen, Peltokorpi \& Rubenstein, 2016; Holmes, Chapman \& Baghurst, 2013; Ibidunn et al., 2016; Rubenstein, Kammeyer-Mueller, Wang \& Thundiyil, 2019). Lee, Sablynski, Burton, and Holtom (2004) examined the dimensions of on-the-job and off-the-job embeddedness separately. There are three-dimensions associated with job embeddedness, fit, sacrifice, and links, all-important both on and off the job. Lee et al. (2004) found that off-the-job embeddedness predicts turnover and absence, and on-thejob predicts organizational citizenship behaviors and job performance. The study's results can be used to increase talent retention as the findings indicate ways to build community and help establish ties to the organization to make employees feel more a part of the organization.

Allen (2006) employed a different approach focused on using job embeddedness to embed newcomers through organizational socialization aspects. Through an examination of job embeddedness as a mediator between socialization tactics and 
turnover among newcomers, Allen (2006) suggested providing newcomers in an organization with an understanding of how they fit into the organization's plans and help them find their place. The results of the study indicated that retention increased when newcomers were embedded into the organization from day one with a positive response as they acclimate, participating in inclusive orientation activities, and provided with clear expectations. In another study, Mallol, Holtom, and Lee (2007) examined job embeddedness from a cultural perspective, specifically with a focus on differences between Hispanics and Caucasians as they found that Hispanics are more entrenched in their jobs than Caucasians. Mallol et al. (2007) not only provided a different perspective that organizations should consider when examining diversity but also provided further support that job embeddedness is a predictor of employee turnover as well as a practical guide for organizations on effective retention strategies.

\section{Turnover}

Previous research conducted over the last six decades provides well-established findings consistently on numerous variables that significantly affect an individual's desire to leave an organization. Griffeth, Hom, and Gaertner (2000) conducted a meta-analysis of over 40,000 employees and revisited decades of research and found several key turnover drivers that impact talent retention. These drivers include job content, external environmental factors, and co-workers; however, the most prominent drivers are work and job satisfaction, leadership, demographics, and stress-related variables (Allen, 2008; Bauer, Erdogan, Liden, \& Wayne, 2006; De Croon, Sluiter, Broersen, Blonk, \& FringsDresen, 2004; Griffeth et al., 2000; Kim, 2014; McKnight, Phillips, \& Hardgrave, 2009; Rousseau \& Aube', 2000; Waldman, Carter, \& Hom, 2015). 
Previous research has found the quality of the relationships between the leader and the employee (LMX) and supervisor satisfaction to be significantly and negatively related to turnover intentions (Allen, 2008; Bauer et al., 2006; Griffeth et al., 2000; McKnight et al., 2009; Waldman et al., 2015). Research findings examining job satisfaction suggest a significant and negative relationship between turnover intentions and job expectations, job involvement, job resource adequacy, work-life balance, creativity, pay satisfaction, and job satisfaction (Allen, 2008; Griffeth et al., 2000; Kim, 2014; McKnight et al., 2009; Ng \& McGinnis Johnson, 2015; Rousseau \& Aube', 2010; Waldman et al., 2015). Previous research has also found demographics to play a role in turnover intentions, such that younger employees (as compared with older employees), early-career employees (as compared with mid and late-career stage employees), and employees without children (as compared to employees with children) are more likely to report higher turnover intentions (Allen, 2008; Griffeth et al., 2000). Research examining compensation suggests a significant and negative relationship between turnover intentions and pay satisfaction and distributive justice (Allen, 2008; Griffeth et al., 2000; McKnight et al., 2009; Waldman et al., 2015). Further, previous research suggests a significant and negative relationship between turnover intentions and role clarity and a positive correlation between turnover intentions and role conflict (Allen, 2008; De Croon et al., 2004; Griffeth et al., 2000; McKnight et al., 2009; Waldman et al., 2015).

In my study, I was not interested in the previously identified drivers of turnover intentions that have already been discussed in previous literature. Instead, I'm interested in adding to the list of variables already identified. My research may replicate some of the same variables that have already been found by previous research and support their 
relevance in the federal government context; however my primary objective is for this study's findings to add to the current body of knowledge. My research will explore variables beyond what has been identified in previous research and offer new variables for USDA agencies and inform the federal government talent retention efforts. The variables that the current study will identify will help inform best practices to address retaining talented employees.

\section{$\underline{\text { Retention Strategies }}$}

Lack of attention to organizational talent retention drivers can lead to misinterpretation about how to manage retention in an organization (Allen, Bryant, \& Vardaman, 2010). This misinterpretation can lead to harmful effects on the organization, such as ineffective retention strategies "that retain the wrong employees while chasing away the most important ones" (Allen et al., 2010, p.49). Deery and Jago (2015) found that work-life balance is a problem and that more strategies need to be in place to reduce its influence on turnover. Talented employees are increasingly devoted to their partners' professions alongside their own; however, organizations haven't yet figured out how to accommodate dual-career millennial couples (Petriglieri, 2018). Naim (2018) found that mentoring as a strategy had an impact on millennial turnover intentions and can produce positive work behaviors. If an organization wants to win this talent war, it must develop strategies that help find, nurture, develop valuable employees through better talent retention strategies. Investing in developing effective talent retention strategies increases an organization's ability to succeed.

These strategies should not be just random; in fact, it's a common misconception that a one size fits all retention strategy is effectual (Allen et al., 2010). Creating an 
evidence-based method to address turnover necessitates the capacity to diagnose the degree to which turnover is a hindrance and acclimate an understanding of essential retention standards to an organizational framework (Allen et al., 2010). An organization must decide what type of evidence-based management strategy is appropriate for retention issues in their organization. There are two types of retention strategies; methodical and directed. Methodical strategies are proposed to decrease turnover rates across the organization; directed strategies influence retention among certain populations of employees (Allen et al., 2010). This study is interested in targeted strategies given the study's focus is on a specific population, the Generation Xers and millennials working for the federal government. These two generations constitute almost $70 \%$ of the federal government workforce (United States Office of Personnel Management, 2019a). Bussin (2018) examined reward strategies and determined that they are not one size fits all and the characteristic of the organization and what its employees value must be considered. According to Bussin (2018), a group of employees may value diverse reward components; as such, the organization must create a balanced strategy that is suitable to equalize the capability and resources of the organization against retention drivers of the organization's employees. Bussin (2018) found that although competitive remuneration (pay) may serve as a useful strategy for retention, it may be more effective to develop a total rewards strategy that includes remuneration, benefits (health insurance retirement plans), work-life balance (plans that allow employees to be successful at home and work), recognition (reward performance and behavior), performance management (measured against clearly defined goals), and talent development (tools to promote employee career growth). 


\section{Leader-Member Exchange (LMX)}

Leader-Member Exchange (LMX) theory was born out of the need to understand better and define the dyadic relationship amongst a leader and a member of the leader's workgroup (Dansereau, Graen, \& Haga, 1975; Graen, 1976; Graen \& Cashman, 1975; Graen \& Scandura, 1987; Liden \& Maslyn, 1998). LMX further develops the theory of Vertical Dyad Linkage (VDL) and its emphasis on dyadic relationships in which one person has direct authority over another individual. Researchers contend that the dyadic relationship between a leader and each member is developed over time through a series of interactions. These interactions happen over some time where the quality of the exchange relationship develops and increases or decreases, and the quality of the leadermember relationship may vary among members of the same workgroup (Dansereau et al., 1975; Greguras \& Ford, 2006; Han \& Jekel, 2011).

LMX research has progressed over the years, and the construct definition has evolved into a multi-dimensional construct (Dienesch \& Liden, 1986; Liden \& Maslyn, 1998). A multi-dimensional examination of LMX allows for a more complete understanding of LMX quality (Greguras \& Ford, 2006), especially within the context of talent management. Liden and Maslyn's (1998) four-dimensional model include affect, loyalty, contribution, and professional respect as the four dimensions of LMX quality. Affect refers to the mutual liking a leader and member may have for each other based mainly on interpersonal attraction rather than work or professional values. Loyalty refers to the level of loyalty for the other member of the dyadic relationship. Contribution refers to the amount and quality of work activity each member of the dyad puts forth 
towards the mutual goals. Professional respect is defined as the extent to which each member of the dyad has a reputation of excelling at their line of work.

Previous research on LMX suggests that effective leadership occurs when there is a high-quality relationship between a leader and a member of the workgroup. This highquality relationship may lead to a preferential treatment that includes a high level of decision latitude, expanded growth opportunities, and higher levels of support (Graen, 1976). According to Han and Jekel (2011), high-quality LMX employees are likely to get different levels of attention and support from their supervisors in exchange for their hard work and loyalty. Also, research has found high-quality LMX relations to contribute to numerous favorable attitudes and behaviors of employees including higher levels of commitment, higher levels of performance, more autonomy when it comes to decision making and unique opportunities as related to mentoring and tools to complete work tasks (Dienesch \& Liden, 1986; Liden \& Maslyn, 1998; Scandura \& Graen, 1984; Pellegrini \& Scandura, 2008). These previous findings suggest a significant and negative relationship between high-quality LMX and turnover intentions, which is specifically relevant for talent retention research. In a meta-analytic study, Griffeth, Hom, and Gaertner (2000) report that the relationship between LMX and actual turnover is significant and negative. In a more recent meta-analysis, Dulebohn, Bommer, Liden, Brouer, and Ferris (2012) found LMX to be significantly and negatively related to both turnover intentions and actual turnover behavior.

Similarly, I expect high-quality LMX relations to play a significant and positive role in talent retention. I included LMX in this study to extend previous findings to the 
federal government context. I will assess LMX quantitatively from the employee's perspective during the interviews, for triangulation of findings.

\section{Theoretical Framework}

The theoretical foundation of this study is based on Resource-Based View (RBV) and Human Capital Theory (HCT) as they each provide direction and a solid foundation for an organization capitalizing on talent retention for competitive advantage.

\section{$\underline{\text { Resource-Based View }}$}

RBV asserts that competitive advantage comes from distinct resources or abilities that organizations manage, something that organizations do specifically well in contrast with their competitors (Barney, 1991). RBV suggests that if an organization's resources are precious, unusual, incomparable, and non-exchangeable that it will aid an organization in maintaining competitive advantage (Barney, 1991). One of the primary purposes of instituting strategies for talent retention is to create a competitive advantage for sustainability and acceleration of performance over industry peers. As a framework, RBV, posits "firms obtain sustained competitive advantage by implementing strategies that exploit their internal strengths through responding to environmental opportunities while neutralizing external threats and avoiding internal weaknesses" (Barney, 1991, p. 99).

For a firm's resources to contribute to attaining a competitive advantage or a sustained competitive advantage they must meet four criteria: they must be valuable, in that they take advantage of opportunities and counteract threats, they must be uncommon among a firm's existing and potential industry players, they must be imperfectly imitable, 
and, they must not have comparable replacements that are valued but neither rare nor imperfectly mobile (Barney, 1991).

In many organizations, talent retention falls under the purview (entirely or at least with some significant involvement) of human resources (HR). When a firm has effective talent retention strategies, it is in large part due to HR leveraging its resources that yield a resource-based competitive advantage (Wright, Dunford, \& Snell, 2001). Hence, Wright et al. (2001) suggest that the RBV has become the most often used theory within the Society for Human Resource Management (SHRM), both in theory development and in empirical research. As such, although Barney's (1991) original conceptualization focused on private corporations, this theory can be applied to the public sector in examining existing competencies and developing new ones, such as talent retention strategies (Bryson, Ackermann \& Eden, 2007).

\section{Human Capital Theory}

Human Capital Theory (HCT) is relevant as a theoretical framework because talent retention is primarily associated with personnel growth; HCT could shed some light on this study's findings. HCT suggests education and training are a form of investment in human resources and therefore helps raise profits and revenue for organizations (Becker, 1993). It also recommends that organizations should utilize social capital to boost efficiency and that human capital is needed for economic expansion (Becker, 1993). According to HCT theory, an essential element of a firm's competitive advantage against other firms comes from the skills and level of competence of the employees (Becker, 1993). Highly skilled employees and increased competence allow firms to produce goods and services more efficiently, thereby having the potential to 
increase revenues and increase an organization's growth. As such, although Becker's discussion was limited to those organizations that produce goods and services for a profit, this theory can also be applied to the public sector in an agency's efforts to become a leader in their federal government sector. Moreover, HCT is concerned with how people in an organization add their expertise, talent, and capabilities to enriching organizational capacity and the importance of that contribution that brings economic value to the organization (Becker, 1993). In the current study, talent retention will be considered successful to the extent the organization can draw upon talent with the requisite knowledge, skills, and abilities to lead the organization to meet its performance goals.

\section{Summary}

Most of the previous research on Generation Xers and millennials have been conducted from the aspect of why employees leave (i.e., turnover) as opposed to why employees stay. However, talent retention must be examined in-depth to determine effective retention strategies. The current state of talent retention research is not sufficiently informative for addressing the dilemma today's organizations face in retaining talented employees and the effective retention strategies to retain them. This research undertakes an essential and timely endeavor in understanding why Generation X and millennials employees choose to stay. Findings should inform talent retention strategies that an organization could employ in addressing the problem of retaining talented employees. The results will also inform research on Generation X, millennials, and talent management by providing an in-depth understanding of the factors that influence talent retention amid shifting workforce demographics. 


\section{Chapter 3: Methodology}

The study employed a qualitative design with semi-structured interviews of talented employees to address the research question: "How can the United States Department of Agriculture retain talent?" Findings from this research will help develop strategies that provide insight into practices RD could use to improve their ability to retain talented employees. First, I describe the method, analysis, and the sampling strategy employed. I then report the results in Chapter 4. The study's findings will contribute to practice as well as the existing body of academic literature on talent retention by extending research to the federal government context and creating a list of strategies agencies can use to retain talented employees. Through a rigorous study of a pressing issue in practice, the results of this study are significant to practice in USDA agencies and help contribute to bridging the gap between rigor and relevance in management research (Banks, Pollack, Bochantin, Kirkman, Whelpley, \& O’Boyle, 2016).

\section{Research Design}

Qualitative research was "developed in the social sciences to enable the study of social and cultural phenomena" (Myers, 2013, p. 8). This approach to research includes observations, fieldwork, interviews that will help to understand a subject's feelings, perceptions, and motives. This study employed a qualitative approach design and included an in-depth examination of employee values and expectations in one federal agency, the USDA. Qualitative research was preferred as it allows the researcher to understand the context in which decisions and actions take place (Myers, 2013). Qualitative research also provides richer data to understand an individual's motivations, 
reasons for their actions, and the context of their beliefs and activities, which are all relevant and vital in informing talent retention research in U.S. Federal Government agencies.

Given my interest in human experiences using descriptive data and an in-depth understanding of retention of high performing talent, quantitative research was not appropriate for this study. The objective of this study was to collect data through expressive discussions relevant to talent retention to inform strategies USDA can use to retain talented employees. Since my study focused primarily on qualitative research, I was able to engage in insightful and comprehensive discussions and gain direct accounts and descriptions that directly inform what strategies Rural Development can employ to retain talent.

Qualitative research allows researchers to choose from among several methods, such as case study research, action research, grounded theory research, and ethnography (Myers, 2013). The current study employed a case study research approach. Yin (2017) suggests that a case study approach should be preferred when "you want to understand a real-world case and assume that such understanding is likely to involve important contextual conditions pertinent to your case" (p. 15). Federal government work context may be different than other business organizations, and therefore the work environment in this study may be a contextual condition that necessitates a case study approach. The case study approach allows the researcher to get closer to the "action" to investigate a question within its real-life context. Through a case study methodology, a researcher can gain more in-depth insight that may not otherwise be discovered via other methods. Case study research is commonly employed in social sciences such as sociology, political 
science, and business to gain an in-depth understanding of an issue in its real-life context (Yin, 2017).

\section{Sampling Process}

I approached RD Business Center staff headquartered in Washington, D.C., with staff offices located in various cities across the United States. I requested a meeting via email to agency leadership, requesting a time to meet to discuss the qualitative survey and make a personal request for voluntary, anonymous participation. After the briefing, approval was granted by senior leadership in the RD Business Center to pursue the study. Senior leadership suggested a focus on all eligible employees with performance ratings of Fully Successful, Superior, or Outstanding for Fiscal Years 2018 and 2019. Since the organization has a bargaining unit, I also reached out to the heads of the various bargaining units where I interviewed representative employees to make them aware of the study and received a positive response (see Appendix F).

Once I received approval, I sent a letter to the human resources (HR) personnel and requested information on employees that met the research criteria. I requested a listing of all employees in the RD Business Center, who were:

(1) Born after 1970 and before 1991 (no birthdates were disclosed) I started Gen X at 1970 (instead of 1965) because participants would have a significant interest in employment at the agency before retirement as they still have several years before they are eligible to retire. Additionally, I used the cutoff of 1991 (instead of 1996) for millennial employees as those participants would have been employed for several years, and they would inform my study better because of their years of experience in the federal workforce. 
(2) Employed with RD for at least three years, (no employee's length of service was disclosed);

(3) Had a performance rating of Fully Successful, Superior, or Outstanding for the last two fiscal years (FY 18 and FY 19) (no employee performance ratings were disclosed).

Millennial and Generation X employees that work for the USDA across the United States and fit all three study inclusion criteria totaled 1,166 employees. The final sample consisted of 25 participants identified (by HR and themselves) as Generation X and millennial; employed with RD for a minimum of three years and received at least a fully successful rating during the last two rating periods (October 01, 2017 to September 30, 2018, and October 01, 2018 to September 30, 2019).

According to the information I retrieved from the USDA, RD website, USDA Service Center Employee Directory and further confirmed by a list I received from the RD Human Resources Office, I first removed any employees working in the Washington, D.C. metro area as agency leadership felt that those employees have several opportunities to move to another agency with most U.S. federal agencies having multiple offices in that location. Then, I removed temporary and part-time employees, senior executive service employees, and student employees. The population of 1,166 employees was reduced to the sample population of 286. Among the 286 employees who qualified for this study, I randomly selected 25 for the interviews.

I created a master spreadsheet that identified the eligible participants representing bargaining and non-bargaining employees at all grade levels and occupational series throughout the country. I included people from all levels and jobs, with a final group of 
25 employees participating from six centers within the RD Business Center as well as three other USDA agencies. It should be noted that as part of the random sample, none of the Civil Rights Office employees were selected to participate in the study as none of those employees met the three requirements identified in this study. Participants held supervisory (includes quasi-supervisor roles such as Team Leader) $(n=18)$ and nonsupervisory $(n=7)$ positions, including accountants, phone representatives, human resource specialists, IT staff, workflows, and analysts. Twelve participants were male (48\%), and 13 were female (52\%), 16 were from the Generation X generation, and 9 were members of the millennial generation, averaging 14.5 years of work experience at USDA $(\mathrm{SD}=6.13)$ with an average of 2.27 years working with their current supervisor $(\mathrm{SD}=$ 3.37) and an average of 15.53 years as a federal employee $(\mathrm{SD}=6.40)$. Six participants (24\%) had bargaining unit status. Participants ranged in pay grade levels from GS-8 to GS-15 across various occupational series within USDA. Respondents were recruited from 11 states across the U.S. Most of the participants (56\%) were from Missouri $(n=14)$, followed by Montana $(n=2)$. Other work locations included Arkansas, Colorado, Iowa, Idaho, Indiana, Minnesota, Pennsylvania, Virginia, and Wyoming. Table 3 provides an overview of the participants in this study $(n=25)$. Limited information is included in Table 3 to ensure anonymity. 
Table 3: Sample Characteristics

\begin{tabular}{|c|c|c|c|c|c|}
\hline Participant & Sex & Generation & Office/Department & $\begin{array}{c}\text { \# of yrs. } \\
\text { USDA }\end{array}$ & $\begin{array}{c}\text { \# of yrs. } \\
\text { Federal } \\
\text { Service }\end{array}$ \\
\hline 1 & F & Gen X & Procurement Office & 15 & 18 \\
\hline 2 & M & Gen X & USDA & 20 & 20 \\
\hline 3 & M & Gen X & Enterprise Office & 15 & 15 \\
\hline 4 & F & Gen X & Enterprise Office & 17 & 17 \\
\hline 5 & M & Gen X & USDA & 17 & 27 \\
\hline 6 & F & Millennial & Enterprise Office & 17 & 17 \\
\hline 7 & F & Millennial & Chief Financial Office & 10 & 13 \\
\hline 8 & M & Millennial & Chief Financial Office & 8 & 8 \\
\hline 9 & F & Millennial & Chief Financial Office & 5 & 10 \\
\hline 10 & M & Gen X & Chief Financial Office & 9 & 9 \\
\hline 11 & M & Millennial & Chief Financial Office & 8 & 8 \\
\hline 12 & M & Millennial & Chief Information Office & 10 & 10 \\
\hline 13 & F & Gen X & Chief Financial Office & 17 & 17 \\
\hline 14 & M & Gen X & Chief Financial Office & 5 & 5 \\
\hline 15 & F & Gen X & Chief Financial Office & 16 & 20 \\
\hline 16 & F & Millennial & Chief Financial Office & 12 & 12 \\
\hline 17 & M & Millennial & Chief Financial Office & 10 & 10 \\
\hline 18 & M & Gen X & Chief Financial Office & 16 & 17 \\
\hline 19 & F & Millennial & Chief Financial Office & 13 & 13 \\
\hline 20 & F & Gen X & Chief Financial Office & 23 & 23 \\
\hline 21 & F & Gen X & Human Resources Office & 10 & 10 \\
\hline 22 & F & Gen X & Chief Financial Office & 30 & 30 \\
\hline 23 & M & Gen X & Chief Financial Office & 15 & 17 \\
\hline 24 & F & Gen X & USDA & 26 & 26 \\
\hline 25 & M & Gen X & Human Resources Office & 18 & 20 \\
\hline
\end{tabular}

\section{Interviews}

Most interviews lasted about 50 minutes, ranging from 33 minutes to 1 hour 45 minutes. After completing the interviews, the recordings were transcribed by the Rev online transcription service (https://www.rev.com/transcription). I conducted the first 13 interviews in person before the pandemic started. I completed my remaining 12 interviews via Zoom in April 2020 during the lockdown. All interviews were audiorecorded or recorded using the Zoom application (https://www.zoom.us.com). Even 
though the 12 final participants had the option to conduct the interview with the use of a camera, none of them elected to use the camera; citing concerns with recently highlighted security issues with the Zoom platform, preferred not to be on a visual recording due to not looking presentable (e.g., not being able to have hair appointments), and concerns about having their workspace at home recorded on camera. As a result, the remaining 12 interviews were conducted via Zoom without video. The last 12 interviews, on average, lasted 58 minutes as compared with an average length of 50 minutes for the first 13 interviews. Perhaps due to the longer interview time, additional categories and subcategories that were not mentioned in the face to face interviews were identified, and the interviews supported previously identified categories/sub-categories. For example, the sub-category corporate social responsibility, and a new category related to leadership, which includes the sub-categories of leadership support, leadership values, and trust in leadership all emerged from the last 12 virtual interviews. These variables were not previously consistently identified by those who participated in the face to face interviews. Perhaps the final 12 participants' ability to participate from home allowed them to focus more. Additionally, the lack of commute and other variables contributed to the participants being more engaged and focused throughout the interview. The participants also seemed to be more comfortable in their own homes and outside of the office work environment while participating in the interview.

Respondent scores on study variables (e.g., LMX) did not significantly differ between the face-to-face and virtual interviews, which suggests that the level of trust during my virtual interviews was sufficiently high to capture novel information (see Table 4). 
Table 5: Means, Standard Deviations, and One-Way Analyses of Variance (ANOVA) Results for Effects of Interview Method on the Study Variables

\begin{tabular}{|l|c|c|c|c|c|c|c|}
\hline & \multicolumn{2}{|c|}{$\begin{array}{c}\text { In-Person } \\
\text { Interviews } \\
(n=13)\end{array}$} & \multicolumn{2}{c|}{$\begin{array}{c}\text { Zoom } \\
\text { Interviews } \\
(n=12)\end{array}$} & \multicolumn{4}{c|}{ ANOVA } \\
\hline Variables & Mean & $S D$ & Mean & $S D$ & $\eta^{2}$ & $F$ & $p$ \\
\hline LMX- Affect & 6.08 & 1.05 & 6.31 & 0.76 & 0.02 & 0.39 & 0.54 \\
\hline LMX- Loyalty & 5.97 & 1.02 & 5.94 & 1.00 & 0.00 & 0.01 & 0.94 \\
\hline LMX- Contribution & 6.51 & 0.78 & 6.33 & 0.49 & 0.02 & 0.47 & 0.50 \\
\hline LMX- Professional Respect & 6.00 & 1.30 & 6.19 & 0.86 & 0.01 & 0.20 & 0.66 \\
\hline $\begin{array}{l}\text { Role's Importance to } \\
\text { Mission }\end{array}$ & 4.50 & 0.65 & 4.46 & 0.89 & 0.00 & 0.02 & 0.89 \\
\hline
\end{tabular}

The study employed a semi-structured interview design. Semi-structured interviews allow the use of pre-formatted questions, without loyalty to them as new questions might arise during the exchange (Myers, 2013). This allowed me to ask supplementary questions as necessary, and I was able to go off the script based on the reply from interviewees. Myers (2013) states that semi-structured interviews allow the interviewee to add significant insights as they arise during the exchange, while formerly arranged questions provide some attention as well.

The general purpose of these interviews was to understand why talented employees choose to stay and take that information to develop best practices to retain talented employees. I developed the semi-structured interview guide and included several measurement scales based on previous research on talent retention. These variables include the 12-item MDM-LMX scale (Liden \& Maslyn, 1998), single items to assess role's importance to the mission, tenure at the USDA, and tenure with their current supervisor. The interview guide consisted of 44 questions (see Appendix C). It included questions on the subject's background at USDA and past federal experience, demographics, their feelings about the organization, and the variables that impact their 
decision to stay as well as any information the respondent may be aware of regarding; other employees' reasons for voluntarily leaving the organization within the last two years. They were invited to describe reasons and episodes of practices and events that made them more committed to the organization, including performance management, communication, growth, and promotional opportunities to capture a broad array of experiences. Open-ended questions were used to identify novel information on the variables that influence talent retention outside of the variables that previous talent retention research has already identified (Allen, 2008).

\section{$\underline{\text { Semi-Structured Interview Transcriptions }}$}

When participants finished describing their experiences related to talent retention, I allowed them to elaborate on their answers that they felt were incomplete and to correct or clarify any previous statements. Reliable audio and written records of the interviews were obtained through audio recording and professional transcription service, which was further reviewed for accuracy by the author. Each interview was transcribed within three days from the time of its completion. Transcribing qualitative data collected during interviews may facilitate data analysis in several ways (Atkinson \& Heritage, 1984). Because the responses of one interview may prompt or shape questions in subsequent semi-structured interviews, preliminary analysis (as facilitated by transcription) is beneficial to complete after each interview in preparation for the next interview. Transcriptions were reviewed and compared against the audio transcript for accuracy, and I corrected them as necessary.

Transcription creates a written record of the data which may be more readily consulted than data stored in audio form, permitting a more thorough analysis of the 
interview data and one that is iterative. A written record additionally allows for secondary analysis by allowing other researchers to reanalyze the data. Lastly, transcription encourages future research by allowing for reanalysis to address the application of new or nuanced research questions, differing analytic strategies, and/or novel theoretical approaches. The transcriptions of the interviews were arranged to correspond with the study's research questions. Instances in which a body of the text is relevant to multiple research questions, the section was cross-referenced. Attempts to manage the volume of data in this manner enables the researcher to examine all data relevant to the research question simultaneously. The purpose of this approach is to achieve data reduction, interpret data, and justify conclusions from the data in an efficient manner (Merriam, 1998; Miles, Huberman, \& Saldana, 1994; Robson 2002).

\section{Data Analysis}

Qualitative data analysis was employed to transform the data into meaningful conclusions for the intended audience of leaders at U.S. federal agencies, to help them understand the results of the study. There are several ways to analyze qualitative data, and for this study's purposes, coding was the method of analysis. Coding helps researchers to reduce the size of the data and is useful for organizing the data (Myers, 2013).

I invited other researchers to the project to bring an external objective perspective to the data analysis, to validate the qualitative content analysis and ensure the validity of the themes emerging from the data. First, I read the transcripts and identified major categories and sub-categories with the aid of the qualitative research software Atlas.ti.

Second, within each code, I used an open coding process to develop unique codes for the 
major codes identified along with the sub-categories identified (Strauss \& Corbin, 1990).

Two additional coders included a management professor at the University of Missouri-St.

Louis, as well as a doctoral candidate in business administration from the same

university. I met with each coder separately at regular intervals to compare notes and definitions of emerging codes. Table 5 provides a summary of the seven categories and their subcategories that emerged from the interview data.

Table 5: Categories and Sub-Categories

\begin{tabular}{|c|c|}
\hline Categories & Sub-Categories \\
\hline 1. Organizational Pride & $\begin{array}{ll}\text { - } & \text { Mission of the organization } \\
\text { - } & \text { Impacting people's lives } \\
\text { - } & \text { National impact } \\
\text { - } & \text { Corporate social responsibility }\end{array}$ \\
\hline 2. Communication & $\begin{array}{l}\text { - } 360 \text { communication } \\
\text { - Communication with direct manager } \\
\text { - Communication with senior leadership } \\
\text { - } \quad \text { Unified messaging }\end{array}$ \\
\hline 3. Workplace Culture & $\begin{array}{ll}\text { - } & \text { Family-like environment } \\
\text { - } & \text { Decentralized organizational structure } \\
\text { - } & \text { Recognition } \\
\text { - } & \text { Flexibility } \\
\text { - } & \text { Diverse workforce } \\
\text { - } & \text { Transparency of organizational goals } \\
\end{array}$ \\
\hline 4. Job Resources & $\begin{array}{l}\text { - Up-to-date technology } \\
\text { - } \quad \text { Efficient procedures }\end{array}$ \\
\hline 5. Learning \& Development & $\begin{array}{l}\text { - Opportunity to continuously move and grow } \\
\text { - Relevance of trainings }\end{array}$ \\
\hline 6. Career Growth & $\begin{array}{l}\text { - Opportunities for promotion } \\
\text { - } \quad \text { Internship programs }\end{array}$ \\
\hline 7. Leadership & $\begin{array}{ll}\text { - } & \text { Feeling valued } \\
\text { - } & \text { Leadership support } \\
\text { - } & \text { Trust in leadership }\end{array}$ \\
\hline
\end{tabular}

As shown in Table 5, many of the categories/sub-categories that emerged from the interviews have been discussed in previous research. However, until now, they have 
not yet been shown to be relevant in the federal government context. This is the first study that provides support to these drivers of talent retention in the federal government context. More importantly, this research uncovered a novel driver of talent retention termed Organizational Pride. During the semi-structured interviews, every single participant $(n=25)$ mentioned an aspect of organizational pride as their reason for staying with the federal government. Organizational pride is an emerging research area, and there's only limited empirical research on organizational pride despite its importance for an organization's success. The interview data suggest that organizational pride should be included in an organization's talent retention strategy, which is consistent with the emerging research available from the business context (El Akremi, Gond, Swaen, De Roeck, \& Igalens, 2018; Jones, Willness, \& Madey, 2014; Ng, Yam, \& Aguinis, 2019). This research also uncovered a novel sub-category termed 360 Communication. During the semi-structured interviews, over half of the participants $(56 \%)$ mentioned an aspect of 360 communication as being important to talent retention in the federal government. The 360 communication that was discussed during the interviews resembles holacracy, a decentralized management and organizational structure that opens lines of communication hierarchy and makes employees feel more connected to the company. Holacracy is an emerging research area, and there's only limited empirical research on holacractic organization structure. Most of the research on holacracy is recent and was conducted in the context of private organizations and state and local governments (Bernstein, Bunch, Canner, \& Lee, 2016; Lee \& Edmondson, 2017). 


\section{Quantitative Measures}

The present study aimed to build upon previous research by synthesizing work on LMX to help inform talent retention in the federal government context. While the primary form of data collected in the present study was qualitative, supplemental quantitative data were also collected (1) to facilitate more direct comparison with previous research and theoretical discussion resulting from the findings, and (2) to ensure triangulation of the study findings. To this end, participants completed the 12-item LMX scale (Liden \& Maslyn, 1998) along with a few more single-item measures, such as tenure with the current supervisor and the impact of the respondent's role in achieving organization's mission.

Leader-Member Exchange. Liden \& Maslyn (1998) developed a 12-item LMX scale to assess the four LMX subscales, affect, contribution, professional respect, and loyalty. Each subscale includes three items. Sample items include; "My supervisor is the kind of person one would like to have as a friend." (Affect); "My supervisor would come to my defense if I were "attacked” by others." (Loyalty); "I do not mind working my hardest for my supervisor." (Contribution); "I admire my supervisor's professional skills" (Professional Respect). Twelve items were rated by participants on a seven-point Likert scale ranging from $1=$ strongly disagree to $7=$ strongly agree. . Reliability for scale scores were in acceptable ranges for overall LMX $(\alpha=.83)$, Affect $(\alpha=.85)$, Contribution ( $\alpha=.89)$, Loyalty $(\alpha=.86)$, and Professional Respect $(\alpha=.93)$.

Respondents reported relatively high scores for LMX subscales $\left(M_{\text {Affect }}=6.19\right.$, $\left.M_{\text {Loyalty }}=5.96, M_{\text {Contribution }}=6.43, M_{\text {Professional Respect }}=6.09\right)$. These results are indicative of the typical high amount of support federal employees receive from their leaders. The 
relationship between the immediate supervisor and their employees remain a high-quality relationship in the federal government context, as highlighted in the 2019 Federal Employee Viewpoint Survey (FEVS) for RD (United States Office of Personnel Management, 2020a). The survey was distributed by the Office of Personnel Management (OPM) via government email, and participants had six weeks to respond. The OPM received 2,308 completed surveys representing a 56\% response rate for RD. The purpose of the 2019 FEVS survey was to allow employees to rate their jobs, leadership, and the agency. The FEVS contained items paired with a five-point Likerttype scale that ranged from "Strongly Agree" to "Strongly Disagree" and two other response options, no bases to judge and do not know. In the survey, five questions reflect the relationship between worker and supervisor, including trust, respect, and support. The average for RD employees who participated was 74\%, which suggests that of the 2,308 employees completing the survey, over 1,700 employees feel that the relationship between them and their first level supervisor is of high-quality, which is consistent with the results of this current study.

\section{Research Perspective: Paradigms and Ethics}

This study takes a positivist approach. Positivism is described as the natural "science model of social research" (Myers, 2013, p.38). According to Lee (1991), the positivist approach involves the handling of theoretical suggestions using the rules of judgment so that the subsequent theory satisfies the requirements of falsifiability, reasonable consistency, relative descriptive power, and survival. Lee (1991) also mentions the use of the interpretive approach. This is defined as measures associated with ethnography, hermeneutics, phenomenology, and case studies. He further states that 
the interpretative approach to organizational research preserves that the methods of normal science are insufficient for the study of social reality. Therefore, Lee (1991) recommends a mutually supportive approach between positivist and interpretive strategies, that is attained in the current research through a case study approach.

Myers (2013) describes the Golden Rule to consider when performing research. This study used the Golden Rule in conducting qualitative research and working with human subjects. I protected human subjects by preparing and requiring the interviewees to complete a Participant Informed Consent Form that enabled interviewees to participate freely and advised interviewees that they could terminate their involvement for any reason at any time (see Appendix D). Their participation and involvement in this research were voluntary and could be stopped at any point in time, and they did not have to answer a question if they choose not to. Once I received the Participant Informed Consent, I followed up with an email that confirmed the interview time and provided PreInterview Reflective Questions for the participant (see Appendix E).

\section{Assumptions}

This study was based on the following assumptions:

1. I assumed subjects were truthful about their responses to the interview questions. I emphasized the privacy of all the information participants provide.

2. I assumed that Resource-Based View and Human Capital Theory (Barney, 1993; Becker, 1964) would provide a theoretical foundation for understanding talent retention, Generation Xers, and millennials to develop strategies to be used in the U.S. federal government. 


\section{Conclusion}

Chapter 3 presented a discussion of the research methodology selected for the study. Chapter 4 will provide a detailed description of the results, followed by a discussion of the study's findings, its limitations, contributions, theoretical implications, and practical contributions, as well as directions for future research in Chapter 5. 


\section{Chapter 4: Results}

This study sought to address the following research question: How can the United States Department of Agriculture retain talent? In this chapter, the qualitative research findings through semi-structured interviews and the quantitative results of the study variables are presented. Data collection to inform my research question took two forms. Qualitative data was collected through interviews that were audio-recorded and recorded using Zoom and analyzed via Atlas.ti with a complimentary brief quantitative survey component. The qualitative findings are described first, followed by the quantitative results.

Results suggest that most of the categories/sub-categories that emerged from the interviews are consistent with previous talent retention research. Findings suggest that much of the previous research on talent retention conducted outside of the federal government extend to the federal government context, such as the respondents' emphasis on the importance of career growth, workplace culture, learning and development, job resources, communication, and leadership. Undoubtedly one of the most important contributions of the current study is that all interviewees (100\%) discussed organizational pride as an essential factor in why they chose to stay. There is limited and only recently emerging empirical research on organizational pride as an essential factor in the success of the organization. Most of the previous research on organizational pride was conducted solely in the context of corporate social responsibility (CSR) (Ng et al., 2019) or corporate social performance (CSP) (Jones, Willness, \& Madey, 2014). Another significant contribution of the current study is that over half of all interviewees $(56 \%)$ mentioned an aspect of 360 communication that resembles holacracy, a decentralized 
organizational structure, as an essential factor for talent retention in the federal government. Most of the research on holacracy is recent and conducted in the context of private organizations and state and local governments (Bernstein et al., 2016; Lee \& Edmondson, 2017).

The semi-structured interviews $(n=25)$ collectively lasted for 22 hours and resulted in seven categories and 23 sub-categories impacting talent retention. Next, each category/sub-category is defined and discussed in detail with selected quotes from interviews.

\section{Category 1: Organizational Pride}

One of the consistent themes that emerged in this study was the importance of organizational pride to the respondents. All respondents (100\%) cited organization pride as a reason for why they have decided to stay with the organization. Respondents mentioned the importance of organizational pride with specific emphasis on the mission of the organization (36\%), impacting people's lives (32\%), national impact (24\%), and corporate social responsibility $(8 \%)$ when describing what is important to them to remain with the organization.

Subcategory: Mission of the Organization. The mission of the organization refers to understanding, believing, and supporting the mission of the organization. The mission is the justification of the agency's existence and tells others the purpose of the organization. A good mission statement motivates employees and provides a focus and direction for setting subordinate level objectives. The mission should guide employees in making choices and establish what the organization does. Twenty-four percent of respondents 
say they remain at the agency because of the mission and its importance to America. For

example, a Generation X employee says:

"I believe in the mission. I grew up in a small rural community...USDA supports the smaller rural communities and the farmers, the farmers, and ranchers... and I believe in the mission, so that's one reason why I do stick around with USDA."

Another respondent, a Generation X employee, states:

"I'm going to be here forever because of the mission...our service, what we give to rural communities, how we help rural communities, our portfolio, and then all of that we are, I'm a big fan."

Another respondent, a Generation X employee says:

I'm driven to provide the best customer service to my customer, which is our internal $[\mathrm{x}]$ staff. This idea of public service, this idea of helping communities, and celebrating with them. There was no other career I want to do for the rest of my life."

Another Generation X employee shares:

"I've chosen to stay because I believe in what we do. I believe in the mission of the agency, and I enjoy working with the people that I work with, and I enjoy the role that I play with my coworkers in helping them and helping them troubleshoot. That's something that's so rewarding too, and I do know that, as I said, what we do in [the agency] in the rural areas. We make a difference in these communities, and it's important to me, and I do enjoy working for the agency."

However, $12 \%$ of respondents, although they remain with the agency, believe there are a few changes that should be considered as related to the mission of the organization, as an improvement. For example, a millennial employee feels:

"I have found that the mission and the reason why the agency was developed is important. The entire department has a function and reason for the American public...USDA agencies are for their protection of both food and animals and plants and so much more. I am committed to continuing to support the mission."

Further, a Generation X employee states:

"I think that while establishing the goals and priorities, they should be communicated to the employees on how each employee, each area aligns with those goals and priorities. I think this would create a clearer picture, and 
employees would feel more of a sense of accomplishment as those goals and priorities are met and want to remain with the agency to accomplish the mission."

Subcategory: Impacting People's Lives. Impacting people's lives refers to knowing that the work employees are responsible for impacts the people that they serve.

Respondents feel it is important for employees to understand how their work is impacting the lives of the communities and customers they serve. Thirty-two percent of respondents feel the work that the agency does impact people's lives. For example, a millennial employee states:

"I feel like it's beneficial to rural America, and it has a direct impact on people's lives and why I am still here."

Another respondent, a Generation X employee, sees the importance of the impact the agency has on individuals lives, she says:

"I do believe in [the agency]. The assistance that we provide helps people...I was here during the time of Hurricane Katrina, and we got a lot of calls from people that had been misplaced...it was a range of things that I heard over the phone. I like to be involved and seeing that big picture of what we're doing and the help we are providing, and that is important to why I am still with the agency."

Another respondent, a millennial employee, agrees that the programs the agency provide impacts many lives:

"The biggest thing that motivates me...I see the impact we give the tenants to help them pay their rent. There are a lot of grandparents raising young kids in the rural community, and they're not ready to do that. But because of our agency, they're able to give their grandchildren their separate rooms. You know that what we do here does make a difference, and I am serving others, which is important for me in a job and why I choose to continue to work at USDA."

Eight percent of respondents feel that the agency could improve how employees feel they are impacting customers beyond the periodic newsletters and videos shared by senior leadership. For example, a millennial employee suggests: 
"One step that the agency can take to make my work more meaningful and more satisfying is to show me how the work that I do impacts the lives of the agency's customers. This would truly help me understand the impact of my work on people's lives."

Subcategory: National Impact. National impact refers to the impact of the work that an employee does and its impacts on the nation. Employees take pride in the fact that the work they do positively impacts the entire nation in some form, and this is an important reason why they have chosen to remain committed. Twenty-four percent of respondents are confident that the work they perform on behalf of the agency impacts the nation. For example, a millennial employee states:

"I already know my work is meaningful. I was there in the field office...I know exactly how we impact the nation...I know what we do as an agency does have a huge impact on our country. It is important for me to be a part of this at the agency."

Another respondent, a Generation X employee goes on to say:

"We look at the environment, the resources that preserve life as we know it. And then, you think about being a steward of those resources. There are areas that I can truly make an impact at a national level...you can protect and preserve something that's going to be here for generations to come, and that is why I have chosen to remain at USDA."

Subcategory: Corporate Social Responsibility. Corporate social responsibility (CSR) refers to the importance of agency responsibility in terms of its impact on the local community or at large. CSR generally refers to a corporation's willingness and ability to help its community (Ismail, 2009). However, in this study, the concept is applied to the federal context. Eight percent of respondents consider the positive impact to the community as an important factor when considering a place to work and why they have chosen to stay. For example, a Generation X employee says:

"I look at [corporate social responsibility] when considering a place to work-the agency's value, whether it be within the local community or just at large. So, 
making the world a better place, or the local community, or so on and so forth. I always look at what it is that I'm doing, or the organization, what are they doing or making, or that sort of thing. So those are the things that I like to look at to decide whether I want to work there in the first place, or whether I want to continue working there and USDA meets that need."

\section{Category 2: Communication}

Most of the respondents (88\%) mentioned the importance of communication with specific emphasis on communication with the direct manager $(8 \%)$, communication with senior leadership (16\%), and unified messaging (8\%) when describing what is important to them to remain with the organization. An important sub-category that emerged in this study was the frequently mentioned 360 communication. Most respondents (56\%) cited the availability of 360 communication as a reason they have decided to stay with the organization.

Subcategory: 360 Communication. 360 communication refers to communication flowing down and up with no risk for retaliation and the creation of a dynamic workplace that gives more autonomy to teams and individuals. Fifty-six percent of respondents discuss this type of communication as a driver of talent retention, and they suggest it has a positive barring on their choosing to stay. For example, a Generation X employee suggests:

"You should hear from above. You should hear from below. You should hear from the people working with you, and you should be expressing yourself, and you should be encouraged to express yourself above, below, without reprisal. Reprisal for expressing myself would make me want to leave."

Another respondent, a Generation X employee, states:

"I think that form of communication empowers us because we can put a face on a name. We know that they're just human beings, and if we needed to, we could reach out to them. I mean, they're all approachable, every single one of them, and I appreciate this, and I enjoy what I do because of it." 
Subcategory: Communication with Direct Manager. Communication with the direct manager refers to how to direct supervisors communicate with their employees and how this takes on many forms, even in an environment where an employee might often not be located with their direct manager. Eight percent of respondents feel that even in an environment where an employee might often not be located with their direct manager, the communication in the agency works. For example, a Generation X employee says:

"We have weekly or biweekly staff meetings, and she consistently communicates items to us at that time, and then sends updates via email. We stay informed, and I feel like a part of the team, and that is important to me and keeps me coming to work every day and is a reason why I continue to stay."

Additionally, a millennial employee says:

"My supervisor is completely remote and to see her acknowledge that she is remote and see her use the different opportunities that she can, whether that's FaceTime meetings or making sure she has a weekly call or biweekly call to ensure that she knows what's going on with things within our state and communicating her expectations, her expectations for me and mine for her. My supervisor's efficient communication impacts my desire to continue to work for her."

Subcategory: Communication with Senior Leadership. Communication with senior leadership refers to employees' desire to express themselves freely without reprisal and work in a collaborative environment with senior leadership. Sixteen percent of the respondent's desire to work closely with senior leaders and have more collaboration without fear of reprisal. For example, a millennial employee says:

"We would have an organization-wide supervisor meeting, and they would last four or five hours...I just felt like we were more of a cohesive group instead of everything just being funneled top-down as much as it seems now. I guess it seemed more collaborative, and there was more discussion about all the various things that were going on. The closer connection we had before was a reason why I stayed." 
Another respondent, a millennial employee, says the ability to express himself to senior leadership without the potential for reprisal is important:

"If senior leadership could truly allow people to express themselves and not feel like they're going to get punished for it...just share things you feel that should be changed or how to move forward without feeling like you're going to try to penalize me. An environment where I feel free to communicate is important to me."

Subcategory: Unified Messaging. Unified messaging refers to communication coming from senior leadership that is consistent and stays the same from one leader to the next, such that all employees hear the same message. Eight percent of respondents feel that there should be one message coming from senior leadership. For example, a millennial employee states:

"I feel like you talk to one person, and they're doing it one way, and then you talk to another person; they're doing it a different way, but they're all under the same leadership."

Also, a Generation X employee states:

"Before, my organization was pretty much under one umbrella and was receiving their communication from really one person, and it was a unified message. And due to the realignment, I think we're now having issues with that unified message coming out for our staff. We just need to be hearing the same thing from one person. Multiple messages are so frustrating."

\section{Category 3: Workplace Culture}

The majority of the respondents $(88 \%)$ mentioned the importance of the workplace culture with specific emphasis on the family-like environment (12\%), decentralized decision making (16\%), recognition (24\%), flexibility (8\%), diverse workforce (12\%), and transparency of organizational goals (16\%) when describing what is important to them to remain with the organization. 
Subcategory: Family-like Environment. The family-like environment refers to employees having compassion for one another to the point where employees feel like each co-worker is a member of one's own family. Twelve percent of respondents expressed desires to help support one another, whether it is support with the completion of work tasks or support with allowing employees flexibility between time allocated for work and non-work aspects of life, and that this is an important reason why they have chosen to stay with the agency. For example, a Generation X employee suggests:

"My peers...we want to help one another out...they're like family...brothers, and sisters. Somebody gets in a pinch or needs advice, or just needs help, or one of us is having some financial difficulties; we do this regularly...we help each other out. If there's a contraction in funding in an office, another office might have available funding. So, we're able to work across the regions or across state lines to support one another."

Another respondent, a millennial employee, is impressed that:

"Everyone here that's in management is very family-oriented...it's a great place to work. It's flexible, and I think that's good. We end up usually putting people and their needs first, and this is important to me."

A Generation X respondent shares:

"I've had a couple of really good supervisors...I've built so much trust with them. While we work together, we recreate together. We go fishing... we have so much in common, it's kind of hard not to be friends and be loyal to them and the organization."

A millennial employee states:

"You build good relationships with people, and you almost don't want to let them down by leaving... I would feel like I'm letting down my branch chief, or the $\mathrm{CFO}$, or director, and other people if I left the agency. Because they've done all this for me and helped me."

Subcategory: Decentralized Organizational Structure. Decentralized organizational structure in this study's context refers to the distribution of responsibility for daily supervision among several departments or persons, rather than being dependent upon 
choices made by an authority figure. It places more power in the subordinate levels of an organization so that senior leadership has the liberty to concentrate on the top issues facing the organization. Organizations that follow decentralized organizational structures are often less likely to adhere to inflexible guidelines or hierarchical rules, and that is important to this study's respondents when choosing to stay. In this environment, giving employee's resources, authority, opportunity, as well as responsibility and accountability for outcomes of their actions may contribute to their engagement, motivation, and retention. Respondents refer to being able to make decisions about the job, and respondents also discuss a process similar to empowerment, where employees can provide unsolicited feedback and insight freely. Sixteen percent of respondents stated that they don't want a structure that is so rigid that employees are reluctant to make any decisions within their job domain without prior approval. For example, a Generation X employee says:

"The nice part about our organization, it's not a rigid chain of command."

Another respondent describes how she left another agency to come to USDA because of a rigid work environment.

This millennial employee states:

"The previous federal agency I worked at before USDA I left. It was a very rigid organization, and the rules were very, very strict. I'll say it was very militant, and there was no opportunity for improvement or to provide insight. That is not the case at USDA, and I am happy about it."

A Generation X employee states:

"The nice part about our organization, it's not a rigid chain of command. Even though we might have a state director, for example, who you can tell is just kind of checked out, there's enough staff underneath him that are involved in the conversations, to keep things going, and that is important to me and why I am still here." 
Eight percent of respondents describe the importance of feeling empowered to make decisions. For example, a millennial employee states:

"I feel like I'm empowered to make a change or provide feedback, and in a lot of positions, you don't get that opportunity. This is why I remain with the organization."

Another respondent appreciates the fact that the supervisor listens. This Generation X employee states:

"Empowerment makes me feel more committed versus having to refer to a supervisor for permission constantly. I do feel empowered. I feel like if I need to come up with an idea or if I have an idea for how to do something better, I can let my supervisor know, and he does listen and takes it into consideration. He'll send it up the chain. With empowerment, you feel connected to the work that you're doing."

Subcategory: Recognition. Recognition refers to employees being acknowledged in various ways for their hard work and accomplishments within the organization. Every employee working in an organization from a technician to an experienced manager expects recognition for their work and wants appreciation for their efforts. Employee acknowledgment and rewarding is a practice through which organizations make a cognizant effort to reward and award employees not just to recognize work but also to encourage them to continue with the same desire. Sixteen percent of respondents feel that not enough is done to recognize the good work of employees, and more effort should be taken by leadership to recognize deserving employees for continued productivity and retention. For example, a millennial project manager talks about his experience in a recent assignment:

"I was the project manager and did not get any credit for that. I'm still upset about it. Nothing, not even "congratulations" or "shout out to [x] for helping to get this done and moved to production from my direct supervisor. I didn't get anything, and that kind of hurt my feelings. Tell me, "thank you," tell me that, 
"[x] I see what you're doing, and it matters. However, because my senior leadership acknowledged my contribution, I remained with the agency."

Another respondent believes the organization never ceases to celebrate the successes, which is the reason for this employee's continued commitment to the agency. This Generation X employee states:

"I'm motivated not necessarily by money, but by knowing that I accomplished something challenging, or that I solved something that someone else couldn't figure out. Getting recognition...through performance ratings, or just verbal "great job" rewards...I think are more valuable to me than getting a monetary reward and is the reason I continue to do my best for the agency and why I am still here."

A millennial employee says:

"I have remained with the agency because management recognized my efforts. I appreciate the fact that my management team recognizes that I put forth effort into making their lives and their jobs easier."

Another respondent, a millennial employee says:

"To have your immediate supervisor or a supervisor further up to recognize [accomplishments] in a public way to either you or your team to say thank you for the hard work is amazing and makes it easier to come to work and do my job every day and increases my commitment to [the organization]."

Subcategory: Flexibility. Flexibility refers to a work environment where employees can make their own choices as to how they engage in work-related tasks and projects. Eight percent of respondents stressed the value they place on flexible working arrangements, and it is important for those flexibilities to remain for employees' willingness to stay with the organization. For example, a millennial employee feels that:

"There are days where I will come in, and I will put in 10, 12 hours, and there are days where I would do six... I'm allowed a flexible schedule. Whether I need to work 10 hours today or eight hours today, to get the mission done, I'm allotted that opportunity. A lot of people don't have that opportunity; a lot of people don't have that flexibility, and I think being able to maneuver around personal life makes it very easy to come in and do my job, and that is why I stay." 
A Generation X employee shares:

"What I like most about my job is the flexibility. I work out of my house, so I don't have a commute. I've always been able to translate that into putting that extra time into my job. They also gave me the flexibility of setting my schedule, and I enjoy that. One of the benefits that keep me with the federal government is flexibility."

Another respondent, a millennial employee says:

"Flexibility is one of the tools I've been given that allows me to manage my job and my workload better. Flexibility is important to me and why I choose to stay with the agency."

Four percent of respondents specifically mention that they enjoy the flexibility of the job, but they are concerned that flexibility seems to be decreasing. For example, a Generation X employee says:

"I like most about my job is the flexibility that the federal government has offered me over the years. However, those flexibilities are starting to go away, and that is disappointing. If the agency continues to decrease that flexibility, I will look for other opportunities."

Subcategory: Diverse Workforce. A diverse workforce refers to having an organization that includes employees from a wide range of diverse backgrounds and recognizing everyone's importance to the organization. Twelve percent of respondents state diversity and inclusion are essential for them to remain with the organization. For example, a Generation X employee says:

"I think that we have done ourselves a great service in targeting underrepresented groups. I do feel very strongly; part of our strength is our inner diversity of opinions and age groups and backgrounds. If diversity doesn't increase, it may impact my commitment to remain with the agency."

Another respondent, a millennial employee states that in the agency:

"There was hardly any diversity in the management. That was in 2008. Over the last ten years, it had changed, and I've started to see a little bit more diversity with people getting the management positions. In the last two years or so, as people are retiring and leaving, I see us sliding back... and I would like to see us on the path 
of actually hiring and promoting a diverse set of management. I think this will help us manage our workforce better and increase retention among our staff."

Another respondent, a millennial employee, shares:

"I think a lot of times some leaders get so stuck in their ways, and they're not open to truly working with millennials because sometimes they're just like, "Oh, you're new here, this is my house, you at my house and you're going to play by my rules." You never know what that person can provide or how much they can advance the organization. As one of those millennials, if this continues, I may leave the agency."

Subcategory: Transparency of Organizational Goals. Transparency of organizational goals refers to agency leadership actively sharing the goals of the organization to keep employees informed, engaged, and committed. Transparency of organizational goals means sharing successes and failures, reporting changes concerning the mission, and ongoing monitoring and evaluation of programs in an open manner, rather than behind closed doors. Sixteen percent of respondents feel that it is necessary that agency leadership share goals so employees can better align themselves and their work units to the organization's goals. If leadership continues not to share goals, engagement, and commitment may decrease, and employees may leave. For example, a Generation X employee states:

"I cannot be the best employee that I can be without knowing what the goals are for the organization to be able to make sure that I have the skills and abilities to be able to support that."

Another respondent, a millennial employee recalls:

"I can't remember the last time we had an all-hands meeting, where we truly discussed our mission and our vision and what's expected of the employees and where we are with the reorganization or where we are as an agency. We haven't had any of that...start with that. Get all the employees on the call and start talking about what is the agency's mission. It is important that I feel like a part of the organization, and currently, I don't... so I think about why I am still here." 
Eight percent of respondents mentioned they feel like they are not getting the whole picture and are receiving information piece-meal. For example, a millennial employee shares:

"Senior leadership should communicate more about what our organization is, where the organization is going, plans they have in mind to improve the organization so I can see how I still fit into those plans and the organization going forward and if I need to look for other opportunities."

\section{Category 4: Job Resources}

Fifty-two percent of the respondents mentioned the importance of having adequate job resources with specific emphasis on up-to-date technology (40\%) and efficient procedures $(12 \%)$ when describing what is important to them to remain with the organization.

Subcategory: Up-to-Date Technology. Up-to-date technology refers to the organization making sure the most efficient processes are in place, and that the agency is taking advantage of the latest available technology. Office productivity software, security systems, computers and networks, phone systems, and more are all impacted by technology, and when using the latest version of these tools, employees and the organization can excel. Forty-eight percent of respondents feel that significant agency improvements need to be made to bring the agency up to date with the latest technology. For example, a Generation X employee says:

"When it comes to advanced technology, we're behind in some areas as an agency. I'm aware of a few employees leaving, some employees were here for a month, and they left. Their concern was that as an agency, we're disconnected from technology, and we're working harder but not smarter."

Further, a Generation X employee says:

"We could have some better tools to help with our budget process entirely because we're trying to make updates to Excel spreadsheets, but a tool that we 
could track changes, submissions versus changes would be beneficial. Taking advantage of available technology is important to me in my daily work."

Subcategory: Efficient Procedures. Efficient procedures refer to the organization having efficient and effectively clear and organized policies, processes, and procedures. Twelve percent of respondents feel that better-quality documentation will increase compliance and allow employees to produce predictable outcomes efficiently. For example, a Generation X employee states:

"Since joining [the agency], I have received a lot of guidance and procedures for completing work. However, there's a struggle coming from the outside into the organization and trying to understand what the organization is about... what my role is... what I'm expected to do. There is so much information, and sometimes it seems like [the agency] lacks efficient procedures in some instances which impact my ability to complete tasks."

\section{Category 5: Learning \& Development}

Most of the respondents (76\%) mentioned the importance of learning and development with specific emphasis on the opportunity to move and grow continuously $(40 \%)$ and the relevance of trainings that are offered (36\%) when describing what is important to them to remain with the organization.

\section{Subcategory: Opportunity to Continuously Move and Grow. Opportunity to}

continuously move and grow refers to the organization providing opportunities for employees to experience professional development and enhance their skills to support the mission of the agency. Thirty-two percent of respondents feel they can move and grow in the organization and that this is a reason why they stay. For example, two Generation X employees state:

"I still have opportunities to grow as a person and a manager, and I feel like I still have opportunities for advancement. That is why I remain, and I still feel there are opportunities for growth." 
"I would consider leaving only if there was no room for growth."

A millennial employee states:

"If the opportunities to grow and learn more things or the ability to move from department to department, if that goes away, yeah, I will be looking for another job.”

Another respondent, a millennial employee agrees:

"I chose to stay at USDA... because of the opportunities I have been allotted, the challenges that I have been given...I chose to take advantage of it."

However, eight percent of respondents feel like they do not have enough opportunities to move and grow. For example, a Generation X employee shares:

"I don't have the certifications required for promotion, and the agency is not willing to invest in me or find the money to fund courses for certifications. Why are you making something a requirement if you're not allowing your current employees to get it? I might as well look for another job after all of these years."

Subcategory: Relevance of Trainings. The relevance of trainings refers to trainings

that are relevant to the employees' job and career. Relevant training provides the employee with the skills necessary to perform to the best of their ability. Thirty-six

percent of respondents desire training that is reflective of the knowledge needed for their job. For example, a Generation X employee says she has looked for other opportunities because she doesn't feel like she is getting appropriate training to do the job:

"We should have more training for our leaders and our supervisors in performance management and not just online training. I'm talking face to face, with a real-life example of the issues, to address the challenges that people are having."

Another respondent, a Generation X employee, agrees, and states:

“There hasn't been any customer service training, or accounting class training or anything technical. So technical training might be lacking a little bit, which will help employees perform their job better."

Another respondent, a millennial employee had to resort to paying for her training: 
"I wish there were more quality training opportunities. I had to go outside, and I had to register at a university to do a leadership program because I couldn't find anything internally that I thought would help me achieve my goals in the future. I feel like the agency is not giving me the opportunity, so I must step outside of the agency and look privately for training. If the agency continues this trend, I will look for another job. Private sector employees seem to get the necessary training."

\section{Category 6: Career Growth}

Most respondents (68\%) mentioned the importance of career growth opportunities with specific emphasis on opportunities for promotion (40\%), and internship programs $(28 \%)$ when describing what is important to them to remain with the organization.

Subcategory: Opportunities for Promotion. Opportunities for promotion refers to an employee's perception that they have ample opportunities to be promoted within the organization. Opportunities for promotion are the chances for the advancement of an employee to a higher-level job with greater responsibilities. Sixteen percent of respondents report that they don't feel they have the opportunity for promotion and that it may impact their decision to stay. They believe that their career is on hold, and the only opportunity for promotion requires them to leave the agency. For example, a Generation $\mathrm{X}$ respondent describes how she feels about her opportunities for promotion:

"I'm stuck...I don't think I feel that I'm getting what I need to advance within [the agency], so I'm just in limbo. There's just no promotion potential or no room for promotion...I'm stuck, very point-blank."

Another respondent, a Generation X employee says:

"I wish there were more [promotion opportunities]. I guess I'm not necessarily happy because I don't feel that there's a true path for advancement where we currently are. To advance, I would have to move outside of the current environment. I don't want to hinder myself by not taking advantage of opportunities outside if that's what I must do." 
Another Generation X respondent shares:

"One of my co-workers left for a promotion that she could not get with [the agency]."

Twenty-four percent of respondents reported that within the organization, there is a significant amount of opportunity for promotion, which is an important reason why they have chosen to stay. For example, a Generation X employee believes:

"The process is fair. You work hard; you're going to get recognized; you're going to move up."

Another respondent, a Generation X employee says:

"Available career paths and other promotional opportunities are abundant right now, and I am happy about it."

A millennial employee states:

"There's been a lot of opportunity for movement for me within the organization. So, I haven't had a reason to leave either for promotion or career fulfillment."

Another millennial employee says:

"Even the promise of promotion potential right now is enough for me to stay based on the planned reorganization."

Subcategory: Internship Programs. Internship programs refer to programs for new and current employees looking to gain experience to enhance their knowledge and strengthen their professional development. Internship programs such as the Pathway Program offers paid opportunities to work in a federal agency and explore federal careers while completing one's education, and programs like this are offered to current students and recent graduates as well as current employees that meet program criteria. Current employees gain new experience and knowledge to enhance their careers for potential future growth with the organization. Twenty-eight percent of respondents suggest the continuation of current internship programs at the agency as an opportunity to increase 
retention among both new and tenured employees. For example, a millennial employee

suggests that spending more time learning about the organization through internship opportunities is essential:

"A week or so in each department, just learning the overall view of what that department does...I think the agency should continue to use the Pathway Program as a tool that would help employees and the organization. It helped me, and because of the program, I was immersed in the agency, and that is the reason I am still here."

Another respondent, a millennial employee says:

"One of the things that important to me is being given some of the opportunities that I see available regarding learning more about leadership or rotating throughout the organization. There was a President Management Council's sixmonth rotation, and I would love to take advantage of those types of opportunities to increase my knowledge and bring that experience back to my current position. I think that when you allow people to do that, not only are you impacting another part of the organization, but that person may bring back knowledge and heavily benefit the organization that they're already in. So, a lot of times, people get the idea of somebody wanting to take a detail or somebody wanting to go to another part of the organization, they perceive that as negative. However, for me, it would increase my commitment to the agency."

\section{Category 7: Leadership}

Sixteen percent of respondents mentioned the importance of leadership with specific emphasis on feeling valued (8\%), leadership support (4\%), and trust (4\%) when describing what is important to them to remain with the organization.

Subcategory: Feeling Valued. Feeling valued by leadership refers to employees feeling valued by senior leadership and the organization and how it impacts their commitment.

The value given to employees by leaders represents what respondents hold most dear and drive their success and happiness, meaning, and fulfillment in all areas. Four percent of respondents believe the leaders know employees are doing the best they can despite the 
current circumstances related to budget cuts and lack of personnel. For example, a

Generation X employee says:

"I feel valued by leadership. I think that they know that out in the field, we're doing the best that we can with the tools that we have right now. That is important to me, and why I have chosen to stay...point blank I am valued, and that is key."

Four percent of respondents don't feel valued by leadership, and it impacts their desire to remain with the agency. For example, a Generation X employee says:

"I wish that upper management would take time to show employees how important they are and that they value what we are doing and value our hard work. So, when you feel like people are viewing you poorly, I think it can reflect in your work. You don't take as much pride in it. But I think if they just changed their view and show federal government employees how important they are and that they value what they're doing and value hard work, then fewer employees would leave."

Subcategory: Leadership Support. Leadership support refers to having the full support of agency leadership and making sure the needs of employees above and below are met. It is a leadership style where a supervisor does not simply delegate tasks and receive outcomes but instead aids an employee until the task is accomplished. A major upside to supportive management is that the manager works with the employee until he or she is empowered and skilled to be the best employee they can be. Four percent of respondents feel that managers are responsible for trying to support the needs of employees while meeting the needs of their leaders. For example, a Generation X employee states:

"There's a focus from the highest level of senior leadership to support strategic efforts of the USDA Secretary. I would say this causes a potential disconnect between senior leadership deciding whether their focus should be to support the secretaries' vision fully or supporting the needs of the entire agency to meet organizational specific goals...either way, it is important for me to feel supported." 
Subcategory: Trust in Leadership. Trust in leadership refers to an employee's faith in the leadership that they are doing everything in the best interest of employees. Workers will do the job requested of them, but without trust in leadership, they're not likely to go above and beyond to help produce a high-performance organization. Four percent of respondents feel that decisions are being made without input from experts in the field, and this has the potential to decrease productivity and commitment to the agency. For example, a Generation X employee says he has been thinking about leaving:

"I have lost trust in the existing upper management. I don't feel they took the time to do a study to make sure [the realignment] was the right thing to do or not. They were like, "We're doing this change, and [they] did it without consulting middle managers. That made me think twice about whether I can trust leadership."

\section{Quantitative Results}

The means, standard deviations, and correlations among study variables are presented in Table 6. The correlation coefficients show that all LMX dimensions (affect, loyalty, contribution, and professional respect) are significantly and positively related to each other. The variables of role's importance to the mission, tenure with USDA, and tenure with current supervisor did not have a significant relationship with any of the LMX dimensions. Interestingly, tenure with USDA was not significantly related to the role's perceived importance to the mission.

The means and standard deviations for all scales are provided in Table 6. With the LMX scale ranging from 1 ("Strongly Disagree") to 7 ("Strongly Agree"), the lowest mean was 5.96 (loyalty). The highest mean was 6.43 (contribution). These scores suggest a relatively high level of LMX quality experience among respondents. The standard deviation for LMX dimensions ranged from .65 to 1.06. The average tenure 
with the current supervisor was 2.27 years, and the average tenure with USDA was 14.49 years. The high scores on the role's importance to the mission (Mean=4.48) are consistent with the previous discussion on the pervasiveness of organizational pride among the respondents.

Cronbach's alpha, a measure for internal reliability, was computed for all scales. The higher the Cronbach's Alpha, the more confidence one can have that a measurement scale is internally consistent or how well each item correlates with the sum of the remaining items (Diedenhofen \& Musch, 2016). Cronbach's Alpha measures how interrelated each item is with each other item on the scale. According to Vaske, Beaman, and Sponarski (2017), it is a measure of consistency because if the items in the scale are correlated to each other, it is an internally reliable measure. Table 6 summarizes the coefficient alpha for each LMX dimension. The internal consistency reliabilities (coefficient alpha) for each of the four LMX dimensions ranged from 0.86 to 0.93 , satisfying Nunnally and Bernstein's (1994) criterion (>0.70).

Table 6 shows the correlations among role's importance to mission, tenure with USDA, tenure with current supervisor, and LMX (affect, loyalty, contribution, and professional respect). The results show that LMX does not have a statistically significant relationship with role's importance to mission $[\operatorname{LMX}$ affect $(r=-.32, p=.12)],[\operatorname{LMX}$ loyalty $(r=-.37, p=.07)],\left[\operatorname{LMX}_{\text {contribution }}(\mathrm{r}=-.15, p=.47)\right]$, and $\left[\operatorname{LMX}_{\text {professional respect }}(r=-.09\right.$ $p=.61)]$, tenure at USDA with $[\mathrm{LMX}$ affect $(r=-.14, p=.52)],[\operatorname{LMX}$ loyalty $(r=-.23, p=$ $.26)],\left[\operatorname{LMX}_{\text {contribution }}(r=.06, p=.78)\right]$, and $\left[\operatorname{LMX}_{\text {professional respect }}(r=-.09, p=.86)\right]$; and tenure with current supervisor with $\left[\operatorname{LMX} X_{\text {affect }}(r=.24, p=.24)\right],[\operatorname{LMX}$ loyalty $(r=.15, p=$ .49)], [LMX contribution $(r=.07, p=.76)]$, and $\left[\operatorname{LMX}_{\text {professional respect }}(r=.27, p=.86)\right]$. LMX 
scales are significantly correlated with each other but not with any of the other variables; role's importance to mission, tenure at USDA, and tenure with current supervisor. Further, correlations between role's importance to mission, tenure at USDA, and tenure with current supervisor are also not statistically significant.

Some of the results are surprising because previous research suggests tenure with current supervisor and organizational tenure may positively influence LMX (Graen \& Scandura, 1987; Maslyn \& Uhl-Bien, 2001; Wayne, Shore, Bommer, \& Tetrick, 2002), however, in this study, there is not a statistically significant relationship. Still, there are a few previous studies that have found insignificant relations between LMX and tenure (Scandura \& Pellegrini, 2008; Schyns, Paul, Mohr, \& Blank, 2005). Further, this study’s small sample size $(n=25)$ may be driving the non-significant associations between LMX, role's importance to the mission, tenure at USDA, and tenure with the current supervisor. Results suggest that the USDA has largely been successful in creating highquality LMX relationships across the organization, regardless of dyad tenure, organizational tenure, or role's significance to the overall mission. Results suggest relatively high scores in all LMX subdimensions, which is consistent with the findings of the 2019 Federal Employee Viewpoint Survey (FEVS) (United States Office of Personnel Management, 2020a), as discussed above. Consistent with the highly-rated quantitative LMX findings, respondents largely acknowledged issues that are beyond the direct manager's control (e.g., workplace culture, learning, development, organizational pride, etc.) in discussing the variables USDA should focus on to improve talent retention. 
Table 6: Means, standard deviations, and correlations among the study variables

\begin{tabular}{|l|c|c|c|c|c|c|c|c|c|}
\hline \multicolumn{1}{|c|}{ Variables } & $\boldsymbol{M}$ & $\boldsymbol{S D}$ & $\mathbf{1}$ & $\mathbf{2}$ & $\mathbf{3}$ & $\mathbf{4}$ & $\mathbf{5}$ & $\mathbf{6}$ & $\mathbf{7}$ \\
\hline & & & & & & & & & \\
\hline 1. Affect & 6.19 & .91 & $(.89)$ & $.63^{* *}$ & $.41^{*}$ & $.58^{* *}$ & -.32 & -.14 & .24 \\
\hline 2. Loyalty & 5.96 & .99 & & $(.88)$ & $.49^{*}$ & $.63^{* *}$ & -.37 & -.23 & .15 \\
\hline 3. Contribution & 6.43 & .65 & & & $(.86)$ & $.57 * *$ & -.15 & .06 & .07 \\
\hline 4. Professional respect & 6.09 & 1.06 & & & & $(.93)$ & -.09 & -.02 & .02 \\
\hline $\begin{array}{l}\text { 5. Role's importance to } \\
\text { the mission }\end{array}$ & 4.48 & .76 & & & & & & .01 & -.13 \\
\hline $\begin{array}{l}\text { 6. Tenure with USDA } \\
\text { (in years) }\end{array}$ & 14.49 & 6.13 & & & & & & & .10 \\
\hline $\begin{array}{l}\text { 7. Tenure with current } \\
\text { manager (in years) }\end{array}$ & 2.27 & 3.37 & & & & & & & \\
\hline
\end{tabular}

Note. $n=25$. $* * p<0.01, * p<0.05$, In parenthesis: Cronbach's alpha for scale scores. 


\section{Chapter 5: Discussion}

The purpose of this primarily qualitative study was to collect data through expressive discussions with high-performing employees to inform talent retention strategies USDA can use to retain talented employees. This study served to contribute to the talent retention literature by incorporating the stories and experiences of Generation $\mathrm{X}$ and millennial federal government employees. The guiding question of this study was: How can the United States Department of Agriculture retain talent? This chapter is organized as follows: first, a discussion of the findings is presented, followed by a discussion of the study's limitations. Next, theoretical contributions, implications for practice, and future research directions will be discussed.

\section{Summary of Findings}

Seven categories emerged from the interviews as drivers of employee retention. These seven categories are labeled organizational pride, communication, workplace culture, job resources, learning and development, career growth, and leadership. Organizational pride refers to employees taking pride in belonging to the organization. The category of organizational pride is further specified by the sub-categories of mission of the organization, impacting people's lives, national impact, and corporate social responsibility. Communication refers to the ability of employees to engage in effective communication to fulfill their jobs and carry out the mission of the organization. The category of communication is further specified by the sub-categories of 360 communication, communication with direct manager, communication with senior leadership, and unified messaging. Workplace culture refers to the culture created by the organization and its reflection on the principles of an organization. The category of 
workplace culture is further specified by the sub-categories of family-like environment, decentralized organizational structure, recognition, flexibility, diverse workforce, and transparency of organizational goals. Job resources refers to employees having the means at their disposal to complete their job. The category of job resources is further specified by the sub-categories of up-to-date technology and efficient procedures. Learning and development refers to increasing employees' skills and knowledge to support the mission of the organization. The category of learning and development is further specified by sub-categories opportunity to continuously move and grow and relevance of the trainings that are offered. Career growth reveals the importance for organizations to support talented employees by investing in career growth. This category is further specified by the sub-categories of opportunities for promotion and internship programs. Finally, the Leadership category refers to providing effective leadership and guidance to employees. The category of leadership is further specified by the subcategories of feeling valued by leadership, leadership support, and trust in leadership. In addition to the qualitative data gathered to address the questions, a brief quantitative survey was employed to complement the qualitative data collected.

Findings of the present study suggest that the existing research on talent retention is important in the federal government context, and the seven categories that emerged from this study will further inform talent retention strategies in the federal government. The two most novel findings of this study are the category of organization pride and the sub-category of 360 communication. Neither of these variables has been previously examined in talent retention research, and they will inform both the existing talent retention literature as well as federal government talent retention efforts. 


\section{Discussion of Findings}

The participant's descriptions of their experiences of why they remain with the federal government are consistent with those that have been identified in previous literature as drivers of turnover intentions. Current results are directly aligned with previous research in which individuals identified why they have chosen to stay with their respective organizations (Allen, 2008; Bauer et al., 2006; De Croon et al., 2004; Griffeth et al., 2000; Kim, 2014; McKnight et al., 2009; Rousseau \& Aube', 2000; Waldman et al., 2015). Additionally, new findings were uncovered during this study, termed organizational pride and 360 communication.

\section{Organizational Pride}

All the respondents discussed the importance of organizational pride as a variable that is important to them and is a critical factor in why they stay with the organization. Every respondent $(n=25)$ mentioned a form of organization pride through discussion of the impact that USDA has on the lives of individuals in Rural America, the importance of the mission, and corporate social responsibility.

Organizational pride is a relatively new construct and has not yet achieved largescale research attention; however, it is an important factor in the success of any organization (Gouthier \& Rhein, 2011). Organizational pride is defined as "the pleasure taken in being associated with one's employer" and is "the extent to which individuals experience a sense of pleasure and self-respect arising from their organizational membership" (Ng, Yam, \& Aguinis, 2019, p.110).

This construct has not only received limited research attention but also none of the limited existing research has been conducted in the federal government context with a 
focus on talent retention. According to previous literature, there are two types of organizational pride, specifically emotional organizational pride and attitudinal organizational pride. Emotional organizational pride is defined as "a discrete and intense, but short-lived, mental experience...caused by a specific stimulus object or a particular event that causes the pride emotion" (Gouthier \& Rhein, 2011, p. 635). Findings suggest emotional organizational pride has a positive effect on the commitment to customer service. Attitudinal organizational pride is "collective, resulting from the employee's need for affiliation with the organization" (Gouthier \& Rhein, 2011, p. 636). Attitudinal organizational pride directly influences turnover intention and results in the employee having a high degree of favor with the organization and impacts turnover intention (Gouthier \& Rhein, 2011; Kraemer \& Gouthier, 2014). Further, research highlights that organizational pride increases if employees have the impression that the company practices a responsible and honest interaction with stakeholders. Additionally, the organizational leadership and creation of a challenging work environment influence employee's organizational pride (Gouthier \& Rhein, 2011).

This study's respondents discussed their need to give back to the community and suggested it as a strategy to retain Generation $\mathrm{X}$ and millennial employees. Respondents also look at company values and leadership's view of CSR to make a decision on their continued employment. Doh, Smith, \& Stumpf (2011) suggest that social responsibility influences retention through its positive effect on new professionals' pride in and satisfaction with the organization. Employee's pride in the organization is highly correlated with their satisfaction with the organization. Elements of pride include being proud of the work completed to maintain the organization's reputation, being willing to 
speak highly of the organization's products and services, and being confident in this organization's ability to do what is right. Organizations without effective professional development opportunities can still [positively] affect their employees' organizational pride and retention through the support their managers provide to the employees and the social responsibility the organization exhibits (Doh et al., 2011). Socially responsible actions are associated with a strong sense of pride in the organization and satisfaction with the organization.

Corporate social responsibility or (CSR) refers to the trust that an organization should be a responsible company and an asset to the societies in which it operates, which was the same sentiment of respondents in this study. $\mathrm{Ng}$ et al. (2019) suggest that perceived CSR relates to organizational embeddedness, and that, in turn, relates to decreased turnover. They found that job embeddedness and organizational pride result in lower turnover. When an employee has a lower level of job embeddedness, previous research reveals that the employee is more likely to look for another job (Peachey, Burton, \& Wells, 2014). Mitchell et al. (2001) found that job embeddedness supports employee perceptions of the organization in ways that connect individuals to the organization and cause them to stay with the organization. The current findings support previous research, where respondents expressed that they don't plan to leave the agency because they believe in the mission and the work done by USDA and are therefore embedded in their jobs.

\section{Communication}

Respondents shared that the ability to communicate with all employees in the organization at all levels is important and impacts their desire to stay. Gaylard, 
Sutherland, and Viedge (2005) found that one of the top ten variables that influenced retention was having an open and honest two-way communication channel with a direct manager. Respondents also shared experiences where they were able to communicate with senior leadership in a collaborative manner, which increases their desire to remain with the organization.

Respondents specifically referred to 360 communication as an important factor for talent retention. Respondents' definition of 360 communication resembles holacracy, a decentralized organizational structure that opens the lines of communication hierarchy and makes employees feel more connected to the organization. The construct of holacracy is a relatively new construct and practiced in the context of private organizations and state and local government but not in the federal government context (Bernstein et al., 2016; Lee \& Edmondson, 2017). Chaudhuri and Ghosh (2012) uncovered that employees want a flat hierarchy to communicate with managerial leadership. Holacracy is defined as a "flat, flexible organizational structure, which gives more autonomy to teams and individuals" (Altman, 2016, p.14). The purpose of holacracy is to create a workplace where bureaucratic policies don't stop innovation, and, based on current findings; flatter two-way communication structures may positively impact the federal government work context and aid in retaining Generation $\mathrm{X}$ and millennial employees.

The organization should have clear roles assigned to each team according to the nature of the department, working autonomously, but with different departments inside the organization. Holacracy is an organizational structure that "allows a team to interact and work with each other, although they are self-managed and organized into distinct, 
separate groups" (Van de Kamp, 2014, p.16). In a holacracy system, employees have the ability to autonomously make decisions about their roles and the autonomy to do what needs to be done to get the job done. It also gives the leader the ability to be freed from the day to day burdens to focus on more important tasks and organizational issues, such as focusing on implementing the mission and vision of the organization instead of dealing with operational aspects. A holacratic environment allows employees to take on the full responsibility of task completion, which gives employees a sense of ownership and pride and therefore increasing retention. With their frequent mention of 360 communication, this study's respondents prefer a decentralized structure where they have the autonomy to talk to those above and below their current level to achieve the mission of the organization. They state this is an important factor when considering whether to stay with the organization.

Respondents further discuss the need for unified messaging where employees receive consistent messages from leadership and that the message stays the same from one leader to the next. Previous research on communication suggests that a diverse set of communication should be used to deliver messages (Gilley, Gilley, \& McMillan, 2009). Mikkelson, York, and Arritola (2015) suggest that clear and effective communication help personnel focus on the significant goals and duties, and that appropriate communication helps build and maintain relationships. These relationships are important and are significantly related to organizational commitment, which this study reveals impacts retention, and helps supervisors and employees build trusting relationships (Jo \& Shim, 2005; Men \& Stacks, 2014; Sokro, 2012). 


\section{Workplace Culture}

The ability to create relationships through interaction with friendly, supportive coworkers is one of the best aspects of the job, according to respondents. According to previous research, family role stressors, such as role ambiguity, role conflict, and role overload, are positively and significantly related to work-family conflict, and familywork conflict which then lead to negative outcomes such as turnover intentions (Asghar, Gull, Bashir, \& Akbar, 2018).

Respondents shared that a decentralized organizational structure is an important cultural aspect for respondents to remain with the organization. Previous literature agrees with the sentiments of respondents, and according to Shaukat, Ashraf, and Ghafoor (2015), companies should encourage employees to participate in activities that allow them to share ideas and opinions, as well as boost their involvement and capture innovative ideas. Supanti, Butcher, and Fredline (2015) suggest employee participation in decision-making helps generate a sense of belonging among employees and may decrease turnover.

Respondents also shared that recognition on the job impacts their desire to remain with the organization. Recognition, acknowledgment, and appreciation of employees' efforts and performance were discussed as key to employee satisfaction and motivation. According to Alshmemri, Shahwan-Akl, and Maude (2017), progression and acknowledgment could positively affect satisfaction, and they found that when leaders acknowledge an employee's accomplishments, the employee might be more effective. Also, verbal praise can enhance company loyalty (Aisha, Hardjomidjojo, \& Yassierli, 
2013), and for some respondents, that was more important than recognition in the form of monetary awards.

Respondents also shared that flexibility impacts their desire to stay with the organization. Flexibility can come in many forms, but the most common is work-life balance defined as "satisfaction and good functioning at work and home, with a minimum role conflict" (Kim, 2014, p. 39). Several studies have indicated that work-life balance has been shown to have positive outcomes related to employee performance, organizational performance, and organizational commitment (Harrington \& Ladge, 2009; Parkes \& Langford, 2008). Additionally, the Office of Personnel Management (OPM) survey found that federal employees reported a strong work-life culture, with $82 \%$ of employees responding that their supervisor supports the need to balance work and other life issues (United States Office of Personnel Management, 2020b).

Respondents also shared that diversity is important to why they continue to stay with the organization. Randel, Galvin, Shore, Ehrhart, Chung, Dean, and Kedharnath (2018) describe an inclusive organization as one that promotes and fosters the integration of its diverse individuals. Shore, Cleveland, and Sanchez (2018) argue that inclusion means eliminating obstacles that prevent employees from fully participating and contributing to the organization. Respondents prefer a diverse workforce where all are accepted and recognized, and respondents expect that the agency will continue to make diversity a top priority. Diversity is in line with the resource-based view, which suggests that organizations allocate resources to critical areas of retention, such as diversity management, to build internal resources and core capabilities for sustainability (Barney, 1991; Holland, Sheehan, \& De Cieri, 2007). 
Respondents also shared that the transparency of organizational goals is an important reason why they stay. The findings resembled those identified in goal-setting theory. The primary principle of the goal-setting theory is that goal setting or goal properties can affect the organization's members' affective responses (e.g., motivation and commitment), their performance, and organizational performance (Latham \& Locke, 2018; Lunenburg, 2011). Respondents agree as they suggest that the agency leadership should share goals and mission changes timely so they can better align themselves and their work units to the organization's goals.

\section{Job Resources}

Respondents shared that having the appropriate job resources makes the decision to stay with the organization much easier. Providing employees with the tools, resources, and/or equipment necessary to do their jobs was important to participants, specifically when it comes to technology. Ratna and Chawla (2012) noted that employees intentionally stay with companies that provide training in new technology. In addition to modern technology, this research also revealed that federal employees desire clear and organized policies and efficient procedures to aid in the completion of job duties.

Previous research defines job resource adequacy as "the extent to which individuals have the means at their disposal in their immediate work situation to fully utilize their relevant abilities and motivation to accomplish work-related goals" (Rousseau \& Aube, 2010, p. 324). Previous research on job resources suggests that job resources have a negative relationship with burnout and have a positive impact on job engagement (Roodt, 2018), which may result in increased retention. 


\section{Learning and Development}

Respondents shared that having opportunities to continuously learn is an important reason why they stay with the organization. This study supports previous research and revealed respondents' need for the agency to provide professional development and enhancement of skills to support the mission of the agency. According to Zaharee, Mehlman, and Neylon (2018), professional development is one of the most important factors in retaining talent and that the more a company provides development, the happier employees are and more likely to stay.

Respondents shared that learning and development are important when they consider staying with the organization. This study supported the importance of proper training that enhances skills and professional development. Ratna and Chawla (2012) noted that employees intentionally stay with companies that provide relevant training. Respondents shared that when given the ability to receive relevant training, they gain the necessary skills to become a better employee and more opportunities for internal career advancement. The results of this study are consistent with previous research, but these findings are not always practiced in business (Kulkarni, Lengnick-Hall, \& Martinez, 2015). The ability to train employees and continue to peek their interests is a strategy that leaders must focus on to give employees a reason to stay.

General training and skill development are in line with the resource-based view, which suggests that organizations allocate resources to critical areas of retention, such as learning and development, to build internal resources and core capabilities for sustainability (Barney, 1991; Holland et al., 2007). This category is also in line with human capital theory, which suggests that education and training are a form of 
investment in human resources and therefore helps organizations to produce goods and services more efficiently, thereby having the potential to increase growth (Becker, 1993).

\section{Career Growth}

According to Mustapha and Zakaria (2013), programs that allow employees to gain additional experience and knowledge build a pipeline of emerging leaders who possess a broad understanding of the organization. Respondents shared that opportunities for promotion and the availability of internship programs are an important aspect for respondents to remain with the organization. Respondents believe that opportunities for growth with the organization and gaining knowledge and experience is a priority to add value to their careers now and in the future. This research supports previous literature, as many respondents suggest that spending time learning more about the organization enhances experience and knowledge and opportunities for potential future growth. According to a study by Weng and McElroy (2012), there is a negative relationship between turnover intentions and career growth. They suggest that employees with met expectations and fulfilled psychological contracts, become more committed to their organizations, making them less likely to leave. When the relationship between an individual's career goals and their current job is strong, the individual may become more attached to their employer, which may reduce their desire to look for other opportunities.

This category is also in line with the resource-based view, which suggests that organizations allocate resources to critical areas of retention, such as skill development and career management, to build internal resources and core capabilities for sustainability (Barney, 1991; Holland et al., 2007). 


\section{Leadership}

Respondents shared that their close relationship with leadership is important and is key to them wanting to stay with the organization. Respondents identified that they need leadership to be supportive, value employees, and establish trust with employees. Respondents shared that when management frequently changes an employee's job duties, expectations, and work policies, those changes become a source of dissatisfaction, stress, and can lead to employees having a desire to leave, particularly when changes are not effectively communicated to employees. These results are aligned with previous research in which individuals feel valued by their leadership. Hamstra, Sassenberg, Van Yperen, and Wisse (2014) found that it was important to employees to know that they are valued for who they are and for their unique worth within the organization. For multiple respondents in this study, they identified being valued as having the ability and autonomy (trust) to execute an idea from start to finish; utilizing their strengths and expertise; and opportunities to make an impact and contribution towards the mission of the organization. Respondents discussed the importance of autonomy, being trusted by their leader to complete the work, and not being micromanaged for tasks. "When a leader communicates trust and respect for followers abilities to perform and achieve, the internal motivation of the followers takes over and drives them to succeed" (Strebel, 1996, p.87). Respondents stressed feelings of empowerment and engagement when their managers were all-encompassing with decision-making and trusted them to complete their work without micromanaging them. 


\section{Leader-Member Exchange (LMX)}

The study examined the respondents' work context concerning the four LMX dimensions of affect, loyalty, contribution, and professional respect. Liden et al. (1997) claimed that leaders and followers that enjoy multiple relational dimensions (affect, loyalty, contribution, and professional respect) might secure better benefits than those whose relationships are based on a single dimension. It is highly probable that followers who assess the exchange with their leaders to be high of affect, loyalty, contribution, and professional respect, also tend to express less turnover intention. Uhl-Bien, Graen, and Scandura (2000) emphasized the importance of the quality of the relationship between leader and member and its implications for the performance of the organization. UhlBien et al. (2000) state that companies do not work in isolation; thus, human resource focus should be "realigned toward the right people, at the right place, at the right time, and with the right relationships" (p.144). This study revealed that the federal government is successfully creating and sustaining high-quality LMX relationships. This may be why all seven categories that emerged from the interviews refer to either organizational or senior leadership issues in discussing important talent retention practices.

\section{$\underline{\text { Limitations }}$}

Despite the ample, novel information that emerged from the interviews, the present study is not without limitations. First, the sample distribution was uneven in terms of gender. Specifically, a slight majority of the sample was comprised of female participants (52\% female). While the larger population of female participants may be a limitation of the present study, it may be valuable in other respects. The higher percentage of women in the current study counteracts the gender gap in previous studies 
in the federal government context that have mostly relied on male participants. As of 2018, women held just $44 \%$ of the jobs of federal government employees (excluding military and postal employees) (United States Office of Personnel Management, 2019a).

Second, the sample was uneven in terms of generational distribution. Specifically, $64 \%$ of the sample was comprised of Generation X employees, and millennials constituted only $36 \%$ of the sample. Including more participants from the millennial generation may have proven more beneficial since Baby Boomers, followed by older Generation $\mathrm{X}$ employees are retiring and having more data that supports the expectations of millennial employees as to what helps increase their retention may be important. Having more millennials in the sample may have led to additional novel constructs beyond organizational pride and 360 communication that are important to the millennial generation concerning retention.

Third, the novel coronavirus (COVID-19) pandemic impacted my ability to conduct in-person interviews for some respondents. I interviewed only half of the respondents in person. I had to result to using Zoom with no video to record the semistructured interviews for approximately $50 \%$ of respondents. It also impacted my ability to travel to other regions of the U.S. to gain insight from respondents in other regions of the country as the responses from a more diverse set of regions may have added new categories to talent retention drivers.

Fourth, the average tenure of respondents working for the federal government was 15.53 years. Although I did purposefully seek out experienced employees, additional findings may have been uncovered if the sample also included employees with less federal work experience. Employees with less experience potentially may have less 
preconceived thoughts than those with many years of federal government work experiences. Less experienced workers may have identified other novel findings currently not offered in talent retention literature.

Fifth, the inability to obtain information on employees that left the federal agency on their own limited our ability to examine other categories and sub-categories that may help produce strategies the agency can use to retain talented employees. However, I did incorporate into the interview protocol an open-ended question asking if the respondents know anyone that left the agency in the last three years, and if so, did they know the reason why? This question did not reveal any new information above and beyond what has been already identified by study participants. However, having access to the actual exit surveys from the agencies, assuming those employees were truthful, would have been a benefit to this research.

\section{$\underline{\text { Theoretical Contributions }}$}

Findings from this dissertation research contribute to the literature by adding several salient findings regarding talent retention in the federal government context. Findings of the present study suggest that the existing research on talent retention is important in the federal government context, and the seven categories that emerged from this study will further inform talent retention literature, specifically as it pertains to the federal government. Talent retention in the federal government context was analyzed from a resource-based view and human capital theory perspective.

Previous research suggests that the resource-based view for organizations that invest in human resources (i.e., training, job design, career management, etc.) turn a potential problem with employee retention into an opportunity to gain industry leadership 
(Barney, 1991; Holland et al., 2007). This study revealed the same finding from a federal government context. Previous research also suggests that human capital theory for organizations that invest through education and training is a form of investment in human resources, the investments through increased skills of employees and their level of competence increases competitive advantage among private industries (Becker, 1993) but can also be applied to the federal government context. Grounded in resource-based view and human capital theory, this study and the findings further inform talent retention in the federal government, and the study further adds to the existing talent retention research through the introduction of two new variables related to talent retention; a category termed organizational pride, and a sub-category termed 360 communication.

The finding of organizational pride impacts the retention of federal government employees, and those findings indicate organizational pride is important in the retention of employees. Organizational pride increases as employees take pride in belonging to the organization and is a top reason for respondents remaining employed with the organization. Organizational pride is a new construct and has received limited research attention. However, none of the limited research has been conducted in the federal government. Still, all respondents in this study mentioned a form of organizational pride through discussion of the impact that USDA has on the lives of individuals in Rural America, the importance of the mission, and corporate social responsibility.

Similarly, the finding of 360 communication impacts the retention of federal government employees, and findings indicate the ability to engage in two-way 360 communication is important in the retention of employees. 360 communication is a structure that opens the lines of communication hierarchy and makes employees feel 
connected to the organization. Holacracy, which resembles 360 communication, has received limited research attention in the context of private organizations and state and local government. Still, none of the limited research was conducted in the federal government context until now. The new findings are supported by previous studies (Altman, 2016; Bernstein et al., 2016; Gouthier, \& Rhein, 2011; Kraemer \& Gouthier, 2014; Lee \& Edmondson, 2017; Ng et al., 2019) and inform talent retention research in the federal government context. These findings contribute to the current talent retention, and the newly emerging organizational pride and holacracy literature with information from experiences of Generation $\mathrm{X}$ and millennial employees describing reasons why they remain with the federal government.

\section{Practical Implications}

Employees want to be known for their contributions, have an impact, feel empowered, receive support, use their abilities, and have opportunities for growth. They want to have sound rapport with their supervisors, colleagues, and senior leadership, as well as a sense of collaboration and mutual mission. They also want a family-friendly environment, and they want to receive acknowledgment for their performance. There is no single plan or retention strategy that will ensure high-performing employees will stay on the job. However, my research does identify several constructs that can be used to enhance the retention strategies USDA already has in place. These strategies will either improve or add to those already in place by the USDA. The goal of this study was to inform talent retention strategies the USDA can use to improve talent retention. Based on the study's findings, I outline below seven actions the USDA can take that reinforce 
the positive value of organizational pride, 360 communication, learning and development, and career growth:

Organizational Pride: The respondents created a vivid picture of the need to have a clear line of sight from employee to organization mission and goals. Their descriptions underscore the need for leaders to keep employees abreast of important things that impact their work related to the agency's mission. Precise measurements of success and progress toward meeting goals help keep employees up to date on the impact of how the work that they do and how it impacts the lives of USDA customers. Leaders should work to develop timely and meaningful connections for employees to continually reinforce organizational pride by illustrating the importance of the organization's national impact, impact on customer's lives, and corporate social responsibility.

1. The USDA has done a great job in building a reputation as a leading agency in the federal government and has a reputation as a Center of Excellence (COE) for different business lines of the agency. COEs consolidate functions of related entities and develop best practices among entities to create efficiencies and revitalize stalled initiatives. Based on rich experiences shared by respondents, the agency should continue to add COEs throughout the organization where applicable as COEs increase organizational pride through creating excellent products and services, cutting cost, and providing a sense of accomplishment for employees. Employees can gain satisfaction from knowing that they work for an agency that has been recognized for its work by providing excellent products and services not sacrificed to control costs, and employees feel a sense of personal accomplishment knowing that they work for an organization that they can be proud of. Intentionally striving to build such a 
reputation can help both attract and retain top talent and may increase organizational pride. Several areas within the USDA have established COEs, and this should be expanded where possible. This collaboration among federal agencies also has the potential to save the federal government taxpayer funds as it would create best practices and efficiencies across the government. Therefore, increased number of COEs would serve a dual purpose in improving organizational pride among employees as well as create efficiencies across the government.

2. USDA is a service organization and supports such things as food safety, natural resources, nutrition, and rural development. However, there is more that the agency can do to highlight the great work of the organization to attract new personnel and retain employees. Several respondents highlighted the importance of an agency that supports the community when considering a place to work and reasons for remaining with the agency. USDA should do more to highlight the positive impact on the nation and community, identifying the great work that is done. USDA should publicize the organization's social responsibility initiatives both internally and externally on websites and other social media platforms, such as the agency's intranet site, World Wide Web, LinkedIn, and Facebook. This serves a dual purpose; the general public sees what the agency does, which may attract potential candidates for future positions, and most importantly, current employees will see that the agency is in the community not only serving their customers but also working to impact communities across the nation. Agency leadership should provide opportunities for employees to participate in socially responsible initiatives and support special interest groups with a board that maintains oversight of the organization's social responsibility initiatives. 
Further, creating forums on the organization's website for employees to share information and encouraging all employees to participate may increase organizational pride and retention, as highlighted by this study's respondents.

3. USDA should work to create a culture that recognizes and creates organizational pride internally to the organization. USDA should implement a national recognition plan at the agency level that would allow employees to nominate extraordinary service-oriented behaviors of their colleagues. These nominations are sent to the team and voted on by senior leadership, and employees are then selected to be recognized nationally. This would contribute to a recognition culture that may increase employees' organizational pride. An organizational pride program should be perceived as a serious approach and not serving as a marketing tool for management to simply highlight the USDA but primarily to recognize the service-oriented behavior of the organization.

4. USDA should create an employee survey that is administered twice a year to assess organizational pride, organizational commitment, and employee evaluation of the agency. Currently, the FEVS serves as a government-wide survey tool to gather some of this information; however, an agency-specific employee measurement tool will be more advantageous to the agency. Unlike the FEVS, this survey would be sent to all agency employees, and pinpoint areas of dissatisfaction and provide a starting point for retention strategies. By examining the gaps in responses to selected questions in the annual FEVS, agency leaders can gain insight into the satisfaction and dissatisfaction of specific groups. This data can then be used by the organization to track employee responses over the years, and then management can analyze the 
data and analyze trends among employees. This is specifically important since as employees retire or leave the agency and new employees are hired, the agency can track the trends and adjust strategies and plans as appropriate. This allows agency leadership to keep a pulse on employee thoughts and concerns related to the performance of the agency as well as the prevalence of agency and organizational pride from an employee perspective.

360 Communication: The respondents highlighted the importance of having twoway communication with senior leadership as an important factor for talent retention.

5. Agencies should create a culture that enables more frequent two-way communication with senior leadership. Instead of retaining the current hierarchical structure, managers should consider a model that increases two-way communication with their employees, leading to a more genuine and transformational experience that nurtures trust between the employees and leadership. Previous research suggested that employees who are supervised by a transformational leader are more likely to observe organizational communication as two-way and encouraging, and thus are more likely to remain with the organization (Men, 2014; Men \& Stacks, 2014). Therefore, USDA should work to develop leaders who exhibit transformational leadership attributes through in-person training where leaders at all levels build the skills necessary to move to a leadership style with the ability to create and inspire a vision for the future, motivate and support staff to buy into the vision, and build a trust-based relationship with employees where employees feel free to discuss their thoughts for the future of the organization and share without fearing reprisal. 
Learning and Development: As a result of the continued human capital issue, USDA should put significant resources in developing the knowledge and skills of current employees. Developing a pipeline of talented employees includes using flexibilities already given to federal agencies that include job rotation, job sharing, phased retirement, and retiree rehiring.

6. The first step in learning and development should be for the agency to create a knowledge management system, where employees share relevant job information, such as job aids, training manuals, list of common procedures and checklist for completing tasks. Knowledge management focuses on the organization's ability to accumulate, change, and transfer knowledge throughout the organization (Bharadwaj, Chauhan, \& Raman, 2015). This will also allow the transfer of knowledge for those who leave the agency as part of normal attrition to make sure the remaining employees have access to and learn from the knowledge that former employees have gained over the years. In addition to continued learning and development for employees, this will aid the agency in continuing the mission without interruption and therefore making sure the agency is viable in the future.

Career Growth: The respondents highlighted their desire to continue to grow professionally, and they specifically mentioned internship programs as an important tool for talent retention.

7. Agencies should encourage employees to gain additional knowledge outside their current department to increase retention. Employees may lack an understanding of what occurs outside of their immediate organization, and without an understanding of how one's work affects others, they can't be as efficient. Agencies should allow 
employees to visit or job shadow other employees within other departments of the agency through the creation of a national rotation program for employees with guidelines for those positions that the agency deems as essential and hard to fill. Educating employees and giving them the opportunity to understand the complete picture of the business of USDA will help them be mindful of how the quality of their work impacts other departments and the department's goals. Helping employees understand the full picture satisfies the employees' need for further career growth and increases organizational pride in the organization, which in turn increase their desire to stay with the agency.

\section{$\underline{\text { Future Directions }}$}

This study fills several gaps in existing research. First, the study explored talent retention that has not been widely studied in the federal government context, incorporating the experiences of Generation $\mathrm{X}$ and millennial employees who have chosen to stay with the federal government. Second, the study explored talent retention from a qualitative viewpoint, a methodology that has rarely been used when researching talent retention in the federal government context. Finally, the categories, findings, and conclusions provide insight into the experiences of Generation $\mathrm{X}$ and millennial employees that have chosen to stay and inspire several directions for additional research and practice.

As the Baby Boomer and early Generation Xers retire and younger Generation X employees and millennials are promoted, Generation Xers and millennials are wellpositioned to take on management roles within their agencies. Collins, Hair, and Rocco (2009) caution that the new relationship between younger employee managers and older 
workers might have negative consequences. A recommendation for further research is to explore the leadership characteristics of Generation $\mathrm{X}$ and millennial managers within the federal government through a dyadic study of the relationship between Generation $X$ and millennial leaders and their subordinates to understand multigenerational LMX dyads and make recommendations for talent retention.

Quantitative research studying talent retention using the leader-member exchange and talent retention measures would prove beneficial for future research. Using quantitative methods allows the researcher to have a larger sample population. Conducting a larger scale quantitative study across the federal government can provide organizations with additional strategies to increase retention. The focus of the current research was to explore LMX relationship quality in the federal government work context by using the four-dimensional LMX-MDM measure (Liden \& Maslyn, 1998), and a larger sample may reveal additional insights relevant to talent retention strategies.

Given the importance of organizational pride and 360 communication as factors driving retention, it is crucial that additional research is undertaken to discover in more detail (via other federal government agencies) strategies that can be developed to address organizational pride and 360 communication problems and the factors impacting their success from a global federal government context. It is the hope that the insights gained from this study might continue to add to the emerging and evolving research on talent retention in the federal government context.

In this study, 360 communication was identified by respondents as a practice that increases their desire to remain with the organization. Future research should examine possible moderators between 360 communication and talent retention to develop specific 
strategies to address talent retention and its relationship with 360 communication. This study's findings revealed that there is a positive relationship between 360 communication and talent retention; however, assessing moderators will further delineate how or why there is a relation between these two variables. Research should also examine whether valence of feedback acts as a moderator of the relationship between 360 communication and talent retention, such that employee to leader feedback with positive valence may strengthen the relationship as compared with feedback with negative valence. Research should also examine whether an employee's level of expertise serves as a moderator of the relationship between 360 communication and talent retention. It may be that employees with a higher level of expertise may strengthen the relationship between 360 communication and talent retention as compared with employees with lower levels of expertise. Finally, future research should examine whether trust in leadership is a moderator of the relationship between 360 communication and talent retention. In this study, trust in leadership emerged as a significant contributor to talent retention and it may be that 360 communication only works in practice when employees have trust in leadership.

Finally, although this research identified a high level of LMX quality between respondents and their direct supervisors, it is interesting that this research also identified a negative relationship with each of the four LMX dimensions (affect, loyalty, contribution, and professional respect) and role's importance to the mission. Based on the high LMX scores reported by respondents, I expected that respondents would have a better understanding of their role's importance in fulfilling the overall mission of the agency. I recommend further research to examine this unexpected negative relationship between 
LMX and role's importance to the mission and determine strategies to increase awareness of how one's job connects to the overall mission of the organization.

\section{Conclusion}

The purpose of this qualitative study was to examine the reasons why highperforming Generation X and millennial federal employees stay with USDA. This study served to contribute to an understanding of talent retention in the federal government context by incorporating the stories and experiences of federal government employees at USDA. The guiding question of this study was: How can the United States Department of Agriculture retain talent? The study's findings contributed to and supported existing research but also indicated that further research should be conducted in examining talent retention, particularly to meet the needs of Generation $\mathrm{X}$ and millennial federal government employees. Respondents shared their need for feeling valued, being included in decision making, and being recognized for their contributions and expertise. Although respondents provided specific examples such as access to resources, recognition, opportunities for growth and professional development as possible facilitators to increased retention, it is primarily their connection to the overall mission, the impact on the lives of borrowers, corporate social responsibility exhibited by the USDA, and the ability to communicate with leadership at all levels that ultimately determine why they stay with the agency.

\section{$\underline{\text { Summary }}$}

Chapter 5 offered conclusions based on data analysis and discussion on the emergence of seven categories and twenty-four sub-categories. Findings emphasized Generation $\mathrm{X}$ and millennial federal government employees have similar experiences as 
those observed in previous talent retention literature. However, federal Generation $\mathrm{X}$ and millennial employees, through this study, identified two novel variables of organizational pride and 360 communication. Through semi-structured interviews, this study provided twenty-five Generation X and millennial federal government employees with a voice to share their reasons for staying and allowed the exploration of talent retention from a perspective that researchers have rarely explored, particularly from a qualitative standpoint. It is my hope that these findings will stimulate future research and contribute to an enhanced understanding of the reasons high performing Generation $\mathrm{X}$ and millennial federal government employees decide to continue building their careers in the federal government. 


\section{References}

Abelson, M.A. (1993). Turnover cultures. Research in Personnel and Human Resource Management, 11, 339-376.

Aisha, A., Hardjomidjojo, P., \& Yassierli, A. (2013). Effects of working ability, working condition, motivation and incentive on employees multi-dimensional productivity. International Journal of Innovation, Management and Technology, 4(6), 1-5.

Allahar, H. (2018). Strategic human resource management practices in a developing country professional services firm. International Journal of Information, Business and Management, 10(4), 30-49.

Allen, D. G. (2006). Do organizational socialization tactics influence newcomer embeddedness and turnover? Journal of Management, 32(2), 237-256.

Allen, D. G. (2008). Retaining talent: A guide to analyzing and managing employee turnover. SHRM Foundation Effective Practice Guidelines Series, 1-43.

Allen, R. S., Allen, D. E., Karl, K., \& White, C. S. (2015). Are millennials really an entitled generation? An investigation into generational equity sensitivity differences. Journal of Business Diversity, 15(2), 14-26.

Allen, D. G., Bryant, P. C., \& Vardaman, J. M. (2010). Retaining talent: Replacing misconceptions with evidence-based strategies. Academy of Management Perspectives, 24(2), 48-64.

Allen, D. G., Peltokorpi, V., \& Rubenstein, A. L. (2016). When “embedded” means “stuck": Moderating effects of job embeddedness in adverse work environments. Journal of Applied Psychology, 101(12), 1670-1686. 
Alshmemri, M., Shahwan-Akl, L., \& Maude, P. (2017). Herzberg's two-factor theory. Life Science Journal, 14(5), 12-16.

Altman, R. (2016). HR Organizational Structure-Past, Present, and Future. Workforce Solutions Review, 7(4), 13-15.

Alton, L. (2017, June 20). How millennials are reshaping what's important in corporate culture. Forbes. https://www.forbes.com

Amos, E. A., \& Weathington, B. L. (2008). An analysis of the relation between employee - organization value congruence and employee attitudes. The Journal of Psychology, 142(6), 615-632.

Andert, D. (2011). Alternating leadership as a proactive organizational intervention: Addressing the needs of the baby boomers, generation xers and millennials. Journal of Leadership, Accountability, and Ethics, 8(4), 67-83.

Armstrong, M. \& Taylor, S. (2014). Armstrong's handbook of human resource management practice. Kogan Page.

Asghar, M., Gull, N., Bashir, M., \& Akbar, M. (2018). The impact of work-family conflict on turnover intentions: The moderating role of perceived family supportive supervisor behavior. Journal of Hotel \& Business Management, 7(178), 2169-0286.

Atkinson, J. M., Heritage, J., \& Oatley, K. (Eds.). (1984). Structures of social action. Cambridge University Press.

Attride-Stirling, J. (2001). Thematic networks: an analytic tool for qualitative research. Qualitative Research, 1(3), 385-405. 
Banks, G. C., Pollack, J. M., Bochantin, J. E., Kirkman, B. L., Whelpley, C. E., \& O’Boyle, E. H. (2016). Management's science-practice gap: A grand challenge for all stakeholders. Academy of Management Journal, 59(6), 2205-2231.

Barney, J. (1991). Firm Resources and Sustained Competitive Advantage. Journal of Management, 17(1), 99-120.

Baruch, Y., Szucs, N., \& Gunz, H. (2015). Career studies in search of theory: the rise and rise of concepts. Career Development International, 20(1), 3-20.

Bauer, T., Erdogan, B., Liden, R., \& Wayne, S. (2006). A longitudinal study of the moderating role of extraversion: Leader-member exchange, performance, and turnover during new executive development. Journal of Applied Psychology, 91, 298-310.

Becker, G. S. (1962). Investment in human capital: A theoretical analysis. Journal of Political Economy, 70(5, Part 2), 9-49.

Becker, G.S. (1993). Nobel lecture: the economic way of looking at behavior. Journal of Political Economy, 101, 385-409.

Beccalori, J. (2017, September 20). Millennials, loyalty, and corporate culture. Forbes. https://www.forbes.com/sites/entrepreneursorganization/2017/09/20/millennialslo yalty-and-corporate-culture/\#701fb56482d4

Becton, J. B., Walker, H. J., \& Jones-Farmer, A. (2014). Generational differences in workplace behavior. Journal of Applied Social Psychology, 44(3), 175-189.

Bernstein, E., Bunch, J., Canner, N., \& Lee, M. (2016). The big idea beyond the holacracy hype. Harvard Business Review, 94(7-8), 38-49. 
Bharadwaj, S. S., Chauhan, S., \& Raman, A. (2015). Impact of knowledge management capabilities on knowledge management effectiveness in Indian organizations. Vikalpa, 40(4), 421-434.

Bowen, D. E., \& Siehl, C. (1997). The future of human resource management: March and Simon [1958] Revisited. Human Resource Management (1986-1998), 36(1), 5763.

Bryson, J. M., Ackermann, F., \& Eden, C. (2007). Putting the resource-based view of strategy and distinctive competencies to work in public organizations. Public Administration Review, 67(4), 702-717.

Bussin, M. (2018). Reward solutions to retention questions. In M. Coetzee, I. Potgieter, \& N. Ferreira (Eds.), Psychology of retention: Theory, research and practice (pp. 379-394). Springer.

Caramela, S. (2018). How companies can change their culture to attract (and retain) millennials. Business. https://www.business.com

Chaudhuri, S., \& Ghosh, R. (2012). Reverse mentoring: A social exchange tool for keeping the boomers engaged and millennials committed. Human Resource Development Review, 11(1), 55-76.

Collins, M. H., Hair, Jr, J. F., \& Rocco, T. S. (2009). The older-worker-youngersupervisor dyad: A test of the reverse pygmalion effect. Human Resource Development Quarterly, 20(1), 21-41.

Costanza, D. P., Badger, J. M., Fraser, R. L., Severt, J. B., \& Gade, P. A. (2012). Generational differences in work-related attitudes: A meta-analysis. Journal of Business and Psychology, 27(4), 375-394. 
Curry, J. P., Wakefield, D. S., Price, J. L., \& Mueller, C. W. (1986). On the causal ordering of job satisfaction and organizational commitment. Academy of Management Journal, 29(4), 847-858.

Dansereau Jr, F., Graen, G., \& Haga, W. J. (1975). A vertical dyad linkage approach to leadership within formal organizations: A longitudinal investigation of the role making process. Organizational Behavior and Human Performance, 13(1), 46-78.

De Croon, E. M., Sluiter, J. K., Blonk, R. W., Broersen, J. P., \& Frings-Dresen, M. H. (2004). Stressful work, psychological job strain, and turnover: A 2-year prospective cohort study of truck drivers. Journal of Applied Psychology, 89(3), 442-454.

Deery, M., \& Jago, L. (2015). Revisiting talent management, work-life balance and retention strategies. International Journal of Contemporary Hospitality Management, 27(3), 453-472.

Deloitte. (2019, May 17). The Deloitte global millennial survey. Deloitte. https: //www2.deloitte.com/global/en/pages/aboutdeloitte/articles/millennialsurvey.html

Diedenhofen, B., \& Musch, J. (2016). Cocor: A web interface and r package for the statistical comparison of Cronbach's alpha coefficients. PLOS One, 10(4), 1-12.

Dienesch, R. M., \& Liden, R. C. (1986). Leader-member exchange model of leadership: A critique and further development. Academy of Management Review, 11(3), 618634.

Doh, J. P., Smith, R. R., \& Stumpf, S. A. (2011). Pride and professionals: Retaining talent in emerging economies. Journal of Business Strategy, 32(5), 35-42. 
Dulebohn, J. H., Bommer, W. H., Liden, R. C., Brouer, R. L., \& Ferris, G. R. (2012). A meta-analysis of antecedents and consequences of leader-member exchange: Integrating the past with an eye toward the future. Journal of Management, 38(6), 1715-1759.

El Akremi, A., Gond, J. P., Swaen, V., De Roeck, K., \& Igalens, J. (2018). How do employees perceive corporate responsibility? Development and validation of a multidimensional corporate stakeholder responsibility scale. Journal of Management, 44(2), 619-657.

Ertas, N. (2015). Turnover intentions and work motivations of millennial employees in federal service. Public Personnel Management, 44(3), 401-423.

Ferri-Reed, J. (2014). Millennializing the workplace. The Journal for Quality and Participation, 37(1), 13-14.

Ferri-Reed, J. (2015). Leading a multi-generational workforce: Learning to leverage the uniqueness of every age group. The Journal for Quality and Participation, 37(2), 17-18.

Festing, M., \& Schäfer, L. (2014). Generational challenges to talent management: A framework for talent retention based on the psychological-contract perspective. Journal of World Business, 49(2), 262-271.

Fishman, A. A. (2016). How generational differences will impact America's aging workforce: strategies for dealing with aging millennials, generation $\mathrm{X}$, and baby boomers. Strategic HR Review, 15(6), 250-257.

Fry, R., Igielnik, R. \& Patten, E. (2018, March 16). How millennials today compare today with their grandparents 50 years ago. Pew Research Center. 
https://www.pewresearch.org/fact-tank/2018/03/16/how-millennials-comparewith-their-grandparents/

Gaylard, M., Sutherland, M., \& Viedge, C. (2005). The factors perceived to influence the retention of information technology workers. South African Journal of Business Management, 36(3), 87-97.

Gilley, A., Gilley, J. W., \& McMillan, H. S. (2009). Organizational change: Motivation, communication, and leadership effectiveness. Performance Improvement Quarterly, 21(4), 75-94.

Gouthier, M. H., \& Rhein, M. (2011). Organizational pride and its positive effects on employee behavior. Journal of Service Management, 22(5), 633-649.

Graen, G.B. (1976). Role-making processes within complex organizations. In M.D. Dunnette (Ed.), Handbook of industrial and organizational psychology, (pp. 1201-1245). Rand McNally.

Graen, G.B., \& Cashman, J. (1975). A role-making model of leadership in formal organizations: A developmental approach, In J.G. Hunt \& L.L. Larson (Eds.), Leadership Frontiers (pp. 143-166). Kent State University Press.

Graen, G.B., \& Scandura, T. (1987). Toward a psychology of dyadic organizing. In B. Staw \& L.L. Cumming (Eds.), Research in Organizational Behavior, (pp.175208). JAI Press.

Greguras, G. J., \& Ford, J. M. (2006). An examination of the multidimensionality of supervisor and subordinate perceptions of leader-member exchange. Journal of Occupational and Organizational Psychology, 79(3), 433-465. 
Griffeth, R. W., Hom, P. W., \& Gaertner, S. (2000). A meta-analysis of antecedents and correlates of employee turnover: Update, moderator tests, and research implications for the next millennium. Journal of Management, 26(3), 463-488.

Hamstra, M. R., Sassenberg, K., Van Yperen, N. W., \& Wisse, B. (2014). Followers feel valued - When leaders' regulatory focus makes leaders exhibit behavior that fits followers' regulatory focus. Journal of Experimental Social Psychology, 51, 3440.

Han, G., \& Jekel, M. (2011). The mediating role of job satisfaction between leadermember exchange and turnover intentions. Journal of Nursing Management, 19(1), 41-49.

Hannam, S. \& Yordi, B. (2011). Engaging a multi-generational workforce: Practical advice for government managers. IBM Center for the Business of Government. http://www.businessofgovernment.org/report/engaging-multi-generationalworkforce-practical-advice-government-managers

Harrington, B., \& Ladge, J. (2009). Present dynamics and future directions for organizations. Organizational Dynamics, 38(2), 148-157.

Hershatter, A., \& Epstein, M. (2010). Millennials and the world of work: An organization and management perspective. Journal of Business Psychology, 25(2), 211-223.

Holland, P., Sheehan, C., \& De Cieri, H. (2007). Attracting and retaining talent: Exploring human resources development trends in australia. Human Resource Development International, 10(3), 247-262. 
Holmes, P., Chapman, T., \& Baghurst, T. (2013). Employee job embeddedness: Why people stay. International Journal of Business Management \& Economic Research, 4(5), 802-813.

Holtom, B. C., Mitchell, T. R., Lee, T. W., \& Eberly, M. B. (2008). 5 turnover and retention research: A glance at the past, a closer review of the present, and a venture into the future. The Academy of Management Annals, 2(1), 231-274.

Hom, P. W., Griffeth, R. W., \& Sellaro, C. L. (1984). The validity of mobley's (1977) model of employee turnover. Organizational Behavior and Human Performance, 34(2), 141-174.

Ibidunn, S., Osibanjo, A. O., Adeniji, A. A., Salau, O. P., \& Falola, H. O. (2015). Talent retention and organizational performance: A competitive positioning in Nigerian banking sector. Periodica Polytechnica Social and Management Sciences, 24(1), 1-13.

Ingraham, P. W., Selden, S. C., \& Moynihan, D. P. (2000). People and performance: Challenges for the future public service - The report from the wye river conference. Public Administration Review, 60(1), 54-60.

Ismail, M. (2009). Corporate social responsibility and its role in community development: An international perspective. Journal of International Social Research, 2(9), 199-209.

Jennings, J., \& Nagel, J.C. (2019, October 24). Federal workforce statistics sources: opm and omb. Retrieved from https://fas.org/sgp/crs/misc/R43590.pdf 
Jo, S., \& Shim, S. W. (2005). Paradigm shift of employee communication: The effect of management communication on trusting relationships. Public Relations Review, 31(2), 277-280.

Jones, D. A., Willness, C. R., \& Madey, S. (2014). Why are job seekers attracted by corporate social performance? Experimental and field tests of three signal-based mechanisms. Academy of Management Journal, 57(2), 383-404.

Joscelyne, K. [Kelly]. (2018, December 09). Millennials will make up 75\% of the global workforce by 2025 and $87 \%$ believe the success of a business should be measured by having a strong sense of purpose beyond financial success [LinkedIn status update]. https://www.linkedin.com/posts/kelly-joscelyne-3823579_millennialswill-make-up-75-of-the-global-activity-6473665041009774592-ZVbJ

Joshi, A. (2012). Human capital management: Strategies for retention of productive work force. International Journal of Management Research and Reviews, 2(11), 19431951.

Kim, H. K. (2014). Work-life balance and employees' performance: The mediating role of affective commitment. Global Business and Management Research, 6(1), 37 51.

Kohnke, B. (2019, January 15) What companies should be doing to retain talent in 2019. Fast Company. http://www.fastcompany.com

Kostanek, E. \& Khoreva, V. (2018). Multigenerational workforce and its implication for talent retention strategies. In M. Coetzee, I. Potgieter, \& N. Ferreira (Eds.), Psychology of retention: Theory, research and practice (pp. 203-221). Springer. 
Kraemer, T., \& Gouthier, M. H. (2014). How organizational pride and emotional exhaustion explain turnover intentions in call centers. Journal of Service Management, 25(1), 125-148.

Kulkarni, M., Lengnick-Hall, M. L., \& Martinez, P. G. (2015). Overqualification, mismatched qualification, and hiring decisions. Personnel Review, 44(4), 529549.

Latham, G. P., \& Locke, E. A. (2018). Goal setting theory: Controversies and resolutions. In D. S. Ones, N. Anderson, C. Viswesvaran, \& H. K. Sinangil (Eds.), The sage handbook of industrial, work \& organizational psychology: Organizational psychology (pp. 145-166). Sage Reference.

Lee, A. S. (1991). Integrating positivist and interpretive approaches to organizational research. Organization Science, 2(4), 342-365.

Lee, M. Y., \& Edmondson, A. C. (2017). Self-managing organizations: Exploring the limits of less-hierarchical organizing. Research in Organizational Behavior, 37, $35-58$.

Lee, T. W., Mitchell, T. R., Sablynski, C. J., Burton, J. P., \& Holtom, B. C. (2004). The effects of job embeddedness on organizational citizenship, job performance, volitional absences, and voluntary turnover. Academy of Management Journal, 47(5), 711-722.

Liden, R.C., \& Graen, G. (1980). Generalizability of the vertical dyad linkage model of leadership. Academy of Management Journal, 23, 451-465. 
Liden, R. C., \& Maslyn, J. M. (1998). Multidimensionality of leader-member exchange: An empirical assessment through scale development. Journal of Management, 24(1), 43-72.

Liden, R.C., Sparrow, R.T., \& Wayne, S.J. (1997). Leader-member exchange theory: The past and potential for the future. Research in Personnel and Human Resources Management, 15,47-119.

Lunenburg, F. C. (2011). Goal-setting theory of motivation. International Journal of Management, Business, and Administration, 15(1), 1-6.

Lyons, S., \& Kuron, L. (2014). Generational differences in the workplace: A review of the evidence and directions for future research. Journal of Organizational Behavior, 35(S1), S139-S157.

Lyons, S. T., Ng, E. S., \& Schweitzer, L. (2014). Changing demographics and the shifting nature of careers: Implications for research and human resource development. Human Resource Development Review, 13(2), 181-206.

Mahal, P. K. (2012). HR practices as determinants of organizational commitment and employee retention. IUP Journal of Management Research, 11(4), 37-53.

Maidani, E. A. (1991). Comparative study of Herzberg's two-factor theory of job satisfaction among public and private sectors. Public Personnel Management, 20(4), 441-448.

Mallol, C. M., Holtom, B. C., \& Lee, T. W. (2007). Job embeddedness in a culturally diverse environment. Journal of Business and Psychology, 22(1), 35-44.

March, J.G., \& Simon, H.A. (1958). Organizations. John Wiley \& Sons. 
Mardanov, I. T., Heischmidt, K., \& Henson, A. (2008). Leader-member exchange and job satisfaction bond and predicted employee turnover. Journal of Leadership \& Organizational Studies, 15(2), 159-175.

Maslyn, J. M., \& Uhl-Bien, M. (2001). Leader-member exchange and its dimensions: Effects of self-effort and other's effort on relationship quality. Journal of Applied Psychology, 86(4), 697-708.

McGuire, D., Todnem By, R., \& Hutchings, K. (2007). Towards a model of human resource solutions for achieving intergenerational interaction in organisations. Journal of European Industrial Training, 31(8), 592-608.

McKnight, D. H., Phillips, B., \& Hardgrave, B. C. (2009). Which reduces IT turnover intention the most: Workplace characteristics or job characteristics? Information \& Management, 46(3), 167-174.

McMahan, G. C., Virick, M., \& Wright, P. M. (1999). Alternative theoretical perspectives for strategic human resource management revisited: Progress, problems, and prospects. Research in Personnel and Human Resource Management, 4(1), 99-122.

Meister, J. C., \& Willyerd, K. (2010). The 2020 Workplace. Harper Collins Publishers. Men, L. R. (2014). Strategic internal communication: Transformational leadership, communication channels, and employee satisfaction. Management Communication Quarterly, 28(2), 264-284.

Men, L. R., \& Stacks, D. (2014). The effects of authentic leadership on strategic internal communication and employee-organization relationships. Journal of Public Relations Research, 26(4), 301-324. 
Merriam, S. B. (1988). Case study research in education: A qualitative approach. JosseyBass.

Meyer, J. P., \& Allen, N. J. (1991). A three-component conceptualization of organizational commitment. Human Resource Management Review, 1(1), 61-89.

Meyer J.P., Allen N.J., \& Smith C.A. (1993). Commitment to organizations and occupations: extension and test of a three-component conceptualization. Journal of Applied Psychology, 78, 538-551.

Miles, M. B., Huberman, A. M., \& Saldana, J. (2014). Qualitative data analysis: A methods sourcebook. SAGE Publications Ltd.

Mikkelson, A. C., York, J. A., \& Arritola, J. (2015). Communication competence, leadership behaviors, and employee outcomes in supervisor-employee relationships. Business and Professional Communication Quarterly, 78(3), 336354.

Mitchell, T. R., Holtom, B. C., Lee, T. W., Sablynski, C. J., \& Erez, M. (2001). Why people stay: Using job embeddedness to predict voluntary turnover. The Academy of Management Journal, 44, 1102-1121.

Mobley, W.H. (1977). Intermediate linkages in the relationship between job satisfaction and employee turnover. Journal of Applied Psychology, 62, 237-240.

Mobley, W.H., Griffeth, R.W., Hand, H.H., \& Meglino, B.M. (1979). Review and conceptual analysis of the employee turnover process. Psychological Bulletin, 86, 493-522.

Mustapha, N., \& Zakaria, Z. C. (2013). The effect of promotion opportunity in influencing job satisfaction among academics in higher public institutions in 
Malaysia. International Journal of Academic Research in Business and Social Sciences, 3(3), 20-26.

Myers, M. D. (2013). Qualitative research in business and management ( $2^{\text {nd }}$ ed.). Sage Publications.

Myers, K. K. \& Sadaghiani, K. (2010). Millennials in the workplace: A communication perspective on millennials' organizational relationships and performance. Journal of Business and Psychology, 25(2), 225-238.

Naim, M.F. (2018). Tap the experienced to care for the inexperienced: Millennial employee's retention challenge? Mentoring is the solution. In M. Coetzee, I. Potgieter, \& N. Ferreira (Eds.), Psychology of retention: Theory, research and practice (pp. 379-394). Springer

Ng, E., Lyons, S. T., \& Schweitzer, L. (Eds.). (2012). Managing the new workforce: International perspectives on the millennial generation. Edward Elgar Publishing. Ng, E.S., \& Johnson, J.M. (2015). Millennials: Who are they, how are they different, and why should we care? In R. J. Burke, C. Cooper, \& A.S. Antoniou (Eds). The multi-generational and aging workforce challenges and opportunities (pp. 121137). Edward Elgar Publishing.

Ng, T. W., Yam, K. C., \& Aguinis, H. (2019). Employee perceptions of corporate social responsibility: Effects on pride, embeddedness, and turnover. Personnel Psychology, 72(1), 107-137.

Nguru, R.M. \& Hichuhi, D. (2018). Influence of work life balance on employee commitment in parastatals: A case study of national hospital insurance fund in 
nakuru, kenya. International Journal of Economics, Commerce and Management, 7(5), 378-407.

Nunnally, J. C., \& Bernstein, I. H. (1994). Psychometric Theory ( $3^{\text {rd }}$ edition). McGraw Hill.

O'Reilly III, C. A., Caldwell, D. F., \& Barnett, W. P. (1989). Work group demography, social integration, and turnover. Administrative Science Quarterly, 34(1), 21-37.

Orgad, L. (2010). The preamble in constitutional interpretation. International Journal of Constitutional Law, 8(4), 714-738.

Pandita, D., \& Ray, S. (2018). Talent management and employee engagement-a metaanalysis of their impact on talent retention. Industrial and Commercial Training, 50(4), 185-199.

Park, J., \& Gursoy, D. (2012). Generation effects on work engagement among US hotel employees. International Journal of Hospitality Management, 31(4), 1195-1202.

Parkes, L. P., \& Langford, P. H. (2008). Work-life balance or work-life alignment? A test of the importance of work-life balance for employee engagement and intention to stay in organisations. Journal of Management \& Organization, 14(3), 267-284.

Peachey, J.W., J. Burton, L., \& E. Wells, J. (2014). Examining the influence of transformational leadership, organizational commitment, job embeddedness, and job search behaviors on turnover intentions in intercollegiate athletics. Leadership \& Organization Development Journal, 35(8), 740-755.

Pellegrini, E. K., \& Scandura, T. A. (2008). Paternalistic leadership: A review and agenda for future research. Journal of Management, 34(3), 566-593. 
Peltokorpi, V., Allen, D. G., \& Froese, F. (2015). Organizational embeddedness, turnover intentions, and voluntary turnover: The moderating effects of employee demographic characteristics and value orientations. Journal of Organizational Behavior, 36(2), 292-312.

Penrose, E. (1959). The theory of the growth of the firm. John Wiley \& Sons.

Pew Research Center (2018, April 11). Millennials are the largest generation in the U.S. labor force. https://www.pewresearch.org/fact-tank/2018/04/11/millennialslargestgeneration-us-labor-force/

Petriglieri, J. (2018). Talent management and the dual-career couple. Harvard Business Review, 106-113.

Pfeffer, J., \& Davis-Blake, A. (1992). Salary dispersion, location in the salary distribution, and turnover among college administrators. ILR Review, 45(4), 753763.

Ployhart, R. E. (2006). Staffing in the 21 st century: New challenges and strategic opportunities. Journal of Management, 32(6), 868-897.

Pitts, D., Marvel, J., \& Fernandez, S. (2011). So hard to say goodbye? Turnover intention among US federal employees. Public Administration Review, 71(5), 751-760.

Porter, L. W., \& Steers, R. M. (1973). Organizational, work, and personal factors in employee turnover and absenteeism. Psychological Bulletin, 80(2), 151-176.

President's FY2018 Budget (n.d.). Strengthening the federal workforce. Retrieved from https://www.gpo.gov/fdsys/pkg/BUDGET-2018-PER/pdf/BUDGET-2018$\underline{\text { PER.pdf }}$ 
Price, J.L., \& Mueller, C.W. (1981). A causal model of turnover for nurses. Academy of Management Journal, 24, 543-565.

Price, J.L., \& Mueller, C.W. (1986). Absenteeism and turnover of hospital employees. JAI Press.

Randel, A. E., Galvin, B. M., Shore, L. M., Ehrhart, K. H., Chung, B. G., Dean, M. A., \& Kedharnath, U. (2018). Inclusive leadership: Realizing positive outcomes through belongingness and being valued for uniqueness. Human Resource Management Review, 28(2), 190-203.

Ratna, R., \& Chawla, S. (2012). Key factors of retention and retention strategies in telecom sector. Global Management Review, 6(3), 35-46.

Robson, C. (2002). Real world research: A resource for social scientists and practitioner-researchers (2nd ed.). Blackwell Publishers.

Roodt, G. G. (2018). A job demands - Resources framework for explaining turnover intentions. Psychology of Retention: Theory, Research and Practice, 5-33.

Rousseau, V., \& Aubé, C. (2010). Social support at work and affective commitment to the organization: The moderating effect of job resource adequacy and ambient conditions. The Journal of Social Psychology, 150(4), 321-340.

Rubenstein, A. L., Kammeyer-Mueller, J. D., Wang, M., \& Thundiyil, T. G. (2019). "Embedded" at hire? Predicting the voluntary and involuntary turnover of new employees. Journal of Organizational Behavior, 40(3), 342-359.

Rural Development. (n.d). About. https://www.rd.usda.gov/about-rd

Rural Development. (n.d). Home. https://www.rd.usda.gov/about-rd 
Sacco, J.M., \& Schmitt, N. (2005). A dynamic multilevel model of demographic diversity and misfit effects. Journal of Applied Psychology, 90, 203-231.

Sassenberg, K., \& Ditrich, L. (2019). Research in social psychology changed between 2011 and 2016: Larger sample sizes, more self-report measures, and more online studies. Advances in Methods and Practices in Psychological Science, 2(2), $107-$ 114.

Scandura, T. A., \& Pellegrini, E. K. (2008). Trust and leader-member exchange: A closer look at relational vulnerability. Journal of Leadership \& Organizational Studies, 15(2), 101-110.

Schyns, B., Paul, T., Mohr, G., \& Blank, H. (2005). Comparing antecedents and consequences of leader-member exchange in a German working context to findings in the US. European. Journal of Work and Organizational Psychology, 14(1), 1-22.

Sekiguchi, T., Burton, J. P., \& Sablynski, C. J. (2008). The role of job embeddedness on employee performance: the interactive effects with leader-member exchange and organization-based self-esteem. Personnel Psychology, 61(4), 761-792.

Shacklock, K., \& Brunetto, Y. (2011). A model of older workers' intentions to continue working. Personnel Review, 40(2), 252-274.

Shaukat, H., Ashraf, N., \& Ghafoor, S. (2015). Impact of human resource management practices on employees performance. Middle-East Journal of Scientific Research, 23(2), 329-338.

Shore, L. M., Cleveland, J. N., \& Sanchez, D. (2018). Inclusive workplaces: A review and model. Human Resource Management Review, 28(2), 176-189. 
Smith, T. J., \& Nichols, T. (2015). Understanding the millennial generation. The Journal of Business Diversity, 15(1), 39.

Sokro, E. (2012). Impact of employer branding on employee attraction and retention. European Journal of Business and Management, 4(18), 164-173.

Steers, R.M., \& Mowday, R.T. (1981). Employee turnover and post-decision justification. In L.L. Cummings \& B.M. Staw (Eds.), Research in Organizational Behavior (pp. 235-282). JAI Press.

Stewart, J. S., Oliver, E. G., Cravens, K. S., \& Oishi, S. (2017). Managing millennials: Embracing generational differences. Business Horizons, 60(1), 45-54.

Strauss, A. \& Corbin, J. (1990). Basics of qualitative research: Grounded theory procedures and techniques. Sage

Strebel, P. (1996). Why do employees resist change? Harvard Business Review, 74(3), 86-92.

Supanti, D., Butcher, K., \& Fredline, L. (2015). Enhancing the employer-employee relationship through corporate social responsibility (CSR) engagement. Management, 27(7), 1479-1498.

Thompson, C., \& Gregory, J. B. (2012). Managing millennials: A framework for improving attraction, motivation, and retention. The Psychologist-Manager Journal, 15(4), 237-246.

Trapero, F. G. A., Castano, L. E. V., Parra, J. C. V., \& Garcia, J. D. L. G. (2017). Differences on self-perception of organizational pride and loyalty in millennial \& generation $\mathrm{x}$, considering gender and seniority variables. Business and Economic Horizons, 13(1232-2017-2421), 270-286. 
Uhl-Bien, M., Graen, G. B., \& Scandura, T. A. (2000). Implications of leader-member exchange (LMX) for strategic human resource management systems: Relationships as social capital for competitive advantage. Research in Personnel and Human Resources Management, 18, 137-186.

United States Department of Agriculture. (n.d.). About. https://www.usda.gov/ouragency/about-usda

United States Government Accounting Office, (2007). Testimony before the subcommittee on financial services and general government, committee on appropriations, house of representatives: Human capital: Federal workforce challenges in the $21^{\text {st }}$ century. Retrieved from https://www.gao.gov/assets/120/115651.pdf

United States Government Accounting Office, (2017). Testimony before the subcommittee on regulatory affairs and federal management, committee on homeland security and governmental affairs, U.S. senate: Human capital: improving federal recruiting and hiring efforts. Retrieved from https://www.gao.gov/assets/710/700657.pdf

United States Office of Personnel Management, (2019a). Fedscope: Federal workforce data employment trends. Retrieved from http://www.fedscope.opm.gov/ United States Office of Personnel Management, (2019b). Fedscope: Federal workforce data separations trend. Retrieved from http://www.fedscope.opm.gov/

United States Office of Personnel Management, (2020a). 2019 federal employee viewpoint survey. https://www.opm.gov/fevs/reports/governmentwidereports/governmentwide-management-report/governmentwide-report/2019/2019governmentwide-management-report.pdf 
United States Office of Personnel Management (OPM), (2020b). 2019 federal workforce priorities report. Retrieved from https://www.opm.gov/policy-dataoversight/human-capital-management/federal-workforce-priorities-report/2019federal-workforce-priorities-report.pdf

Van De Kamp, P. (2014). Holacracy-A radical approach to organizational design. Elements of the Software Development Process-Influences on Project Success and Failure. University of Amsterdam, 13-26.

Vaske, J. J., Beaman, J., \& Sponarski, C. C. (2017). Rethinking internal consistency in Cronbach's Alpha. Leisure Sciences, 39(2), 163-173.

Viator, R.E., \& Scandura, T.A. (1991). A study of mentor-protégé relationships in large public accounting firms. Accounting Horizons, 5(3), 20-30.

Vigoda, E. (2000). Organizational politics, job attitudes, and work outcomes: Exploration and implications for the public sector. Journal of Vocational Behavior, 57(3), 326-347.

Waldman, D. A., Carter, M. Z., \& Hom, P. W. (2015). A multilevel investigation of leadership and turnover behavior. Journal of Management, 41(6), 1724-1744.

Wayne, S. J., Shore, L. M., Bommer, W. H., \& Tetrick, L. E. (2002). The role of fair treatment and rewards in perceptions of organizational support and leadermember exchange. Journal of Applied Psychology, 87(3), 590-598.

Weng, Q., \& McElroy, J. C. (2012). Organizational career growth, affective occupational commitment and turnover intentions. Journal of Vocational Behavior, 80(2), 256265. 
Wernerfelt, B. (1984). A resource-based view of the firm. Strategic Management Journal, 5(2), 171-180.

Wright, A. D. (2018, April 26). Employers say accommodating millennials is a business imperative. SHRM. https://www.shrm.org/resourcesandtools/hr-topics/employee$\underline{\text { relations/pages/accommodating-millennials-is-a-business-imperative.aspx }}$

Wright, P. M., Dunford, B. B., \& Snell, S. A. (2001). Human resources and the resourcebased view of the firm. Journal of Management, 27(6), 701-721.

Yin, R. K. (2017). Case study research and applications: Design and methods (6 ${ }^{\text {th }}$ ed.). Sage Publications.

Zaharee, M., Lipkie, T., Mehlman, S. K., \& Neylon, S. K. (2018). Recruitment and retention of early-career technical talent: What young employees want from employers: A study of the workplace attributes that attract early-career workers suggests that millennials may not be so different from earlier generations. Research-Technology Management, 61(5), 51-61. 


\section{Appendix A: Determining Study Participants}

\section{Selection Criteria One:}

Employee must be born between the following years:

1970-1991

Employee's year of birth should not be disclosed.

\section{Selection Criteria Two:}

Employee must have been employed with the agency for at least three years.

\section{Selection Criteria Three:}

Employee must have had a performance rating for the last two fiscal years (FY 18 and FY 19) of at least a fully successful.

Note: If employee meets all criteria above, they are eligible to participate in the study. 


\section{Attachment B: Recruitment Email Initial Invitation to Participate}

Date

John.Doe@usda.gov

Dear Mr. Doe,

I am the Division Director, Financial Operations Division, and this email is an invitation to participate in my doctoral study "Talent Retention: An Empirical Examination of a $21{ }^{\text {st }}$ Century United States Department of Agriculture." I am conducting this study in fulfillment of my Doctor of Business Administration degree at the University of Missouri - St. Louis. The purpose of this research is to identify employee values and expectations that have implications for talent retention. Ultimately, my goal is to determine effective strategies federal agencies can use for talent retention among Generation $\mathrm{X}$ and millennial employees.

The semi-structured interview should take no more than 60 minutes from beginning to end. Should you choose to participate, your information will be kept confidential and your name will not be recorded or identified in any documents. This research has been reviewed and approved by my dissertation committee at the University of Missouri-St. Louis. In addition, approval to interview employees within Rural Development's Business Center was approved by Angilla Denton, Chief Operating Officer.

The incredible work that you perform as an employee within USDA Rural Development is critical to the continued success of the Agency. The information you provide will play a vital role in creating strategies that Rural Development can use to retain talented employees. Your participation in this study is very much appreciated.

To confirm your eligibility for the study, please confirm the following statements:

1. I was born between the years of 1970-1991.

- TRUE

- FALSE

2. I have been at Rural Development for 3 years or more.

- TRUE

- FALSE

3. I have received at least a rating of Fully Successful during the FY 18 and FY 19 rating period.

- TRUE

- FALSE

If you would like to inform this study, please review and sign the Informed Consent attached to this email. The Informed Consent is required prior to participating. If you are interested in participating but would like to learn more or have questions, you may contact me directly via email at james.jordan3@usda.gov or james.jordan@ mail.umsl.edu or via phone at 314-516-4528. Once your Informed Consent is submitted, I will send you an email to confirm receipt and provide next steps for your participation in the study. 
Thank you

James E. Jordan Jr.

Director, Financial Operations Division

Rural Development Business Center|National Financial and Accounting Operations Center United States Department of Agriculture

4300 Goodfellow Blvd|Bldg. 105|St. Louis, MO 63120

Ph: 314.679.6710| Mobile: 314.637.8774|Fax: 1-844-655-2424

www.rd.usda.gov | "Committed to the future of rural communities"

Stay Connected with USDA:

USDA is an equal opportunity provider and employer. 


\section{Attachment C: Semi-Structured Interview Guide}

Key: Using this Interview Guide

Italics $=$ Information given by the researcher to guide the participant and provide explanation

ALL CAPS = Fill in as appropriate for each interview

$* *=$ Action to be taken by the researcher

Introduction -3 minutes

Thanks so much for meeting with me today! I am working towards my Doctor of Business Administration at University of Missouri- St. Louis. Your participation helps inform my dissertation research, where I am trying to understand why you have chosen to stay at USDA Rural Development (RD). I am looking for your help and you are the expert in knowing your reasons for staying. I want to know your perspective!

Before we start, I want to remind you that our conversation is for research purposes only. Your individual responses will not be shared with anyone in RD nor will your name be shared in any publications resulting from this study. I am interested in gaining an accurate and comprehensive understanding of talented employee retention and, therefore, I want you to feel as comfortable as possible in sharing the richness of your experiences through details and examples. Where relevant, quotes (excluding identifying information such as names, locations, etc.) may be used to support assertions made in the paper.

Do you have any questions or concerns regarding confidentiality before we turn on the recorder?

*Turn on recorder*

Opening Questions - 5-10 minutes

First, I would like to ask you a few questions to get to know you and your role at USDA RD:

An employee's role is a prescribed or expected behavior of a worker who performs certain functions associated with a position or status within a group or organization. (Provide RD Mission.)

1) As an employee of RD, do you feel your role helps to fulfill the mission of the organization? Please explain. 
a. On a scale of 1 to 5 with 1 being "no impact" and 5 being "very highly impacted", please rate the impact you believe your role has in fulfilling the mission of the organization.

2) What is your current job position (ex. Accountant, Processor, Specialist)?

3) How long have you worked in your current field as a(n) XX?

4) How long have you worked at USDA?

a. During this time, how many departments have you worked in?

5) How long have you worked with your current supervisor?

6) How long have you been an employee in the federal government?

7) Have you worked in any other federal agency?

a. Yes

b. No

If yes, what were the reasons for leaving that organization?

8) Have you applied for any other employment opportunities in the past 3 years either internal or external to RD? Why or why not?

9) How would you best describe yourself?
a. American Indian or Alaska Native
b. Asian
c. Black or African American
d. White
e. Hispanic, Latino or Spanish
f. Other (Please specify)
g. Prefer not to say

Thank you - that gives me some helpful background. We are here to talk about talent retention, and I am trying to understand why you choose to stay. I want information from you that will later be used to develop retention strategies. Findings from this research will help in developing strategies that provide insight into practices $R D$ should develop to retain talented employees. Therefore, I am looking for information that will inform my research to determine strategies outside of the turnover drivers that over 6 decades of research has already found that was included in the reflections, questions and statements sent to you previously. I want to identify variables that have not yet been recognized yet in research.

Does that make sense? 
I am looking forward to learning information from our discussion on retention here at $R D$. Feel free to give examples where you can and any other details that might help me understand your perspective.

Interview Questions - 45 - 60 minutes

1) Why have you chosen to stay at USDA?

2) What has motivated you the most during your time at RD (please feel free to name more than one thing)?

3) What are the rewards/awards you have received in the last 5 years?

4) Do you believe you receive recognition for your hard work?

a. Is it financial/nonfinancial; which do you care more about?

5) Do you feel like you have reached your full potential at RD?

The next three questions focus on support...when I say support, I am talking about resources to do your job, support for your ideas, technological advances...

6) As an employee of RD, do you feel supported by your supervisor? Please explain.

a. Can you give me an example of a time when your supervisor was supportive?

7) As an employee of RD, do you feel supported by your co-workers? Please explain.

a. Can you give me an example of a time when a co-worker was supportive?

8) As an employee of RD, do you feel supported by senior leadership? Please explain.

a. Can you give me an example of a time when senior leadership was supportive?

It is important for every employee in an organization to have effective communication skills. With that being said:

9) Does your supervisor communicate effectively? Please explain.

a. If you could change the communication methods used, how would you? 
10) Do your co-workers communicate with you in an effective manner? Please explain.

a. If you could change the communication methods used, how would you?

11) Does RD senior leadership communicate effectively?

a. If you could change the communication methods used, how would you?

12) How do you feel about your work environment in terms of having the necessary tools (example: training, advance technology, etc.) to complete your job?

13) Do you feel loyal to your supervisor? What has she or he done to cause you to feel the way you do?

14) Are you aware of available career paths and promotion opportunities? If so, are you happy about it?

15) What would you need, if anything, to be the best employee you could be?

16) Name one process, if eliminated, that would make you more productive with your daily duties?

17) What are some things your supervisor could realistically do to make you feel more committed to the organization?

18) What are things that senior leadership could do to make you feel more committed to the organization?

19) Please discuss any recognition during your tenure at RD that you have received that increased your commitment.

a. Is there any additional recognition you received that increased your commitment?

20) What are some of the things, if any, that have negatively impacted your commitment to the organization?

21) If you had to do it all over again, would you apply for your job at RD again? Please explain.

22) What conditions would cause you to seek employment elsewhere?

23) What is the greatest challenge for you at RD? 
24) Please explain what steps RD would need to take, if any, to make your work more meaningful and satisfying?

25) Do you feel like a valuable member of RD?

26) For the following statements please rate them on a scale of 1-7 (Liden \& Maslyn, 1998):

1 - Strongly Disagree

2 - Disagree

3 - Mildly Disagree

4 - Undecided

5 - Mildly Agree

6 - Agree

7 - Strongly Agree

\section{Affect}

1. I like my supervisor very much as a person.

2. My supervisor is the kind of person one would like to have as a friend.

3. My supervisor is fun to work with.

\section{Loyalty}

4. My supervisor defends my work actions to a superior even without complete knowledge of the issue in question.

5. My supervisor would come to my defense if I were "attacked" by others.

6. My supervisor would defend me to others in the organization if I made an honest mistake.

\section{Contribution}

7. I do work for my supervisor that goes beyond what is specified in my job description.

8. I am willing to apply extra efforts, beyond those normally required, to meet my supervisor's work goals.

9. I do not mind working my hardest for my supervisor.

\section{Professional Respect}

10. I am impressed with my supervisor's knowledge of his/her job.

11. I respect my supervisor's knowledge and competence on the job.

12. I admire my supervisor's professional skills.

27) Is there anything important that we have not covered that you feel would be important in understanding factors that influence employee retention? 
28) During the last 2 years, how many of your co-workers have left departed from $\mathrm{RD}$ ? Please discuss the factors that led to their leaving, if you are aware.

29) Despite these factors that led your co-workers to leave, why have you chosen to stay at USDA?

30) Are you a member of Generation $X$ born after 1971 but before 1981 or a member of the millennial generation born in 1981 or later?

31) Tell me what is most important to you in terms of your own professional development?

32) Are there growth opportunities at RD?

33) In previous interviews the concept of 360 communication has been a common theme. 360 communication is defined as an employee having frequent communication with all the people they work with, including clients, senior leadership above the employee's direct supervisor, and peers. Please explain how you feel about this in Rural Development. Is it important to you and does it make a difference in your willingness to stay with the agency?

34) Specifically, being able to have access and frequent communication with senior leadership above the employee's direct supervisor has been a common theme in previous interviews. Please explain how you feel about this in Rural Development. Is it important to you to have easy access to senior leadership and does it make a difference in your willingness to stay with the agency?

35) In previous interviews performance management has been a common theme. Please explain how you feel regarding the agency's performance management process. Do you believe the performance management process is sufficient as it is presently? If not, what improvements do you recommend?

Ending the Interview -2 minutes

Thank you for meeting/speaking with me today. In about 10 days, I will follow up to ensure I understand and have accurately recorded your answers as well as give you an opportunity to share anything else you think of after we wrap up today. 


\section{Appendix D: Informed Consent}



College of Business Administration

One University Blvd

St. Louis, Missouri 63121

Telephone: 314-516-4528

E-mail: james.jordan@mail.umsl.edu

\section{Informed Consent for Participation in Research Activities}

Talent Retention:

An Empirical Examination of a $21^{\text {st }}$ Century U.S. Federal Agency

HSC Approval Number 1529641-2

Principal Investigator: James E. Jordan Jr. $\quad$ PI’s Email: james.jordan@mail.umsl.edu

You are invited to participate in a research study conducted by James E. Jordan Jr. (Graduate Student). James E. Jordan Jr.is the Principal Investigator for this research as part of his role as a Graduate Student at the University of Missouri-St. Louis, Doctor of Business Administration program and not in his capacity as a Division Director for Rural Development, National Financial and Accounting Operations Center. The purpose of this research is to identify worker values and expectations that have implications for talent retention. This study is being conducted as part of a doctoral dissertation at the University of Missouri-St. Louis. Ultimately, we hope to determine effective strategies federal agencies can use for talent retention among millennials and Generation Xers.

\section{What You Will Be Asked to Do:}

1. You are invited to participate in a research study conducted by James E. Jordan Jr. (Graduate Student) and Dr. Ekin Pellegrini (Faculty Advisor). The purpose of this research is to better understand worker values and expectations that have implications for talent retention. The overall findings of this study will be shared with the organization to provide information for improvement of talent retention. Findings from the interviews will be compiled and shared collectively, without any identifiers, to ensure confidentiality.

2. You were invited to participate in this study because of your qualifications a participant for the current study align with the following criteria:

a. Received a FY 18 and FY 19 Rating of Outstanding or Superior;

b. Born between the years of 1970-1991; 
c. Worked at the Agency for 3 years or more.

To help ensure your alignment with the focus of the current study, there is a brief screening on the following page.

3. Your participation will involve: answering interview questions (approximately 45 minutes).

The total amount of time involved in your participation will be about 1 hour.

4. There are no known risks associated with this research other than the potential for mild boredom or fatigue.

5. There are no direct benefits or compensation for you participating in this study.

6. Your participation is voluntary, and you may choose not to participate in this research study or withdraw your consent at any time. You will NOT be penalized in any way should you choose not to participate or withdraw.

7. The contents of the meetings will remain confidential. All data from the present study will be stored on a secure, password protected laptop. Only the primary investigator and faculty advisor will have access to the raw data. All materials will be blinded and all names and identifiers will be removed. The interviews will be recorded with an anonymous code, such as STL01 or DC01. After the transcription process, all videos and recordings will be deleted and permanently destroyed. Any potential identifiers will be removed from the transcribed text to protect confidentiality. Quotes will only be used with the participant's permission, stripped of identifying information.

8. As part of this effort, neither your identity nor your company's identity will be revealed in any publication that may result from this study. The Principal Investigator will only share de-identified summary information in the dissertation. In rare instances, a researcher's study must undergo an audit or program evaluation by an oversight agency (such as the Office for Human Research Protection) that would lead to disclosure of your data as well as any other information collected by the researcher.

9. There are certain risks or discomforts associated with this research. They include potential risks to your professional reputation if you choose to disclose damaging information. While we will do everything, we can to protect your privacy, and you will not be interviewed by anyone from within your chain of command, you should use your judgment when choosing what types of information to share with the interviewer.

10. If you have any questions or concerns regarding this study, or if any problems arise, you may contact the Principal Investigator, James Jordan (james.jordan@mail.umsl.edu) or the Faculty Advisor, Dr. Ekin Pellegrini 
(pellegrinie@umsl.edu). You may also ask questions or state concerns regarding your rights as a research participant to the Office of Research, at 516-5899.

I have read this consent form and have been given the opportunity to ask questions. (You may print a copy of this consent form for your records).

$\square$ By checking here, I acknowledge I have read this consent form and hereby consent to participate in the research described above

$\square$ If you do not consent to participate in the research described above, please check this box and then inform the researcher. 


\section{Attachment E: Pre-Interview Reflection Questions}

\section{Hi PARTICIPANT NAME,}

This email is to confirm our interview appointment on DATE at TIME and LOCATION.

Prior to our conversation, I would like you to read and reflect on questions that may help you prepare for the interview. These questions are intended to facilitate a productive meeting.

\section{Reflection Questions Prior to the Interview:}

- Think about the reasons why you remain with the organization.

- Previous research on turnover and retention has already identified several drivers of turnover. I would like you to think beyond what has already been identified and to think about additional variables that have not yet been identified by research.

- Please talk about variables that are not included in the list below, but that you deem within your COMPANY's control. The variables research has already identified are:

○ The quality of the relationship between supervisor and the employee;

- Job satisfaction;

- Job expectations (employee's job expectations are misaligned with the job);

○ Job involvement (employee's interest in their job);

○ Job resource adequacy (employee has the tools necessary to complete their job);

○ Work-life balance (employee has balance between work and home life);

○ Compensation - specifically pay satisfaction and pay fairness;

- Role conflict (employees in multiple roles);

- Role clarity (employee has a clear understanding of the tasks, responsibilities and processes at work).

Thank you and I look forward to learning from you on DAY/TIME at LOCATION. 


\section{Attachment F: Union "Notice" Correspondence}

Date

John.Doe@usda.gov

Dear Mr. Doe,

I am the Division Director, Financial Operations Division, and this email is an invitation to participate in my doctoral study "Talent Retention: An Empirical Examination of a 21st Century United States Department of Agriculture." I am conducting this study in fulfillment of my Doctor of Business Administration degree at the University of Missouri - St. Louis. The purpose of this research is to identify employee values and expectations that have implications for talent retention. Ultimately, my goal is to determine effective strategies federal agencies can use for talent retention among millennial and Generation $\mathrm{X}$ employees.

Currently, organizations are experiencing a loss of employees as a result of normal attrition and an increase in retirements. As this trend continues, organizations will continue to experience large gaps in talent. Federal agencies need to strengthen efforts and use of tools to retain talent. Ultimately, my goal is to determine effective strategies federal agencies can use for talent retention among Generation $\mathrm{X}$ and millennial employees.

The semi-structured interview should take no more than 60 minutes from beginning to end. Should employees choose to participate their information will be kept confidential and your name will not be recorded or identified in any documents. This research has been reviewed and approved by my dissertation committee at the University of MissouriSt. Louis. In addition, approval to interview employees within Rural Development's Business Center was approved by Angilla Denton, Chief Operating Officer.

Identifying the factors that influence employee retention and using that information to develop strategies that positively influence employee retention is necessary for continued growth and efficiency. I am seeking participants to help develop strategies that can be used to retain talented employees and I want your constituents' voices to be heard.

The incredible work that employees perform within USDA Rural Development is critical to the continued success of the Agency. The information will play a vital role in identifying strategies that Rural Development can use to retain talented employees. Your assistance in encouraging participation in this study is very much appreciated.

Thank You

James E. Jordan Jr.

Director, Financial Operations Division 
Rural Development Business Center|National Financial and Accounting Operations Center

United States Department of Agriculture

4300 Goodfellow Blvd|Bldg. 105|St. Louis, MO 63120

Ph: 314.679.6710| Mobile: 314.637.8774|Fax: 1-844-655-2424

www.rd.usda.gov | "Committed to the future of rural communities" 


\section{Attachment G: IRB Approval Letter}

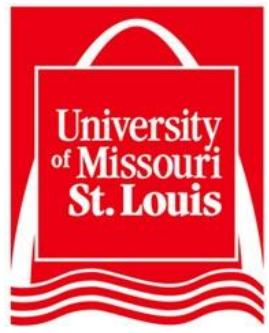

DATE:

TO:

FROM:

PROJECT TITLE:

REFERENCE \#:

SUBMISSION TYPE: Revision

ACTION:

DECISION DATE:

REVIEW CATEGORY:

\section{Office of Research Administration}

\author{
One University Boulevard \\ St. Louis, Missouri 63121-4499 \\ Telephone: 314-516-5899 \\ Fax:314-516-6759
}

E-mail:ora@umsl.edu

January 5, 2020

James Jordan

University of Missouri-St. Louis IRB

[1529641-2] Talent Retention: An Empirical Examination of a 21st Century U.S. Federal Agency

DETERMINATION OF EXEMPT STATUS

January 5, 2020

Exemption category \# 2

The chairperson of the University of Missouri-St. Louis IRB has APPROVED the above mentioned protocol for research involving human subjects and determined that the project qualifies for exemption from full committee review under Title 45 Code of Federal Regulations Part 46.101b. The time period for this approval expires one year from the date listed above. You must notify the University of MissouriSt. Louis IRB in advance of any proposed major changes in your approved protocol, e.g., addition of research sites or research instruments.

You must file an annual report with the committee. This report must indicate the starting date of the project and the number of subjects to date from start of project, or since last annual report, whichever is more recent.

Any consent or assent forms must be signed in duplicate and a copy provided to the subject. The principal investigator must retain the other copy of the signed consent form for at least three years following the completion of the research activity and they must be available for inspection if there is an official review of the UM-St. Louis human subjects research proceedings by the U.S. Department of Health and Human Services Office for Protection from Research Risks.

This action is officially recorded in the minutes of the committee.

If you have any questions, please contact Carl Bassi at 314-516-6029 or bassi@umsl.edu. Please include your project title and reference number in all correspondence with this committee. 